Florida International University FIU Digital Commons

$7-2-2012$

\title{
A Study of Stock Market Linkages between the US and Frontier Markets
}

Galin Kostadinov Todorov

gtodo001@fiu.edu

DOI: $10.25148 /$ etd.FI12071115

Follow this and additional works at: https://digitalcommons.fiu.edu/etd

\section{Recommended Citation}

Todorov, Galin Kostadinov, "A Study of Stock Market Linkages between the US and Frontier Markets" (2012). FIU Electronic Theses and Dissertations. 658.

https://digitalcommons.fiu.edu/etd/658

This work is brought to you for free and open access by the University Graduate School at FIU Digital Commons. It has been accepted for inclusion in FIU Electronic Theses and Dissertations by an authorized administrator of FIU Digital Commons. For more information, please contact dcc@fiu.edu. 


\section{FLORIDA INTERNATIONAL UNIVERSITY}

Miami, Florida

\section{A STUDY OF STOCK MARKET LINKAGES BETWEEN THE US AND FRONTIER COUNTRIES}

A dissertation submitted in partial fulfillment of

the requirements for the degree of

DOCTOR OF PHILOSOPHY

in

ECONOMICS

by

Galin Todorov

2012 
To: Dean Kenneth G. Furton

College of Arts and Sciences

This dissertation, written by Galin Todorov, and entitled A Study of Stock Market Linkages between the US and Frontier Markets, having been approved in respect to style and intellectual content, is referred to you for judgment.

We have read this dissertation and recommend that it be approved.

Brice Dupoyet

$\begin{array}{r}\text { Sheng Guo } \\ \hline \text { Cem Karayalcin } \\ \hline \text { Prasad Bidarkota, Major Professor }\end{array}$

Date of Defense: July 02, 2012

The dissertation of Galin Todorov is approved.

Dean Kenneth G. Furton

College of Arts and Sciences

Dean Lakshmi N. Reddi

University Graduate School

Florida International University, 2012 


\section{ACKNOWLEDGMENTS}

I wish to thank my committee chair Dr. Prasad Bidarkota for his patience, support, and guidance throughout the dissertation stage of my education.

I also wish to thank Dr. Cem Karayalcin for his useful comments, advice, and support in all aspects of my academic journey.

Dissertation year fellowship, generously awarded by the FIU Graduate School, is gratefully acknowledged. 


\author{
ABSTRACT OF THE DISSERTATION \\ A STUDY OF STOCK MARKET LINKAGES BETWEEN THE US \\ AND FRONTIER COUNTRIES \\ by \\ Galin Todorov \\ Florida International University, 2012 \\ Miami, Florida \\ Professor Prasad Bidarkota, Major Professor
}

My dissertation investigates the financial linkages and transmission of economic shocks between the US and the smallest emerging markets (frontier markets).

The first chapter sets up an empirical model that examines the impact of US market returns and conditional volatility on the returns and conditional volatilities of twenty-one frontier markets. The model is estimated via maximum likelihood; utilizes the GARCH model of errors, and is applied to daily country data from the MSCI Barra. We find limited, but statistically significant exposure of Frontier markets to shocks from the United States. Our results suggest that it is not the lagged US market returns that have impact; rather it is the expected US market returns that influence frontier market returns.

The second chapter sets up an empirical time-varying parameter (TVP) model to explore the time-variation in the impact of mean US returns on mean Frontier market returns. The model utilizes the Kalman filter algorithm as well as the GARCH model of errors and is applied to daily country data from the MSCI Barra. The TVP model detects statistically significant time-variation 
in the impact of US returns and low, but statistically and quantitatively important impact of US market conditional volatility.

The third chapter studies the risk-return relationship in twenty Frontier country stock markets by setting up an international version of the intertemporal capital asset pricing model. The systematic risk in this model comes from covariance of Frontier market stock index returns with world returns. Both the systematic risk and risk premium are time-varying in our model. We also incorporate own country variances as additional determinants of Frontier country returns. Our results suggest statistically significant impact of both world and own country risk in explaining Frontier country returns. Time-variation in the world risk premium is also found to be statistically significant for most Frontier market returns. However, own country risk is found to be quantitatively more important. 


\section{TABLE OF CONTENTS}

$\begin{array}{ll}\text { CHAPTER PAGE } & \text { PAT }\end{array}$

I. ON INTERNATIONAL FINANCIAL

SPILLOVERS TO FRONTIER MARKETS ….................................................. 1

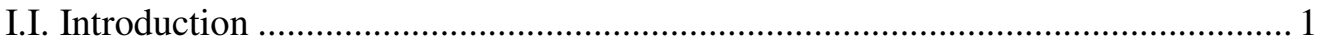

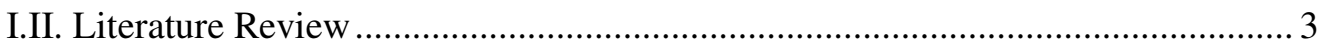

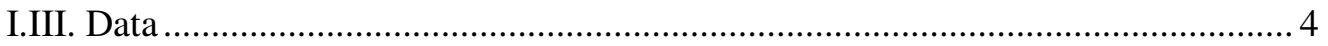

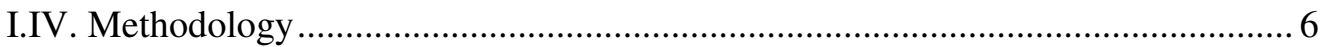

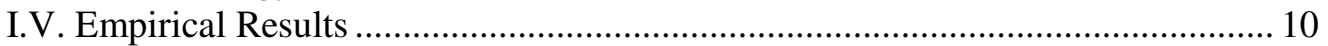

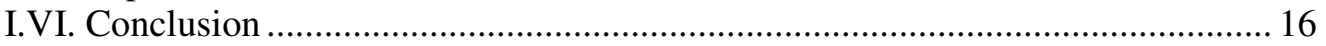

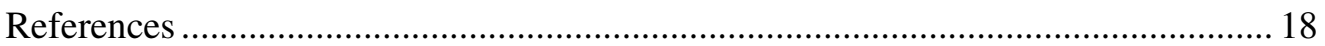

II. TIME-VARYING FINANCIAL SPILLOVERS

FROM THE US TO FRONTIER MARKETS

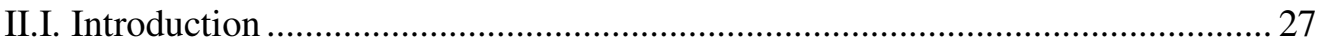

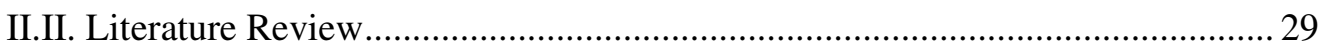

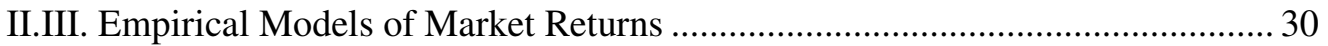

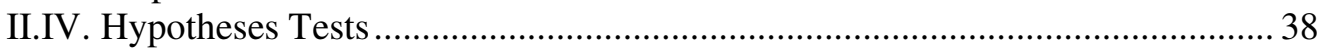

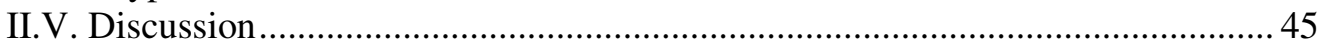

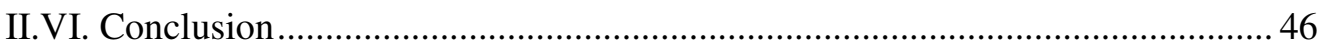

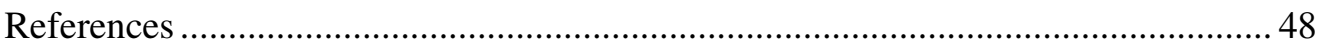

III. TIME-VARYING RISK AND RISK

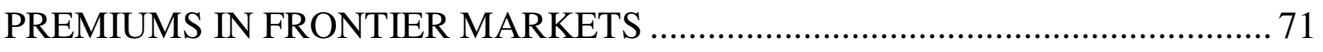

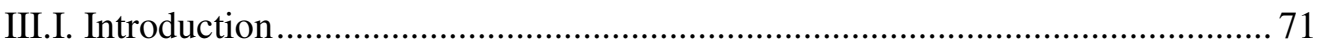

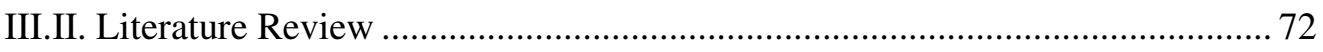

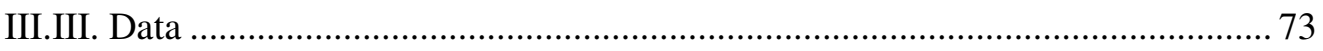

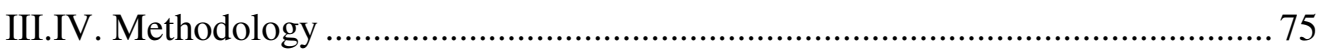

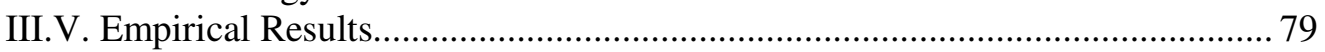

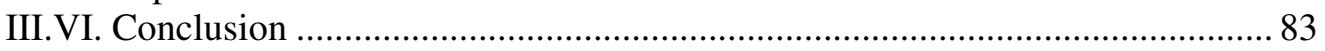

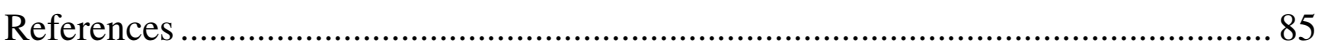

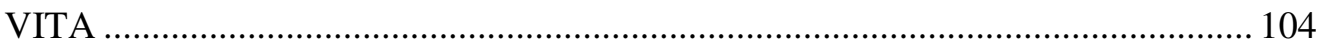




\section{LIST OF TABLES}

TABLE

PAGE

Table 1.1 Distributional Characteristics of Annualized Daily Percentage Country Logarithmic Returns...20

Table 1.2 Summary of Best-Fitting Univariate Models ........................................................ 21

Table 1.3 Summary of Best-Fitting Bivariate Models ............................................................ 23

Table 1.4 Likelihood Ratio Tests with Best-Fitting Model of Spillovers................................... 25

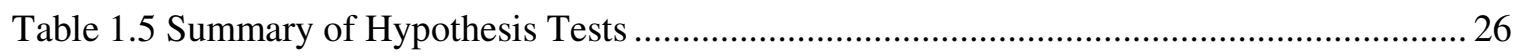

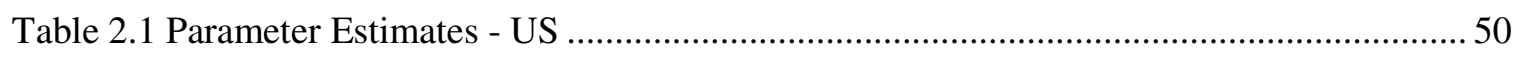

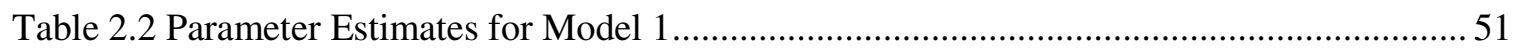

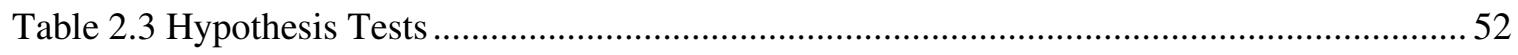

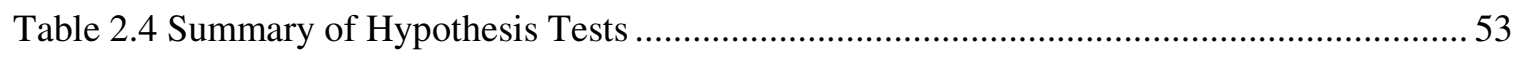

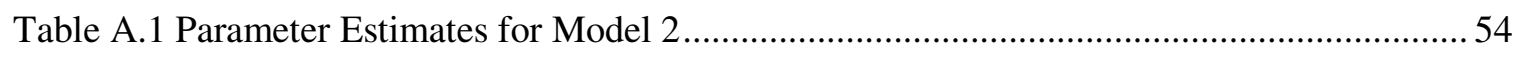

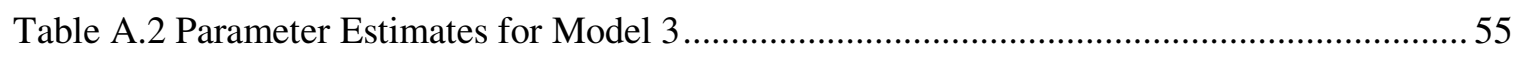

Table A.3 Parameter Estimates for Model 4 ......................................................................... 56

Table A.4 Parameter Estimates for Model 5 ......................................................................... 57

Table 3.1 Distributional Characteristics of Annualized Daily Percentage Logarithmic Returns. . 87

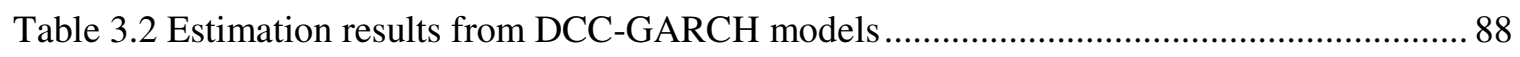

Table 3.3 Dynamic Conditional Correlations (DCCs) statistics for frontier market returns versus

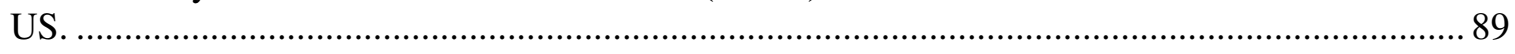

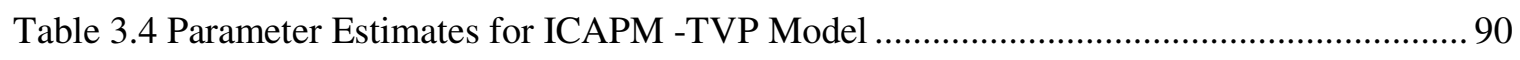

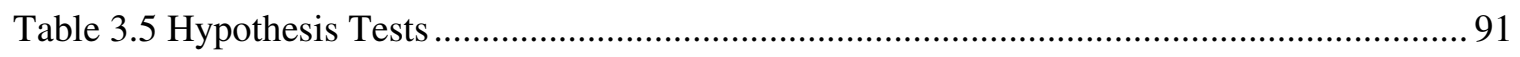




\section{LIST OF FIGURES}

\section{FIGURE}

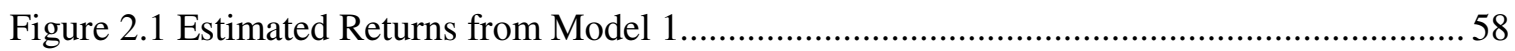

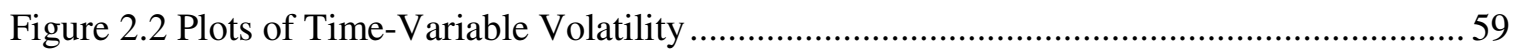

Figure 2.3 Time-Variable Return Spillover Parameter Estimated by Model 1 for Frontier Countries 60

Figure 2.4 US and Own-Country Lagged Components of Returns Estimated by Model 1. 61

Figure 2.5 Conditional Volatility Components from Model $1 .$. 62

Figure B.1 US Components of Frontier Country Returns Estimated by Model 1 and Model 2 .... 63

Figure B.2 US Components of Frontier Country Conditional Volatility Estimated by Model 1 and Model 2. 64

Figure B.3 US Components of Frontier Country Returns Estimated by Model 1 and Model 3 .... 65

Figure B.4 US Components of Frontier Country Conditional Volatility Estimated by Model 1 and Model 3.

Figure B.5 Own-Country Lagged Components of Frontier Country Returns Estimated by Model 1 and Model 4 .

Figure B.6 Own-Country Components of Frontier Country Conditional Volatility Estimated by Model 1 and Model 4

Figure B.7 US Components of Frontier Country Returns Estimated by Model 1and Model 5 ..... 69

Figure B.8 Own-Country Components of Frontier Country Conditional Volatility Estimated by Model 1 and Model 5

Figure 3.1 Dynamic Conditional Correlations between US and Frontier Markets ....................... 92

Figure 3.2 Frontier Market Returns and Fitted Values from the ICAPM-TVP Model.................. 96

Figure 3.3 US and Local Market Components of Frontier Market Returns Estimated by the ICAPM-TVP Model... 


\section{ON INTERNATIONAL FINANCIAL SPILLOVERS TO FRONTIER MARKETS}

\section{I.I. Introduction}

The main issue investigated in this article is the extent to which contemporaneous returns and conditional volatility of 21 frontier markets were affected by the fluctuations in returns and conditional volatility on the American stock market during the period between December 1st, 2005 and January 15th, 2010.

The World Bank defines emerging markets as markets for which GDP per capita falls bellow a certain time-dependent hurdle. Frontier markets are defined as emerging markets that are investable, but have lower capitalization and market liquidity compared to the more developed emerging markets.

Financial spillovers exist because of real economic and financial ties between world economies. As a result of the existence of such ties, new information arising in one country affects not only local returns and volatility, but also the returns and volatility of assets traded on other markets. The impact of a change in returns of one stock market on the returns of another stock market is defined as returns spillovers, and the impact of a change in returns volatility of one stock market on the returns volatility of another stock market is defined as volatility spillovers. The new information may be absorbed immediately by other markets, or with a delay, depending on the presence and number of informed investors, information asymmetry, level of market liquidity, existence of feed back traders and herding behavior, high transaction costs and other potential market specific factors. The magnitude and speed of spillovers provide valuable insight into the nature and swiftness of dissemination of such new information among countries. The size of spillovers reflects how global investors feel about news, as well as their appraisal of its impact on asset prices across markets.

In order to travel across borders, information needs transmission channels. In the short run, asset price changes are the primary channel for transmission of financial shocks across borders. Owing to the dependence of frontier markets on common bank creditors and cross market portfolio re-balancing by investment funds, financial markets and institutions have been shown to act as a major tool for cross-border shock transmission (Kodres and Pritsker (2002), Calvo (1999), Pritsker (2001)). Detailed review of spillover transmission channels is offered by Pritsker (2001), and Kaminsky and Reinhart (2002).

The great majority of theoretical and empirical work has so far been concentrated on exploring spillovers among the mature and more developed emerging markets. However, the growing size and 
importance of frontier markets naturally draw considerable interest from investors, policy makers, and academics alike. In this study we extend the existing literature by analyzing the extent to which small markets are vulnerable to shocks from the USA, as represented by the returns and volatility spillovers from the US market to 21 frontier stock markets.

The exposure of the smallest developing markets to financial shocks from US is a matter of substantial concern for international investors. Frontier markets are often considered very risky. That however, might not stem from those markets not being fundamentally sound; it might just be that investors do not know much about them. This study may provide financiers with further information about potential investment and portfolio diversification opportunities in those 21 small economies. Direct investment, project risk evaluation, cost of capital calculation, asset pricing and allocation, in addition to the development of hedging techniques can potentially benefit from this article as well.

Policy makers may take advantage of this study since understanding inter-market connections could provide for more informed decisions, improve macroeconomic management, as well as advance their ability to time, predict, and evaluate susceptibility of a country to shocks from abroad. Improved assessment of the nature and origin of a financial shock and possible subsequent economic downturn may facilitate the adaptation of more appropriate anti-crisis techniques and thus alleviate, or at least shorten, the suffering of those most affected by the deterioration of economic conditions.

Exploration of potential inter-market linkages may also aid academics in shedding more light on the outcome of market liberalization on capital flows and mobility. Enhanced awareness of market co-movement may expand their understanding of the significance of the structure and potential effects of free cash flows as well as any subsequent restrictions. Furthermore, this study may assist academics in forecasting and evaluating the reaction of international financial markets to global and local shocks, as well as in achieving deeper understanding of the shock transmission mechanisms.

Last but not least, when analyzing these economies, we should not be confused with the meaning of the word small: it refers only to the per capita income, not to the number of people living in those economies. The population of Argentina alone is close to 40 million, Romanian population is over 20 million, and in any one of those small economies live people struggling to survive every day. This paper will try to answer the question of how quickly, and how badly were those markets affected by the recent economic downturn and may even provide some insights about future macroeconomic policy course. 
The evidence presented in this article suggests that spillovers from USA to frontier markets are rather weak, albeit statistically significant. One possible implication is that the global economic downturn worked its way in these countries through a different transmission channel, or that the economic deterioration in those frontier markets is mainly the result of an idiosyncratic country specific shock. Furthermore, our results put forward the notion that it is not the lagged US market returns that have influence, rather it is the expected US market returns that have impact on frontier market returns. The inference is that despite different opening hours, non- synchronous trading, stale orders, information asymmetry and other possible small market inefficiencies, the frontier markets absorb news from the USA almost immediately at the time of the news release. This finding leads us to the conjecture that frontier market might not at all be inefficient, rather, their real and financial sectors might be resilient to influence from the US. From the perspective of a global financier, this finding means that there might exist some diversification benefits from investing in these developing economies. From the perspective of a developing country policy maker it means that a potential increase in capital flows from the US does not necessarily increase local market volatility even in times when the US economy is deteriorating.

In section I.II. of this article we proceed with relevant literature review on financial spillovers; in section I.III we present the data and offer some descriptive statistics; section I.IV develops the empirical models; in section I.V. we report and discuss our results; section I.VI. concludes.

\section{I.II. Literature Review}

Interdependency and correlations among world financial markets have been investigated since the mid 1960s, however, this area of international finance gained most of its popularity after the stock market crash of 1987 with King and Wadhwani (1990) establishing the unidirectional impact of the US stock returns on other markets, Hamao, Masulis, and $\mathrm{Ng}$ (1990) confirming the unidirectional impact of US market return volatility, and Eun and Shim (1989) examining the interdependency across nine stock markets. Harvey (1995) found that adding emerging market assets to a portfolio significantly enhances its opportunity set. He showed that the exposure of emerging markets to common factors is low and that it is more likely that local variables have stronger influence than do global variables. Aggarwal, Inclan, and Leal (1999) support the last claim, reporting that important local events in each country, rather than global factors, tend to be associated with sudden changes in volatility. Bekaert and Harvey (1997) ascertain that capital market liberalization increases return spillovers across markets but does not affect market volatility, while Tanizaki and Hamori (2009) determine that market volatility 
is increasing in the amount of information available. From asset allocation point of view, increasing spillover effects are generally associated with an increase in cross market correlations and thus reduced opportunities for cross border portfolio diversification (Bekaert, Harvey (2000), (2003)).

The literature on financial spillovers received a significant boost after the 1997 Asian crisis. Sola, Spagnolo, and Spagnolo (2001) find unidirectional volatility spillovers from Thailand, the country where the crisis originated, to most of the countries in the region. Caporale, Cippollini, and Spagnolo (2003) confirm unidirectional spillovers in returns from the Thai stock market. Kim (2005) and Gebka and Serwa (2006) affirm the significant influence of the American market on the Asian markets at all times, and Gebka and Serwa (2007) find significant contemporaneous spillovers from the USA during the same period.

Egert and Kocenda (2009), as well as Fadhlaoui, Bellalh, Dherry, and Zonaouri ( 2009) find some evidence for short term spillovers, but no long term relations, between developed and emerging markets of Central and Eastern Europe. Yu and Hassan (2006) and Al-Kulaib, Najand, and Mashayekh (2009) find no spillovers from the USA to the Middle East, North African, and Gulf Cooperation Countries, while Chen, Firt, and Rui (2000) suggest high correlation of Latin American countries with world markets and thus limited potential for portfolio diversification.

Psillaki, and Margaritis (2008) claim no long term relationship, but some short term interdependence between the USA stock market and the French and German stock markets. Pollard, Sapra, and Canarella (2007), on the other hand, find significant impact from both the USA market returns and volatility on the Canadian and Mexican markets. Beirne, Caporale, Schulze-Ghatts and Spagnolo (2008) suggest that mature markets influence the conditional variances in many emerging markets. Sgherri and Galesi (2009) clarify for 27 countries that asset prices are the main channel of transmission of financial shocks internationally in the short run.

\section{I.III. Data}

In this article we use daily MSCI Barra index closing prices to explore the returns on the US stock market and 21 frontier markets for the period from December 1st, 2005 to January 15th, 2010. The daily returns for each country are calculated as follows:

$$
R_{\mathrm{it}}=100 * \ln \left(P_{\mathrm{it}} / P_{\mathrm{i}(\mathrm{t}-1)}\right) * 252
$$

where $\mathrm{P}_{i t}$ is the value for each country's index closing price at time $t$. 
We choose daily data since it will better account for the stock market dynamics and provides greater insight on cross-market interactions. The countries included are: Argentina, Bahrain, Bulgaria, Croatia, Estonia, Jordan, Kazakhstan, Kenya, Kuwait, Lebanon, Mauritius, Nigeria, Oman, Pakistan, Qatar, Romania, Saudi Arabia, Slovenia, Sri Lanka, Tunisia, and United Arab Emirates. The countries and duration of the period under study are chosen such that the longest index series is available for the greatest number of countries. Lithuania, Serbia, Ukraine, Bangladesh, Trinidad and Tobago, Jamaica, Botswana and Ghana are also defined by the World Bank as frontier markets, but are not included in this study because of the lack of data for a sufficiently long period.

Morgan Stanely Composite Indices indices are established consistently across countries and thus provide an adequate ground for exploration of inter-market relations. They are value-weighted and calculated with the dividends reinvested. In order to avoid double counting, stock prices of companies set up abroad are not included. All indices are in US dollars, which provides additional comparability across markets and implicitly takes care of currency market effects.

Descriptive statistics for the US and 21 frontier markets are reported in Table 1.1. The statistics include annualized arithmetic and geometric means, median, maximum, and minimum geometric returns for each country, as well as skewness, excess kurtosis, Jarque-Bera, Ljung-Box (6), and Arch (6) test statistics. Annualized arithmetic mean returns range from $0.09 \%$ for Kazakhstan to $-0.08 \%$ for UAE and $-0.0003 \%$ for the US market. The annualized geometric mean returns range from $25.29 \%$ for Kazakhstan to $-34.58 \%$ for UAE and $-2.36 \%$ for the USA. The annualized standard deviation of geometric returns ranges from $801.3 \%$ for Kazakhstan to $279.07 \%$ for Tunisia and $405.58 \%$ for the USA. The mean returns are low as anticipated, considering that the period under study incorporates the economic downturn of 2007-2009. The standard deviation is quite high for the frontier markets, as expected (Harvey (1995)). It could be resulting from various liquidity effects or heterogeneous information sets of investors. The standard deviation is quite high for the US returns as well, representing the turmoil on the US market. The null hypothesis for no skewness is rejected at $5 \%$ significance level for Kazakhstan, Kenya, Mauritius, and Sri Lanka; the values for skewness are positive for all four countries. All countries display high and significant excess kurtosis, possibly because of time variation of conditional variance, as well as significant non normality as represented by the Jarque-Bera test statistic. The returns for all countries are highly serially correlated at 6 lags. No statistically signifi- 
cant auto-correlation is exhibited by the returns from Argentina, Bahrain, Kuwait, Romania, and Saudi Arabia.

The summary statistics provided in Table 1.1 offer an insight that contrasts with the existing literature. The average returns and standard deviation for frontier markets are not much different than for the USA. One implication could be that these markets, however young, may not represent a considerable diversification opportunity for foreign investors. This could be the result of the fact that these markets are economically and financially integrated with the US market. Another possibility is that the frontier market indices under study may be comprised mainly of internationally operating companies for which shocks from the US have greater impact than local market shocks. These indices may or may not truly represent the financial and economic sectors of the respective countries, in which case we can infer nothing about integration.

\section{I.IV. Methodology}

In the Data section we have demonstrated the presence of substantial deviations from normality and considerable leptokurtosis in the country data series. One type of models that can capture these characteristics is the Arch type models. Arch type models were first introduced by Engle (1982) to account for the influence of changing volatility in time series. Engle (1982) represents the conditional variance as a linear function of lagged squared residuals. The basic specification for an Arch model has the form

$$
\begin{gathered}
R_{\mathrm{t}}=a+u_{\mathrm{t}} \\
u_{\mathrm{t}}=h_{\mathrm{t}}^{1 / 2} z_{\mathrm{t}} \\
z_{\mathrm{t}} \sim \operatorname{iidN}(0,1) \\
h_{\mathrm{t}}=b_{0}+b_{1} u_{\mathrm{t}-1}^{2}
\end{gathered}
$$

Because only one lag of squared residual is incorporated, a model such as the above is called $\operatorname{Arch}(1)$. 
Bollerslev (1986) modified the Arch model by allowing lagged values of the conditional variance to be incorporated in the conditional variance equation. A basic $\operatorname{GARCH}(\mathrm{p}, \mathrm{q})$ model describes the conditional variance as

$$
\begin{gathered}
R_{\mathrm{t}}=a+u_{\mathrm{t}} \\
u_{\mathrm{t}}=h_{\mathrm{t}}^{1 / 2} z_{\mathrm{t}} \\
z_{\mathrm{t}} \sim \operatorname{iidN}(0,1) \\
h_{\mathrm{t}}=c_{0}+\sum_{\mathrm{i}=1}^{\mathrm{p}} c_{\mathrm{i}} u_{\mathrm{t}-\mathrm{i}}^{2}+\sum_{\mathrm{i}=1}^{\mathrm{q}} b_{\mathrm{i}} h_{\mathrm{t}-\mathrm{i}}
\end{gathered}
$$

In order to avoid negative conditional variance the parameters of the variance equation must be non-negative, $c_{0}>0, c_{\mathrm{i}} \geq 0, b_{\mathrm{i}} \geq 0$.

Generalized Auto Regressive Conditional Heteroskedasticity models are shown to better account for fat tails and volatility clustering resulting from time variation in conditional volatility. It has also been found that GARCH $(1,1)$ specification is the most appropriate for capturing these effects ( Bollerslev 1986, Enders 2001, Hamilton 1994).

In this paper we utilize two separate models to describe the evolution of returns in emerging markets. First, we utilize univariate $\operatorname{GARCH}(1,1)$ model to specify market returns as a function of own past values; then we specify a bivariate model that accounts for the impact of returns and volatility from the US market.

\section{UNIVARIATE MODEL}

The univariate model is defined as follows:

$$
\begin{gathered}
R_{\mathrm{t}}^{\mathrm{j}}=b_{0}+\sum_{\mathrm{i}=1}^{12} b_{\mathrm{i}} R_{\mathrm{t}-\mathrm{i}}^{\mathrm{j}}+u_{\mathrm{t}}^{\mathrm{j}} \\
u_{\mathrm{t}}^{\mathrm{j}}=\sqrt{h_{\mathrm{t}}^{\mathrm{j}} z_{\mathrm{t}}}
\end{gathered}
$$




$$
z_{\mathrm{t}} \sim \operatorname{iidN}(0,1)
$$

$$
h_{\mathrm{t}}^{\mathrm{j}}=a_{0}+a_{1} u_{\mathrm{t}-1}^{\mathrm{j} 2}+a_{2} h_{\mathrm{t}-1}^{\mathrm{j}}
$$

$R_{\mathrm{t}}^{\mathrm{j}}-\log$ index return for country $\mathrm{j}$.

$b_{0}-$ the portion of the returns explained by factors other than shocks and past returns.

$b_{\mathrm{i}}-$ parameter representing the impact of own country lagged returns on current returns.

$u_{\mathrm{t}}^{\mathrm{j}}$-represents the unexplained portion of the country returns.

$h_{\mathrm{t}}^{\mathrm{j}}$-conditional variance for country $\mathrm{j}$. It is interpreted as a proxy for market sentiment towards news originating within the country.

$a_{0}-\mathrm{GARCH}$ regression constant; represents the portion of the conditional volatility explained by factors other than the lagged excess returns and lagged conditional volatility. It is the portion of the market sentiment that is due neither to market sentiment towards news in the past, nor to excess returns.

$a_{1}$-parameter representing the impact of lagged excess returns.

$a_{2}$-parameter representing the impact of market sentiment towards past news originating within the country .

The above specification is estimated for returns from all 21 frontier markets, as well as the United States. The number of lagged returns included in the best-fitting model is determined using the Schwarz-Bayesian Criterion (SBC). A summary of the best-fitting models is presented in Table 1.2; discussion is offered in section I.V.

\section{BIVARIATE MODEL}

In this section we upgrade the best-fitting univariate model to a bivariate model in order to account for the effect of the USA returns and conditional volatility on the market returns of individual countries. The bivariate model is defined as follows:

$$
R_{\mathrm{t}}^{\mathrm{j}}=b_{0}+\sum_{\mathrm{i}=1}^{12} b_{\mathrm{i}} R_{\mathrm{t}-\mathrm{i}}^{\mathrm{j}}+\sum_{\mathrm{i}=0}^{12} c_{\mathrm{i}} R_{\mathrm{t}-\mathrm{i}}^{\mathrm{us}}+u_{\mathrm{t}}^{\mathrm{j}}
$$




$$
\begin{gathered}
u_{\mathrm{t}}^{\mathrm{j}}=\sqrt{h_{\mathrm{t}}^{\mathrm{j}}} z_{\mathrm{t}} \\
z_{\mathrm{t}} \sim \operatorname{iidN}(0,1) \\
h_{\mathrm{t}}^{\mathrm{j}}=a_{0}+a_{1} u_{\mathrm{t}-1}^{\mathrm{j} 2}+a_{2} h_{\mathrm{t}-1}^{\mathrm{j}}+a_{3} h_{\mathrm{t}}^{\mathrm{us}}+a_{4} h_{\mathrm{t}-1}^{\mathrm{us}}
\end{gathered}
$$

where the variables and parameters additional to the univariate model are defined as follows: $R_{\mathrm{t}-\mathrm{i}}^{\mathrm{us}}-\log$ index returns for the US market representing shocks originating from the USA. When $i=0$ we consider shocks on the US market that occur on the same day as the returns of the country under study. When $i>0$, we consider past shocks to the US market.

$c_{\mathrm{i}}$-parameter represents return spillovers from the US market to the market of the country under study. When $i=0, c_{0}$ represents the impact on returns of contemporaneous US shocks, and when $i>0$, $c_{\mathrm{i}}$ represents the impact on returns of past US shocks.

$h_{\mathrm{t}}^{\mathrm{us}}$-conditional variance for the USA market. It is interpreted as a proxy for market sentiment of traders on the USA market towards news originating in the USA and is derived from the univariate model of US market returns.

$a_{3} \& a_{4}$ parameters representing the impact of market sentiment of US investors towards contemporaneous news originating in the USA on the sentiment of the individual frontier country investors.

We choose to consider a GARCH model without any asymmetry, although the asymmetric impact on financial series volatility of negative news has long been studied (Glosten, Jagannathan, Runkle (1993)). For emerging markets, however, no asymmetry effects have been shown and any potential asymmetry is assumed to enter through the idiosyncratic shock $u_{\mathrm{t}}^{\mathrm{j}}$ (Bekaert, Harvey, \& $\mathrm{Ng} 2005$ ).

The above specification is estimated for returns from all 21 frontier markets. The number of lagged US returns included in the best-fitting bivariate model is determined using the Schwarz-Bayesian Criterion (SBC). Table 1.3 reports a summary of the best-fitting models; discussion is offered in section I.V. 
In this text we investigate whether the country's own lag market return effects $b_{\mathrm{i}}$ and the US current and lagged market return effects $c_{\mathrm{i}}$ have any statistical significance. We utilize the LR test to explore the null hypothesis of whether $b_{\mathrm{i}}=0$ and $c_{\mathrm{i}}=0$, where the number of lags $i$ of local and US returns is determined using the SBC. Further, we apply the LR test to examine the impact of the volatility spillover effects $a_{3}$, and $a_{4}$; the hypotheses tested are $a_{3}=0$ and $a_{4}=0$. We also study the possibility for homoscedasticity of the error term; we do that by applying the LR test to the null hypothesis: $a_{1}=a_{2}=a_{3}=a_{4}=0$. At the $5 \%$ significance level and the null for homoscedasticity is rejected in favor of the Garch specification. The test statistics derived from the significance tests performed on the best-fitting bivariate models are presented in Table 1.4 and a summary is reported in Table 1.5.

\section{I.V. Empirical Results}

\section{UNIVARIATE MODEL}

For each country we investigate 12 models, where each model is specified based on a different number of included own country lagged returns. The number of lagged returns under consideration ranges from 1 to 12, and the best-fitting model is determined using the Schwarz-Bayesian Criterion (SBC). A summary of the coefficients from the estimation the best-fitting univariate models for all countries is presented in Table 1.2

According to the Schwarz-Bayesian criterion (SBC), for the US and 20 out of the 21 frontier markets, with Kenya being the only exception, the best-fitting univariate model is one that includes only one period lagged home returns, and is defined as follows:

$$
\begin{gathered}
R_{\mathrm{t}}^{\mathrm{j}}=b_{0}+b_{1} R_{\mathrm{t}-1}^{\mathrm{j}}+u_{\mathrm{t}}^{\mathrm{j}} \\
u_{\mathrm{t}}^{\mathrm{j}}=\sqrt{h_{\mathrm{t}}^{\mathrm{j}} z_{\mathrm{t}}} \\
z_{\mathrm{t}} \sim i i d N(0,1) \\
h_{\mathrm{t}}^{\mathrm{j}}=a_{0}+a_{1} u_{\mathrm{t}-1}^{\mathrm{j} 2}+a_{2} h_{\mathrm{t}-1}^{\mathrm{j}}
\end{gathered}
$$


One possible implication that can be inferred from this finding is that the influence of shocks from home is no more persistent for the frontier markets than for the USA market.

For Kenya, the best-fitting univariate model is

$$
R_{\mathrm{t}}^{\mathrm{j}}=b_{0}+b_{1} R_{\mathrm{t}-1}^{\mathrm{j}}+b_{2} R_{\mathrm{t}-2}^{\mathrm{j}}+u_{\mathrm{t}}^{\mathrm{j}}
$$

with the other equations as described above.

Table 1.2 suggests magnitude of the regression constant $b_{0}$ greater than 0.1 for more than half of the countries. The presence of a significant positive constant means the unconditional expected returns are positive. This suggests optimistic outlook of investors about the future. The constant captures latent factors determining the mean of the returns, as well as unobservable variables affecting the returns, but omitted in our model. The existence of such factors may be due to potential unavailability of data other than lagged returns, or poor quality of the available data. Potential latent factors could be political instability, government regulations, corruption, international compatibility of accounting standards, as well as different regional factors.

For several countries, Table 1.2 reports lower magnitude of the constant, relative to their peers. The relatively low magnitude of the constant implies low, or even negative mean returns for these countries, low or negative expected returns, and thus relatively pessimistic prospects about the future. The low magnitude may also imply that there is more data available for these countries, as well as better quality of the data, which is fully captured by the index returns. One implication of such possibility could be that markets in these countries are more efficient, which results in the weaker presence of latent factors and unobservable variables. Another possibility is that while home markets as a whole may be unable to incorporate all relevant information, the returns of the companies having most weight in the MSCI index are resilient to local factors other than past returns. This resilience could be because the companies in question operate mostly internationally, there is more and better quality data available for them, or they are large enough to not be affected by home market processes.

According to Table 1.2, for most of the countries the influence of past returns $b_{\mathrm{i}}$ is below 0.1. For eight countries, the impact of past returns is greater than 0.1 . The greater the impact of past returns, the longer it takes for those markets to evaluate the full effect of past shocks. One possibility is that the economies of these countries are not that well diversified, and a shock to one sector trickles to other sectors and that trickle takes time to be evaluated. 
The magnitude of the variance constant $a_{0}$ for most of the countries is between zero and one, as presented in Table 1.2. For the USA the value of the variance constant is 0.086 , which is the lowest for all countries. Since the US market has been shown to be efficient in incorporating information (Fama (1998)), the effect of any unobservable variables or latent factors is absorbed immediately through a change in returns. For the frontier markets, the lowest constant value is for Kenyan returns: 0.098. For four markets the magnitude of the constant is greater than one. Those markets are Argentina (1.711), Lebanon (2.5), Mauritius (1.549), and Pakistan (1.4).

Table 1.2 further indicates the influence of one period lagged events on current market sentiment $a_{1}$ is between 0.5 and 1 , for almost all countries, including the US (0.919). Considering that the period under study incorporates periods of great market turbulence and uncertainty, it seems reasonable to assume that the impact of any past news is being continuously reassessed. A high coefficient of impact may imply not only abundance of information, but also abundance of important information, such as announcement of structural reforms, or lack there of, announcements of new government policies or regulations, outdated statistical information. The only country with relatively low impact of past local news is Estonia (0.087). Considering that Estonia is a small, export oriented economy, it is realistic to believe that the index data is composed of predominantly export oriented companies, for which local information is relatively unimportant relative to global news and thus the coefficient of impact of past local news is relatively low.

\section{BIVARIATE MODEL}

A summary of the results from the estimation of bivariate models for each of the 21 frontier markets is presented in Table 1.3. For each country we investigate 13 models, where each model is specified based on a different number of included US lagged returns. The number of lagged returns under consideration ranges from 0 to 12, and the best-fitting model is determined using the Schwarz-Bayesian Criterion (SBC). According to the Schwarz-Bayesian criterion (SBC), for 16 out of the 21 frontier markets the best-fitting bivariate model is one that includes only contemporaneous US market returns and no US lagged returns. The model is specified as follows:

$$
\begin{gathered}
R_{\mathrm{t}}^{\mathrm{j}}=b_{0}+b_{1} R_{\mathrm{t}-1}^{\mathrm{j}}+c_{0} R_{\mathrm{t}}^{u s}+u_{\mathrm{t}}^{\mathrm{j}} \\
u_{\mathrm{t}}^{\mathrm{j}}=\sqrt{h_{\mathrm{t}}^{\mathrm{j}} z_{\mathrm{t}}}
\end{gathered}
$$




$$
\begin{gathered}
z_{\mathrm{t}} \sim \operatorname{iidN}(0,1) \\
h_{\mathrm{t}}^{\mathrm{j}}=a_{0}+a_{1} u_{\mathrm{t}-1}^{\mathrm{j} 2}+a_{2} h_{\mathrm{t}-1}^{\mathrm{j}}+a_{3} h_{\mathrm{t}}^{\mathrm{us}}+a_{4} h_{\mathrm{t}-1}^{\mathrm{us}}
\end{gathered}
$$

where $h_{\mathrm{t}}^{\mathrm{us}}$ is derived from the uni-variate model for US returns.

For four countries, Bahrain, Kuwait, Oman, and Tunisia, Table 1.3 suggests the bivariate model contains one period US lagged returns, along with the contemporaneous returns:

$$
R_{\mathrm{t}}^{\mathrm{j}}=b_{0}+b_{1} R_{\mathrm{t}-1}^{\mathrm{j}}+c_{0} R_{\mathrm{t}}^{u s}+c_{1} R_{\mathrm{t}-1}^{u s}+u_{\mathrm{t}}^{\mathrm{j}}
$$

with the other equations the same as above.

For the Kenyan market, the bivariate model contains two period lagged domestic returns and contemporaneous returns from the US. This model is as follows:

$$
R_{\mathrm{t}}^{\mathrm{j}}=b_{0}+b_{1} R_{\mathrm{t}-1}^{\mathrm{j}}+b_{2} R_{\mathrm{t}-2}^{j}+c_{0} R_{\mathrm{t}}^{u s}+u_{\mathrm{t}}^{\mathrm{j}}
$$

with other equations as above.

\section{DISCUSSION OF SPILLOVERS}

The center piece of the bivariate model, summarized in Table 1.3, is the investigation of return and volatility spillovers from the US to the local markets as measured by the parameters $c_{0}, a_{3}$, and $a_{4}$. The greatest return spillovers from the USA are to Argentina (0.957), Kazakhstan (0.237), and Romania (0.329). For majority of the countries the impact coefficients fall between 0.0 and 0.1 , with 4 markets experiencing negative spillovers: Jordan (-0.021), Lebanon (-0.059), Nigeria (-0.027), and Kenya (-0.028) at lag one.

For Argentina, Kazakhstan, and Romania the high impact coefficients may indicate deep economic inter-dependence between those countries and the US, rather than financial relations only. The economies of these four countries are predominantly export oriented and trade relations might be one reason for economic integration. If the trade export of those economies is predominantly to the USA, then they might not be well diversified and thus vulnerable to shocks from the American market. One 
implication is that in these four countries, international investors may find little or no scope for diversification. Not such is the situation with the markets experiencing negative impact from the US: Jordan, Lebanon, Nigeria, and Kenya. The negative relation between the US returns and returns in those countries implies low degree of inter-dependence between local economies and the US economy and thus presence of possible diversification opportunities from the standpoint of international portfolio managers. From a policy maker's point of view, those countries seem resilient to shocks from the US market. One implication is that downturn in USA should not be blamed for recession in those countries, and any economic slow down is more likely to be "home grown" rather than "imported" from US, at least not through this channel.

It is interesting to note that although the local and US market returns occur on the same date, the markets under study open before the US market and have little or no overlap in trading hours. Most of those markets open seven or more hours before the US market opens, with the exception being Argentina opening one hour ahead, Nigeria and Tunisia five hours ahead, and Slovenia six hours ahead. One important implication of this finding is that it might not be the actual US returns that matter, but the expected US returns. Any announcements made in the USA after closing of the stock exchanges on day one, and before opening on day two, are absorbed by the US market on day two. Throughout the trading day on local frontier markets, investors observe those announcements, and incorporate them in their asset valuation immediately, while they only get incorporated in the US returns on the next trading day in the US, which in most cases starts just after closing of local markets. To better describe such a situation, we could say that it is the US overnight returns that affect the local markets, rather than the actual daily returns, where the overnight returns are defined as the change in price between closing on day one and opening on day two. The overnight returns form the expected returns, and are reflected in the US daily returns on the next day, so those returns seem to affect the local market returns despite the fact that local markets may close for the day before the US market opens. Similar discussion and more details on the international transmission of overnight returns can be found in Hamao, Masulis, and $\mathrm{Ng}$ (1994), Lin, Engle, and Ito (1994), and Baur and Jung (2006).

For thirteen of the twenty one frontier markets, Table 1.3 reports the impact coefficient of lagged home returns $b_{1}$ is greater than the impact coefficient of the current US returns $c_{0}$. This finding implies that for the period under study for those markets, the average impact of domestic shocks is stronger than the average impact of shocks from the US market. As a result, the economies of those countries 
may be less vulnerable to US market deterioration relative to their peers. The opposite is true for the remaining eight markets. For those, the average influence of shocks from the US is greater than the average influence of domestic shocks, and their economies may be more vulnerable to US market shocks relative to their peers.

The impact coefficients $a_{3}$ and $a_{4}$ representing volatility spillovers give us the scale of transmission of market sentiment from the US stock market to the local markets of the countries under study. In accordance with literature on emerging markets, Table 1.3 reports that volatility spillovers are weaker relative to return spillovers. Current period spillover parameter $a_{3}$ for most of the countries falls between 0.00 and 0.05 . The low magnitude of impact coefficients imply weak, albeit statistically significant, cross-market transmission of market sentiment from the US market. The degree of transmission of market sentiment might also be indicative of the presence of feed back trading and herding behavior. The low parameter values imply very limited presence of those inefficiencies. Exception are Argentina (0.084), Bulgaria (0.158), Croatia (0.103), Mauritius (0.33), Romania (1.836), and Saudi Arabia (0.122). Similarly for one period lagged spillovers, majority of the countries fall in the range between 0.00 and 0.05. Exceptions are Bahrain (0.693), Bulgaria (0.112), Kenya (0.119), Lebanon (0.066), Nigeria (0.161), Oman (0.686), Romania (0.436), and Saudi Arabia (0.28). For these markets, and especially for Romania, there is stronger indication for cross-border transmission of market sentiment and thus more prominent presence of herding behavior and feed back trading.

It is worth exploring whether the market sentiment of local market investors $h_{\mathrm{t}}^{\mathrm{j}}$ is affected mostly by the current and lagged market sentiment of US investors $h_{\mathrm{t}}^{\mathrm{US}}$ and $h_{\mathrm{t}-1}^{\mathrm{US}}$, or by the local investors' sentiment towards domestic lagged events $h_{\mathrm{t}-1}^{\mathrm{j}}$. For most of the countries, Table 1.3 indicates magnitude of the impact coefficient of lagged own market news $a_{1}$ between 0.5 and 1.0. This result implies that past local news and local market sentiment on average have stronger impact on local investors compared to both current and lagged news from the US market. For several countries like Kenya, Lebanon, Nigeria, Romania, and Saudi Arabia, the coefficient capturing the effect of local news on market sentiment is not significantly different from null. For these countries, the sentiment of US investors is more important than local factors. For five countries, the value of variance constant $a_{0}$ is quite high: 6.033 for Kenya, 8.194 for Lebanon, 6.081 for Nigeria, 9.675 for Romania, and 22.271 for Saudi Arabia. Implication is that for these frontier markets there is significant influence of international and domestic factors other than those included in the Garch specification. One possible explanation is 
that those economies are mostly export oriented and their exports are sensitive to a wide variety of international factors.

To summarize, for half of the countries, the influence of local shocks and market sentiment is stronger than the influence stemming from the US market. The interdependence of most of the frontier markets with the US market is weak, albeit significant. The weak interdependence can be attributed to fluctuations in the relative significance of market specific shocks versus shocks from the US. When shocks from US dominate domestic shocks, markets will move closer together and will appear more integrated. When domestic shocks dominate shocks from the US, the markets will move further apart and will appear more segmented. In addition, frontier markets could be underrepresented in global portfolios and thus be insulated from portfolio re-balancing. Last but not least, the US and frontier market indices may have significantly different structure which may further reduce the cross-border market co-movement. Furthermore, we find that local markets absorb information from US as soon as it appears which implies frontier markets are highly informationally efficient.

\section{I.VI. Conclusion}

In this article we examine the degree to which the returns and conditional volatility of 21 frontier markets were affected by the fluctuations in returns and conditional volatility of the American stock market during the period between December 1st, 2005 and January 15th, 2010. Using SchwarzBayesian criterion we find that for seventeen countries the best-fitting model is one that includes only the contemporaneous US returns, and for four countries, the best-fitting model includes one period lagged US returns as well. We find weak, albeit significant, mostly positive return spillovers from the US market. For four countries, Jordan, Lebanon, Nigeria, and Kenya, we find weak negative spillovers, implying possible diversification opportunities. For thirteen markets, the influence of past local shocks is greater than the influence of current shocks from the US, and for sixteen markets local past volatility has stronger impact than volatility from US.

We find that frontier markets incorporate new information as soon as it arrives and for most of the countries local information is weighted heavier relative to information from the USA.

The research presented in this article may be extended using time-varying parameter techniques to better account for market dynamics and possible switching dominance overtime of domestic and US shocks. Other extensions could be the investigation of the effects of incomplete information and 
fat tails on market interdependence, as well as an empirical assessment of various shock transmission channels across frontier markets. 


\section{REFERENCES}

Aggarwal R, Inclan C, Leal R. Volatility in emerging stock markets. Journal of Financial and Quantitative Analysis. 1999;34(1):33.

Alkulaib Yaser A., Najand Mohammadm Mashayekh A . Dynamic linkages among equity markets in the Middle East and North African countries. Journal of Multinational Financial Management. 2009; 19:43-53.

Baur, Dirk, Jung RC. Return and volatility linkages between the US and the German stock market. Journal of International Money and Finance 2006;25:598-613.

Beirne J, Caporale G, Schulze-Ghattas M, Spagnolo N. Volatility spillovers and contagion from mature to emerging stock markets. IMF WP08-286; 2009.

Bekaert G, Harvey C, Ng A. Market integration and contagion. Journal of Business. 2005;78(1).

Bekaert G, Harvey C. Emerging markets finance. Journal of Empirical Finance. 2003;10(1-2):3-56.

Bekaert G, Harvey C. Foreign speculators and emerging equity markets. Journal of Finance. 2000;55(2):

$565-613$.

Bekaert, Geert HC. Emerging equity market volatility. Journal of Financial Economics. 1997;43:2977

Bollerslev T. Generalized autoregressive conditional heteroskedasticity. Journal of Econometrics. 1986;31(3):

307-327.

Calvo G. Contagion in emerging markets: When Wall Street is a carrier. IEA Conference Volume Series.Vol 136. Citeseer; 2004:81-94.

Caporale G, Pittis N, Spagnolo N. Volatility transmission and financial crises. Journal of Economics and Finance. 2006;30(3):376-390.

Chen G, Firth M, Meng Rui O. Stock market linkages: evidence from Latin America. Journal of Banking \& Finance. 2002;26(6):1113-1141.

Egert B, Kocenda E. Interdependence between Eastern and Western European stock markets: evidence from intraday data. Economic Systems. 2007;31(2):184-203.

Enders W. Applied econometric time series. Wiley \& Sons;1995.

Engle R. Autoregressive conditional heteroskedasicity with estimates of the variance of U.K. inflation. Econometrica. 1982;50(4):987-1008.

Eun CS, Shim S. International transmission of stock market movements. Journal of Financial and Quantitative Analysis. 1989;24(2):241.

Fama E. Market efficiency, long-term returns, and behavioral finance. Journal of Financial Economics. 1998;49(3):283-306. 
Fadhlaoui Kais, Bellalah Makram, Dherry Armand ZM. An empirical examination of international diversification benefits in central european emerging markets. International Journal of Business. $2009 ; 14(2)$.

Gebka B, Serwa D. Are financial spillovers stable across regimes? Evidence from the 1997 Asian crisis. Journal of International Financial Markets, Institutions and Money. 2006;16(4):301-317.

Gebka B, Serwa D. Inter-regional spillovers between emerging capital markets around the world. Research in International Business and Finance. 2007;21:203-221.

Hamao Y, Masulis R, Ng V. Correlations in price changes and volatility across international stock markets. Review of Financial Studies. 1990;3(2):281-307.

Hamilton J. Time series analysis. Princeton Univ Pr; 1994.

Harvey C. Predictable risk and returns in emerging markets. Review of Financial Studies. 1995;8(3):773-816.

Kaminsky G, Reinhart C. Financial markets in times of stress. Journal of Development Economics. 2002;69(2):

451-470.

Kim S. The spillover effects of US and Japanese public information news in advanced Asia-Pacific stock markets. Pacific-Basin Finance Journal. 2003;11(5):611-630.

King, M. , Wadhawani S. Transmission of volatility between stock markets. Review of Financial Studies. 1990;3(1):5-33.

Kodres, Laura E, Pritsker M. A rational expectations model of financial contagion. Journal of Finance. 2002;57(2):769-799.

Lin W, Engle R, Ito T. Do bulls and bears move across borders? International transmission of stock returns and volatility. Review of Financial Studies. 1994;7(3):507-538.

Pollard S, Sapra S, Canarella G. Asymmetry and spillover effects in the North American equity markets. econstor.eu. 2007;1:323-343.

Pritsker M. The channels for financial contagion. International financial contagion. 2001;(202):

$67-95$.

Psillaki M, Margaritis D. Long-run interdependence and dynamic linkages in international stock markets: evidence from France Germany and the US. Journal of Money, Investment and Banking. $2008 ;(4)$.

Sgherri S, Galesi A. Regional financial spillovers across Europe: a global VAR analysis. IMF WP09-23; 2009.

Sola M, Spagnolo F, Spagnolo N. A test for volatility spillovers. Economics Letters. 2002;76(1):77-84.

Tanizaki H, Hamori S. Volatility transmission between Japan, UK and USA in daily stock returns. Empirical Economics. 2009. 


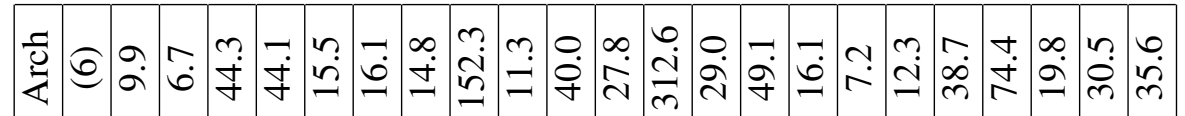

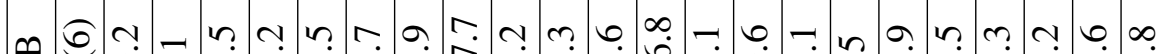

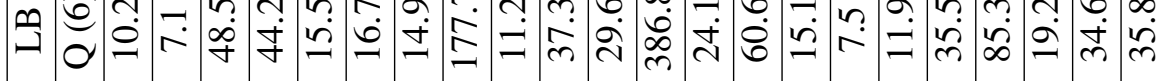

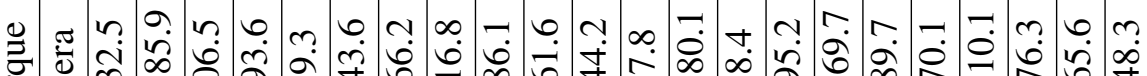

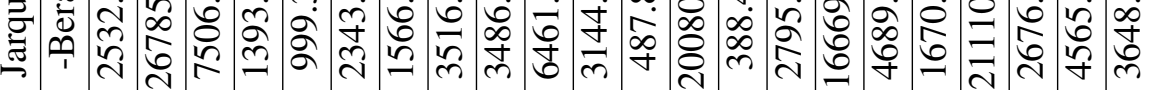

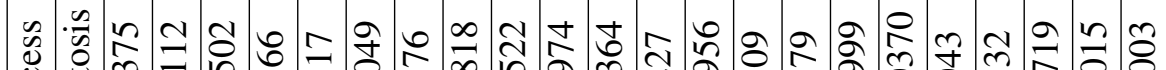
U

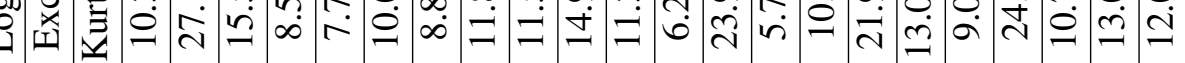

రీ จิ

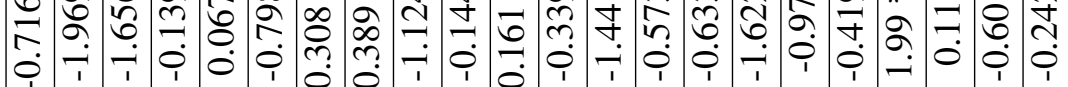

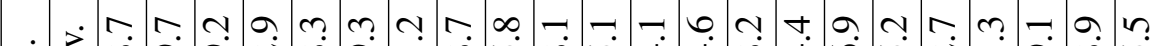

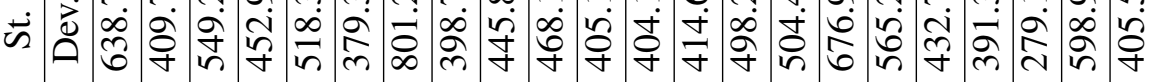

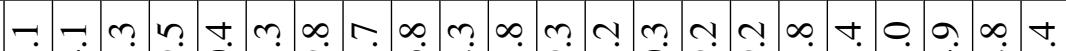

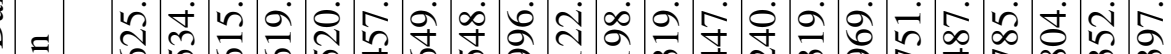

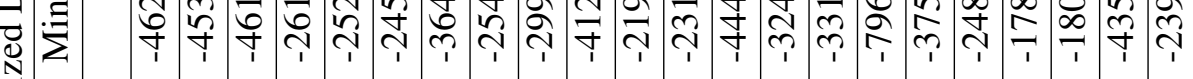

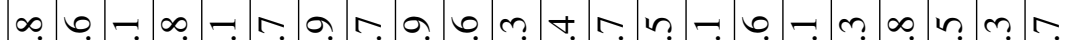

வ்

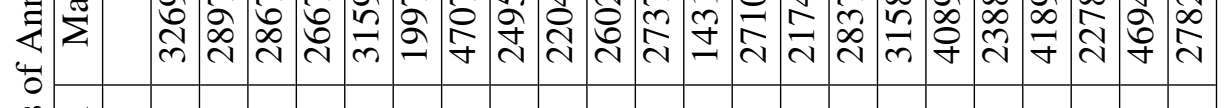

矛

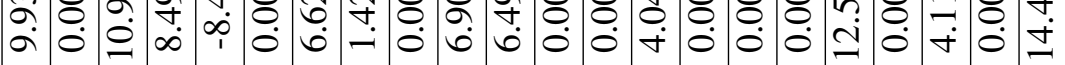

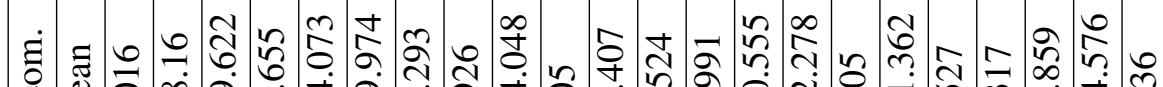

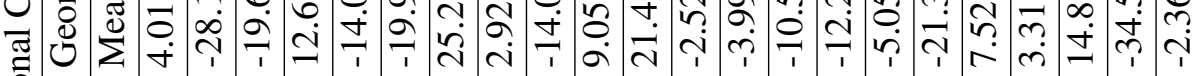

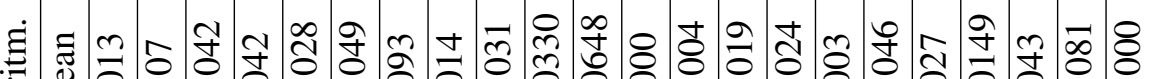

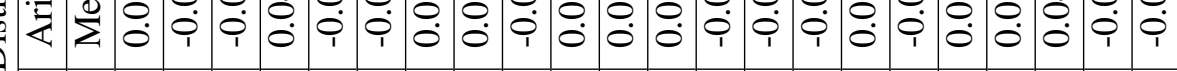

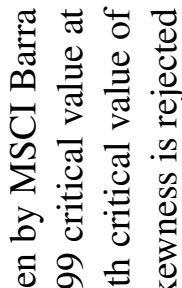

ญे

की

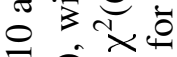

तิ

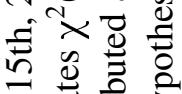

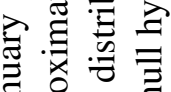

灵

구 त्ञ⿰氵

สิ $\tilde{0}$ :

\&ै.

部哥.

苛焉

ॠ

घี

岕总莽

จี

\& $\bar{\sigma}$

$\sum_{0} \sum^{ \pm}$

जी

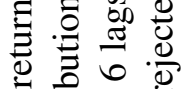

놈ำ

包

\& : :

4

命䒕

. ญ. ठ

至

㟧

$\gtrsim . \Xi \stackrel{0}{=}$

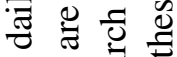

人 क षे

을 矛

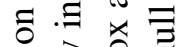

ठ

‡

$\because=$ वे

过是

.$\stackrel{0}{0} \bar{F}$

.

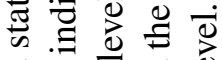

$\overrightarrow{4} \frac{1}{2}$

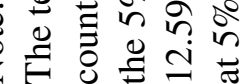


Table 1.2. Summary of the best-fitting univariate models for the US and each of the 21 frontier markets.

\begin{tabular}{|l|l|l|l|l|l|l|}
\hline \multicolumn{7}{|c|}{ Univariate Model } \\
\hline Country & $b_{0}$ & $b_{1}$ & $b_{2}$ & $a_{0}$ & $a_{1}$ & $a_{\text {a }}$ \\
\hline Argentina & 0.359 & 0.013 & & 0.629 & 0.084 & 0.133 \\
& $(0.14)$ & $(0.03)$ & & $(0.11)$ & $(0.02)$ & $(0.02)$ \\
\hline Bahrain & -0.11 & 0.09 & & 0.629 & 0.843 & 0.126 \\
& $(0.09)$ & $(0.04)$ & & $(0.11)$ & $(0.02)$ & $(0.02)$ \\
\hline Bulgaria & 0.198 & -0.084 & & 0.318 & 0.887 & 0.109 \\
& $(0.11)$ & $(0.04)$ & & $(0.13)$ & $(0.02)$ & $(0.02)$ \\
\hline Croatia & 0.263 & 0.114 & & 0.792 & 0.844 & 0.114 \\
& $(0.11)$ & $(0.03)$ & & $(0.31)$ & $(0.05)$ & $(0.03)$ \\
\hline Estonia & -0.052 & 0.119 & & 0.25 & 0.087 & 0.133 \\
& $(0.1)$ & $(0.03)$ & & $(0.09)$ & $(0.02)$ & $(0.02)$ \\
\hline Jordan & -0.064 & 0.045 & & 0.144 & 0.922 & 0.07 \\
& $(0.09)$ & $(0.03)$ & & $(0.05)$ & $(0.01)$ & $(0.01)$ \\
\hline Kazakhstan & 0.37 & -0.024 & & 0.597 & 0.91 & 0.076 \\
& $(0.17)$ & $(0.03)$ & & $(0.22)$ & $(0.02)$ & $(0.02)$ \\
\hline Kenya & -0.003 & 0.27 & 0.085 & 0.098 & 0.913 & 0.089 \\
& $(0.09)$ & $(0.04)$ & $(0.04)$ & $(0.042)$ & $(0.01)$ & $(0.01)$ \\
\hline Kuwait & 0.133 & 0.063 & & 0.166 & 0.933 & 0.06 \\
& $(0.1)$ & $(0.04)$ & & $(0.05)$ & $(0.01)$ & $(0.00)$ \\
\hline Lebanon & 0.006 & 0.121 & & 2.505 & 0.593 & 0.361 \\
& $(0.1)$ & $(0.04)$ & & $(0.59)$ & $(0.07)$ & $(0.07)$ \\
\hline Mauritius & 0.23 & 0.215 & & 1.549 & 0.644 & 0.321 \\
& $(0.09)$ & $(0.04)$ & & $(0.37)$ & $(0.06)$ & $(0.06)$ \\
\hline Nigeria & 0.023 & 0.447 & & 0.613 & 0.77 & 0.19 \\
& $(0.08)$ & $(0.03)$ & & $(0.173)$ & $(0.04)$ & $(0.04)$ \\
\hline Omakistan & 0.121 & 0.099 & & 0.294 & 0.878 & 0.111 \\
& $(0.09)$ & $(0.04)$ & & $(0.06)$ & $(0.01)$ & $(0.02)$ \\
\hline & 0.248 & 0.091 & & 1.4 & 0.742 & 0.2 \\
& $(0.12)$ & $(0.03)$ & & $(0.27)$ & $(0.03)$ & $(0.03)$ \\
\hline
\end{tabular}




\begin{tabular}{|l|l|l|l|l|l|l|}
\hline Qatar & -0.018 & 0.098 & & 0.798 & 0.868 & 0.104 \\
& $(0.122)$ & $(0.04)$ & & $(0.17)$ & $(0.02)$ & $(0.02)$ \\
\hline Romania & 0.237 & 0.04 & & 0.21 & 0.976 & 0.02 \\
& $(0.18)$ & $(0.03)$ & $(0.06)$ & $(0.00)$ & $(0.00)$ \\
\hline S. Arabia & 0.023 & 0.038 & & 0.251 & 0.933 & 0.062 \\
& $(0.13)$ & $(0.04)$ & $(0.08)$ & $(0.01)$ & $(0.01)$ \\
\hline Slovenia & 0.227 & 0.189 & & 0.555 & 0.848 & 0.117 \\
& $(0.1)$ & $(0.03)$ & $(0.35)$ & $(0.07)$ & $(0.05)$ \\
\hline Sri Lanka & -0.04 & 0.237 & & 0.278 & 0.826 & 0.18 \\
& $(0.08)$ & $(0.04)$ & & $(0.06)$ & $(0.02)$ & $(0.03)$ \\
\hline Tunisia & 0.145 & 0.064 & & 0.454 & 0.776 & 0.189 \\
& $(0.07)$ & $(0.04)$ & & $(0.12)$ & $(0.03)$ & $(0.03)$ \\
\hline UAE & -0.058 & 0.136 & & 0.329 & 0.922 & 0.076 \\
& $(0.134)$ & $(0.04)$ & & $(0.1)$ & $(0.01)$ & $(0.01)$ \\
\hline USA & 0.124 & -0.097 & & 0.086 & 0.919 & 0.074 \\
& $(0.07)$ & $(0.03)$ & & $(0.02)$ & $(0.01)$ & $(0.01)$ \\
\hline
\end{tabular}

Note:

The estimation is done via ML utilizing 1077 daily observations of country returns between December 1st, 2005 and January 15th, 2010 as given by MSCI Barra country indices. 
Table 1.3. Summary of the best-fitting bivariate models for each of the 21 frontier markets.

\begin{tabular}{|l|c|c|c|c|c|c|c|c|c|c|}
\hline \multicolumn{1}{|c|}{ Bivariate Model } \\
\hline Country & $b_{0}$ & $b_{1}$ & $b_{2}$ & $c_{0}$ & $c_{1}$ & $a_{0}$ & $a_{1}$ & $a_{2}$ & $a_{3}$ & $a_{4}$ \\
\hline Argentina & 0.18 & 0.111 & & 0.957 & & 1.31 & 0.72 & 0.185 & 0.084 & 0.017 \\
& $(0.12)$ & $(0.03)$ & & $(0.05)$ & & $(0.44)$ & $(0.07)$ & $(0.04)$ & $(0.314)$ & $(0.31)$ \\
\hline Bahrain & -0.11 & 0.101 & & 0.017 & 0.1 & 3.126 & 0.000 & 0.123 & 0.000 & 0.693 \\
& $(0.09)$ & $(0.04)$ & & $(0.03)$ & $(0.1)$ & $(0.47)$ & $(0.00)$ & $(0.03)$ & $(0.00)$ & $(0.07)$ \\
\hline Bulgaria & 0.19 & -0.065 & & 0.085 & & 0.67 & 0.728 & 0.112 & 0.158 & 0.112 \\
& $(0.11)$ & $(0.04)$ & & $(0.05)$ & & $(0.31)$ & $(0.07)$ & $(0.03)$ & $(1.21)$ & $(1.219)$ \\
\hline Croatia & 0.24 & 0.107 & & 0.13 & & 1.672 & 0.676 & 0.155 & 0.103 & 0.000 \\
& $(0.11)$ & $(0.04)$ & & $(0.04)$ & & $(0.54)$ & $(0.09)$ & $(0.05)$ & $(0.05)$ & $(0.00)$ \\
\hline Estonia & -0.02 & 0.131 & & 0.111 & & 0.17 & 0.83 & 0.14 & 0.039 & 0.04 \\
& $(0.1)$ & $(0.03)$ & & $(0.04)$ & & $(0.12)$ & $(0.03)$ & $(0.02)$ & $(0.65)$ & $(0.65)$ \\
\hline Jordan & -0.06 & 0.044 & & -0.02 & & 0.144 & 0.91 & 0.073 & 0.009 & 0.000 \\
& $(0.09)$ & $(0.03)$ & & $(0.03)$ & & $(0.07)$ & $(0.02)$ & $(0.01)$ & $(0.01)$ & $(0.00)$ \\
\hline Kazak. & 0.34 & -0.003 & & 0.237 & & 0.613 & 0.897 & 0.081 & 0.016 & 0.016 \\
& $(0.17)$ & $(0.03)$ & & $(0.06)$ & & $(0.23)$ & $(0.02)$ & $(0.02)$ & $(0.00)$ & $(0.00)$ \\
\hline Kenya & -0.02 & 0.216 & 0.11 & -0.028 & & 6.039 & 0.000 & 0.409 & 0.001 & 0.119 \\
& $(0.09)$ & $(0.03)$ & $(0.1)$ & $(0.03)$ & & $(0.47)$ & $(0.00)$ & $(0.06)$ & $(0.02)$ & $(0.04)$ \\
\hline Kuwait & -0.01 & 0.064 & & 0.003 & 0.1 & 6.71 & 0.000 & 0.031 & 0.000 & 0.781 \\
& $(0.11)$ & $(0.04)$ & & $(0.04)$ & $(0.0)$ & $(0.64)$ & $(0.00)$ & $(0.02)$ & $(0.00)$ & $(0.08)$ \\
\hline Lebanon & -0.36 & -0.249 & & -0.059 & & 8.194 & 0.000 & 1.088 & 0.000 & 0.066 \\
& $(0.1)$ & $(0.03)$ & & $(0.03)$ & & $(0.87)$ & $(0.00)$ & $(0.13)$ & $(0.00)$ & $(0.042)$ \\
\hline Mauritius & 0.25 & 0.213 & & 0.037 & & 2.095 & 0.196 & 0.512 & 0.33 & 0.008 \\
& $(0.08)$ & $(0.04)$ & & $(0.03)$ & & $(0.48)$ & $(0.06)$ & $(0.08)$ & $(0.00)$ & $(0.000)$ \\
\hline Nigeria & 0.02 & 0.49 & & -0.027 & & 6.081 & 0.000 & 0.261 & 0.000 & 0.161 \\
& $(0.09)$ & $(0.03)$ & & $(0.03)$ & & $(0.57)$ & $(0.00)$ & $(0.05)$ & $(0.00)$ & $(0.05)$ \\
\hline
\end{tabular}




\begin{tabular}{|l|c|c|c|c|c|c|c|c|c|c|}
\hline Oman & 0.071 & 0.111 & & -0.004 & 0.1 & 3.216 & 0.000 & 0.081 & 0.000 & 0.686 \\
& $(0.09)$ & $(0.04)$ & & $(0.03)$ & $(0.1)$ & $(0.04)$ & $(0.03)$ & $(0.03)$ & $(0.00)$ & $(0.07)$ \\
\hline Pakistan & 0.25 & 0.092 & & 0.019 & & 1.394 & 0.743 & 0.197 & 0.000 & 0.000 \\
& $(0.12)$ & $(0.03)$ & & $(0.02)$ & & $(0.27)$ & $(0.03)$ & $(0.03)$ & $(0.00)$ & $(0.000)$ \\
\hline Qatar & -0.05 & 0.098 & & 0.003 & & 0.762 & 0.838 & 0.103 & 0.01 & 0.05 \\
& $(0.12)$ & $(0.04)$ & & $(0.04)$ & & $(0.22)$ & $(0.03)$ & $(0.02)$ & $(0.00)$ & $(0.00)$ \\
\hline Romania & 0.17 & 0.07 & & 0.329 & & 9.675 & 0.000 & 0.114 & 1.836 & 0.431 \\
& $(0.16)$ & $(0.03)$ & & $(0.06)$ & & $(1.59)$ & $(0.00)$ & $(0.04)$ & $(0.00)$ & $(0.00)$ \\
\hline S. Arabia & -0.12 & 0.04 & & 0.086 & & 2.271 & 0.001 & 0.072 & 0.122 & 0.28 \\
& $(0.16)$ & $(0.04)$ & & $(0.05)$ & & $(1.30)$ & $(0.00)$ & $(0.02)$ & $(1.19)$ & $(1.19)$ \\
\hline Slovenia & 0.21 & 0.198 & & 0.096 & & 1.479 & 0.575 & 0.13 & 0.174 & 0.056 \\
& $(0.1)$ & $(0.03)$ & & $(0.04)$ & & $(0.47)$ & $(0.12)$ & $(0.03)$ & $(2.34)$ & $(2.35)$ \\
\hline S. Lanka & -0.04 & 0.237 & & 0.061 & & 0.382 & 0.732 & 0.24 & 0.018 & 0.017 \\
& $(0.08)$ & $(0.04)$ & & $(0.03)$ & & $(0.11)$ & $(0.05)$ & $(0.05)$ & $(0.19)$ & $(0.19)$ \\
\hline Tunisia & 0.16 & 0.12 & & 0.078 & 0.1 & 4.458 & 0.000 & 0.217 & 0.000 & 0.093 \\
& $(0.08)$ & $(0.04)$ & & $(0.02)$ & $(0.1)$ & $(0.39)$ & $(0.00)$ & $(0.05)$ & $(0.00)$ & $(0.03)$ \\
\hline UAE & -0.06 & 0.13 & & 0.01 & & 0.351 & 0.902 & 0.082 & 0.016 & 0.018 \\
& $(0.14)$ & $(0.04)$ & & $(0.05)$ & & $(0.14)$ & $(0.02)$ & $(0.01)$ & $(0.3)$ & $(0.3)$ \\
\hline
\end{tabular}

Note:

The estimation is done via ML utilizing 1077 daily observations of country returns between December 1st, 2005 and January 15th, 2010 as given by MSCI Barra country indices. All country indices are in US currency. 


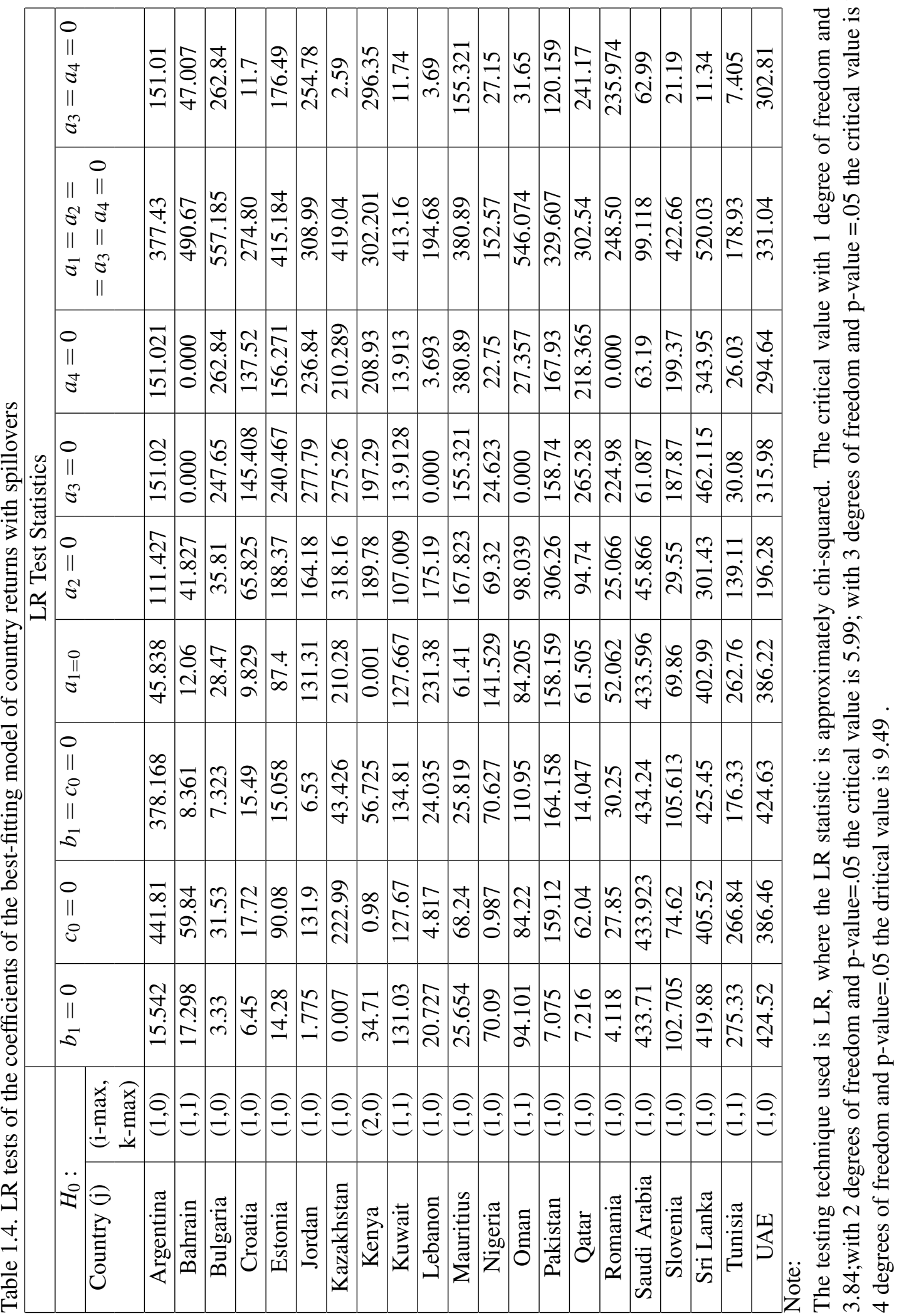


Table 1.5. Summary of hypothesis test results

\begin{tabular}{|c|c|c|c|c|}
\hline Country & $\begin{array}{c}\text { Spillovers } \\
\text { in Mean }\end{array}$ & $\begin{array}{c}\text { Spillovers from Current } \\
\text { Period US Volatility }\end{array}$ & $\begin{array}{c}\text { Spillovers from one-period } \\
\text { Lag US Volatility }\end{array}$ & Garch \\
\hline Argentina & yes & yes & yes & yes \\
\hline Bahrain & yes & no & no & yes \\
\hline Bulgaria & yes & yes & yes & yes \\
\hline Croatia & yes & yes & yes & yes \\
\hline Estonia & yes & yes & yes & yes \\
\hline Jordan & yes & yes & yes & yes \\
\hline Kazakhstan & yes & yes & yes & yes \\
\hline Kenya & yes & yes & yes & yes \\
\hline Kuwait & yes & yes & yes & yes \\
\hline Lebanon & yes & no & yes & yes \\
\hline Mauritius & yes & yes & yes & yes \\
\hline Nigeria & no & yes & yes & yes \\
\hline Oman & yes & no & yes & yes \\
\hline Pakistan & yes & yes & no & yes \\
\hline Qatar & yes & yes & yes & yes \\
\hline Romania & yes & yes & yes & yes \\
\hline S. Arabia & yes & yes & yes & yes \\
\hline Slovenia & yes & yes & yes & yes \\
\hline Sri Lanka & yes & yes & yes \\
\hline Tunisia & yes & yes & yes &
\end{tabular}

Note:

Presence of garch effects, and return and volatility spillovers for each of the 21 frontier markets. 


\section{TIME-VARYING FINANCIAL SPILLOVERS FROM THE US THE FRONTIER MAR-}

KETS

\section{II.I. INTRODUCTION}

The impact of a change in returns of one financial market on the returns of financial markets abroad (called return spillovers) depends on the financial openness of the foreign countries, as well as the nature of cross-country economic and financial linkages. As a result of such linkages, news released in one country may affect not only local market returns, but the returns of foreign markets as well. The newly arrived information may be reflected either instantly in the foreign market returns, or with a lag, depending on informational asymmetries, market liquidity, and other local market factors. The more financially open a stock market is, the more synchronized its returns are with the returns of foreign markets, and the greater the scope for return spillovers.

Conventional econometric models often assume a stable relationship between dependent and independent variables, embodied in fixed parameters. In the context of return spillovers, this assumption asserts constant sensitivity of local market returns to changes in returns of other stock markets. However, in a dynamically changing economic environment, such an assumption may not be realistic. For example, markets under study may be undergoing structural changes during the period of interest, or they may be experiencing macroeconomic reforms. Such an assumption could be particularly inappropriate when Frontier markets are in consideration, since as those markets evolve and mature, sensitivity of local returns to shocks coming from abroad may be evolving as well. Furthermore, the parameter stability assumption may not fully utilize all information embodied in the sequential nature of market returns and thus may not fully account for the dynamic evolution of the economic system. As a result, the estimated time-invariant sensitivity will be hardly useful in deriving any inferences or for any forward projections (Wells 1996).

Time-variation in return spillovers affect opportunities for international portfolio diversification and thus are of considerable interest for rational international investors. Hedging strategies depend on shocks to stock markets being relatively isolated, but if shocks travel quickly across international borders, the benefits of diversification may be undermined. Considering time-variable spillovers allows investors to better assess the speed and magnitude of shock transmission, and thus better utilize all available information. This may improve financial series forecasting, cost of capital calculation, and asset allocation. Knowledge about the evolution of spillovers could provide Frontier market policy 
makers with improved and more up-to-date information about the state of the economy, as well as about the nature and origin of any unrest in the local markets. It could enable them to better predict and assess the effects of shocks originating abroad, and thus facilitate adoption of more appropriate and better-timed monetary and fiscal policy decisions. Investigation of time-varying cross-market linkages may also be of interest to academics seeking to shed more light on the evolution of local economies and financial markets. It would enhance evaluation of the impact of local and global shocks on international financial markets, as well as improve understanding of shock transmission mechanisms. The scale of financial spillovers may provide important insights about the propagation of information across countries and enhance awareness of market co-movements.

In this study we investigate potential time-variability in the impact of US stock market returns on the returns of twenty-one Frontier markets during the period between December 1st, 2005 and January 15th, 2010. In addition to possible time-varying return spillovers, we also investigate the impact of the conditional volatility of US returns on the conditional volatilities of the Frontier markets (referred to as returns volatility spillovers). In our analysis, we only consider time-invariant volatility spillovers. Nonetheless, the transmission of volatility is an important subject of consideration. With volatility being a proxy for stock market uncertainty, volatility spillovers are the primary process by which financial unrest is transmitted internationally. Understanding volatility spillovers thus becomes important for international portfolio diversification and hedging strategies.

To investigate time-varying returns spillovers, we set up a a time-varying parameter (TVP) model. Spillover effects in volatility are modeled by augmenting a standard $\operatorname{GARCH}(1,1)$ model with volatility effects stemming from current period and one-period lagged US conditional volatility. The model can be cast into a state space form. However, it is not time-invariant as the 'coefficient' multiplying the state variable (the TVP parameter) is current period US returns. The model is estimated by the Kalman Filter. Several restricted versions of the general model are also estimated with Frontier country returns. Statistical tests on constancy of the mean spillovers parameter (i.e. a test for constant parameter), tests for no spillover effects in mean returns and/or volatility, as well as other hypotheses of interest are performed. Relative contributions from the US and own-country lagged effects on both mean and volatility of Frontier countries' returns are explored.

The rest of the paper is organized as follows. Section II.II. reviews relevant literature on TVP models that have been used to study financial market spillovers. Section II.III. presents the data, the 
main empirical TVP model and estimation results. Section II.IV. considers some important hypotheses of interest, and reports statistical inferences that can be drawn on these hypotheses from the data. Section II.V. provides a discussion of the results obtained. Section II.VI. offers concluding remarks and prospects for future research.

\section{II.II. LITERATURE REVIEW}

Time-variation in financial spillovers has long been recognized in international finance literature. Two approaches are commonly adopted to address non-constancy in parameters. The first approach is to divide the sample into turbulent and calm periods. To determine turbulent and non-turbulent periods, Dungey et al. (2005) suggest using post-sample rationalizations, Kaminsky and Schmukler (1999) uses news release data in studying the Asian crisis, and Aggarwal et al. (1999) divide their sample based on local and global events in studying the volatility of emerging markets.

The second approach is to use the sample data itself to distinguish turbulent from calm periods. Bialkowski et al. (2006) use a Markov switching framework to distinguish between turbulent and nonturbulent periods in studying spillovers among mature markets. Gebka and Serwa (2006) differentiate between calm and and turbulent periods using a threshold VAR in exploring spillovers between US and eight South-East Asian countries. Beirne et al. (2008) use dummy variables to capture parameter shifts when examining spillovers from mature to emerging markets. Diebold and Yilmaz (2009) incorporate parameter variability using rolling-sample regressions.

Although the literature cited above admits that spillover parameters are variable over time, it addresses this variability by distinguishing only between turbulent and calm periods. There is nothing, however, to guarantee that the spillovers are constant within either period. It could be that in turbulent times, as financial institutions re-balance portfolios, the liabilities of economies grow, and their exposure to cross-border shocks increases exponentially. It could be that the economies, as well as the financial institutions, evolve over time. It could be that major structural, political, and macroeconomic reforms are taking place on an ongoing basis. Or, it could be that the place of the country on the international trade scene is evolving over time.

In order to incorporate potential time-varying spillovers effects from such causes, we explore timevariability of return spillovers using time-varying parameter (TVP) models. These models can be cast in state space form and, hence, are amenable to estimation using the Kalman filter. The Kalman filter facilitates examination of return spillovers regardless of the state of the economy (whether turbulent 
or not). The picture of international return spillovers the filter portrays is more detailed and comprehensive, as the technique allows spillover parameters to be updated every period using all information available at the time. The incorporation of GARCH-like model of errors allows us to account for heteroscedasticity inherent in financial series, as well as to investigate volatility spillovers within the context of the TVP model.

The Kalman Filter has been used in an international setting to investigate evolving market efficiency and integration. For instance, Zalewska-Mitura and Hall (1999) use it in combination with GARCH errors to investigate efficiency of the Hungarian stock market. Rockinger and Urga (2001) use a similar model to investigate market efficiency of the Czech, Polish, Hungarian, and Russian stock markets. Brooks et al. (2002) compare the performance of GARCH and Kalman filter models in investigating time-varying country risk. Jochum (1998) uses it in combination with bivariate GARCH-M errors to investigate the behavior of the risk premium on the Swiss stock market. Choudhry and Wu (2009) find the Kalman filter to be overwhelmingly superior in forecasting weekly stock returns of twenty UK firms compared to GARCH models. Further review of applications of the Kalman filter in economics can be found in Pasricha (2006) and Bouye (2009).

\section{II.III. EMPIRICAL MODELS OF MARKET RETURNS}

To explore evolution of financial spillovers from the US, we use daily closing prices of the MSCI Barra Index for the United States and twenty-one Frontier markets. Our sample spans the period from December 1st, 2005 to January 15th, 2010 and contains 1077 observed closing prices.

We obtain percentage annualized returns for each country $K$ as a log difference in daily closing prices:

$$
R_{\mathrm{t}}^{\mathrm{K}}=100 *\left(\ln P_{\mathrm{t}}^{\mathrm{K}}-\ln P_{(\mathrm{t}-1)}^{\mathrm{K}}\right) * 252
$$

where $P_{\mathrm{t}}^{\mathrm{K}}$ stands for closing price of each country's index at day $t$ and 252 represents the average number of trading days in a calendar year.

Daily returns have been chosen for our investigation to better account for stock market dynamics. Market efficiency would suggest that news is quickly and efficiently incorporated into stock prices (Fama 1998). Therefore, while information generated yesterday may be significant in explaining prices today, it is less likely that information generated last week would have much impact today. Furthermore, changes in rates of return are news-driven. Announcements such as declarations of war, profit forecasts 
and changes in interest rates are factors that affect market sentiment and drive equity prices in the short run. Using daily stock data permits an analysis of how investor sentiment can be transmitted from one market to another.

The following Frontier markets are included in our sample: Argentina, Bahrain, Bulgaria, Croatia, Estonia, Jordan, Kazakhstan, Kenya, Kuwait, Lebanon, Mauritius, Nigeria, Oman, Pakistan, Qatar, Romania, Saudi Arabia, Slovenia, Sri Lanka, Tunisia, and United Arab Emirates. The markets and length of the sample have been chosen such that the longest time series are attainable for the greatest number of countries. Lithuania, Serbia, Ukraine, Bangladesh, Trinidad and Tobago, Jamaica, Botswana and Ghana are also classified as Frontier markets by the World Bank, but they are not analyzed in this study due to lack of a sufficiently long sample series. Since MSCI indexes are designed consistently across countries, they offer an adequate platform for investigation of cross-market spillovers. The MSCI indexes are value-weighted and compounded with dividends reinvested. To avoid double counting, stock prices of companies set up abroad are not included. All indexes are in US dollars, providing additional comparability across markets and implicitly taking care of currency market effects.

\section{Model of US Market Returns}

We begin with an investigation of US market returns. Our most general Model 1 describing US returns incorporates time-varying impact of one-period lagged US returns. It is specified as follows:

$$
\begin{gathered}
R_{\mathrm{t}}^{\mathrm{US}}=\theta^{\mathrm{US}}+a_{\mathrm{t}}^{\mathrm{US}} R_{\mathrm{t}-1}^{\mathrm{US}}+u_{\mathrm{t}}^{\mathrm{US}} \\
u_{\mathrm{t}}^{\mathrm{US}} \sim \operatorname{iid} N\left(0, H_{\mathrm{t}}^{\mathrm{US}}\right) \\
H_{\mathrm{t}}^{\mathrm{US}}=b_{0}+b_{1} H_{\mathrm{t}-1}^{\mathrm{US}}+b_{2} u_{\mathrm{t}-1}^{2 \mathrm{US}} \\
a_{\mathrm{t}}^{\mathrm{US}}=c(1-\rho)+\rho a_{\mathrm{t}-1}^{\mathrm{US}}+n_{t}^{\mathrm{US}} \\
n_{\mathrm{t}}^{\mathrm{US}} \sim N\left(0, Q^{\mathrm{US}}\right)
\end{gathered}
$$


In the model above, $R_{\mathrm{t}}^{\mathrm{US}}$ is US index returns, and $\theta^{\mathrm{US}}$ its unconditional mean. The time-varying impact of lagged US returns is captured by the parameter $a_{\mathrm{t}}^{\mathrm{US}}$. Using the terminology of state space models, Eq. (2) is the measurement equation. It relates the observed (explained) variable $R_{\mathrm{t}}^{\mathrm{US}}$ to the state variable (time-varying parameter) $a_{\mathrm{t}}^{\mathrm{US}}$. The 'coefficient' multiplying the state variable is current period US returns. Eq. (4) is the state equation describing the evolution of $a_{\mathrm{t}}^{\mathrm{US}}$ as an $\operatorname{AR}(1)$ process. Detailed exposition of such state space models, along with their estimation via the Kalman filter, can be found in Harvey (1989) and Hamilton (1994).

The term $u_{\mathrm{t}}^{\mathrm{US}}$ is the unexplained portion of US returns and $H_{\mathrm{t}}^{\mathrm{US}}$ its conditional variance, a proxy for US financial market uncertainty. Equation (3) is a standard $\operatorname{GARCH}(1,1)$ model for the conditional variance of the observation equation error $u_{\mathrm{t}}^{\mathrm{US}}$. The GARCH parameters $b_{1}$ and $b_{2}$ capture the impact of previous period US conditional volatility (uncertainty) and unexpected news about mean returns on current volatility, respectively. In what follows, we estimate the above model as well as several restricted versions of it using US returns data.

Model of Frontier Market Returns

Model 1 for Frontier country market returns is specified as follows:

$$
\begin{gathered}
R_{\mathrm{t}}^{\mathrm{K}}=\theta^{\mathrm{K}}+a_{\mathrm{t}}^{\mathrm{US}} R_{\mathrm{t}}^{\mathrm{US}}+a^{\mathrm{K}} R_{\mathrm{t}-1}^{\mathrm{K}}+u_{\mathrm{t}}^{\mathrm{K}} \\
u_{\mathrm{t}}^{\mathrm{K}} \sim N\left(0, H_{\mathrm{t}}^{\mathrm{K}}\right) \\
H_{\mathrm{t}}^{\mathrm{K}}=b_{0}+b_{1} H_{\mathrm{t}-1}^{\mathrm{K}}+b_{2} u_{\mathrm{t}-1}^{2 \mathrm{~K}}+b_{3} H_{\mathrm{t}}^{\mathrm{US}}+b_{4} H_{\mathrm{t}-1}^{\mathrm{US}} \\
a_{\mathrm{t}}^{\mathrm{US}}=c(1-\rho)+\rho a_{\mathrm{t}-1}^{\mathrm{US}}+n_{\mathrm{t}}^{\mathrm{US}} \\
n_{t}^{\mathrm{US}} \sim N\left(0, Q^{\mathrm{US}}\right) \\
E\left(u_{\mathrm{t}}^{\mathrm{K}} n_{\mathrm{t}}^{\mathrm{US}}\right)=0
\end{gathered}
$$


The term $R_{\mathrm{t}}^{\mathrm{K}}$ represents index returns of Frontier country $K$, and $\theta^{\mathrm{K}}$ its unconditional mean. The effect of contemporaneous US returns on Frontier country mean returns is captured by the parameter $a_{\mathrm{t}}^{\mathrm{US}}$. It accounts for time-varying spillovers in mean returns from the US to the Frontier country. The impact of one-period lagged own-country returns is captured by the parameter $a^{\mathrm{K}}$, assumed to be fixed rather than time-varying for simplicity. This does not interfere with our main object of study here, which is an investigation of time-variation in return spillovers from US to Frontier markets. The volatility specification in eq. (6) is a standard $\operatorname{GARCH}(1,1)$ model, augmented with current and past US volatility terms. Accordingly, the parameters $b_{3}$ and $b_{4}$ represent volatility spillovers from US to the individual country. The conditional variance of the unexplained portion of Frontier market returns $H_{\mathrm{t}}^{\mathrm{K}}$ is a proxy for local market uncertainty.

In earlier analysis, for sixteen of the twenty-one Frontier markets, Bidarkota and Todorov (2010) determine the best-fitting model to incorporate only current period US returns in Eq. (5). For Bahrain, Kuwait, Oman, and Tunisia, they determine the best-fitting model to include not only current, but also one-period lagged, US returns. For Kenya, they determine the best-fitting model to incorporate 2-period own country lagged returns as well. For simplicity, we omit lagged US returns as well as 2-period own country lagged returns. Accordingly, we estimate Eq. (5) for all countries in our sample.

It is interesting to note that most Frontier markets open five or more hours before the US market opens, with the exception being Argentina (opening one hour ahead). One important implication is that return spillovers may not reflect the impact of actual realized US returns, but expected US returns. Any announcements made in the US after closing of the stock exchanges on day 1, and before opening on day 2, are reflected in the US market on day 2. Throughout the trading day on day 2 on local Frontier markets, investors observe those announcements, and incorporate them in their asset valuations immediately. To better describe such a situation, we could say that it is the US overnight returns that affect the local markets, rather than the actual daily returns, where the overnight returns are defined as the change in price between closing on day 1 and opening on day 2. The overnight returns form the expected returns, and are reflected in US daily returns on the next day. Those returns seem to affect local market returns despite the fact that local markets may close for the day before the US market opens. Similar discussion and more details on the international transmission of overnight returns can be found in Lin, Engle, and Ito (1994), Hamao, Masulis, and Ng (1994), and Baur and Jung (2006).

\section{Estimation Issues}


Model 1 for US returns and for Frontier market returns can be cast as linear conditionally Gaussian state space models. An important point worth noting about Model 1 is that the state space model is not time-invariant. The 'coefficient' multiplying the state variable (the TVP parameter) is current period US returns. Nonetheless, they can be easily estimated using the Kalman filter algorithm. The filter also enables estimation of the spillover parameter (the state variable) every period utilizing all available information to date. With linear Gaussian models, the Kalman filter provides the most efficient estimator. A somewhat similar model is estimated by Rockinger and Urga (2001). With non-linear and/or non-Gaussian models, the filter is no longer optimal. Modified versions of the filter such as the extended Kalman filter are available. Detailed description of the Kalman filter and the conditions for its optimality can be found in Harvey (1989) and Hamilton (1994).

The GARCH model of errors accounts for volatility clustering that has been well-documented in returns data. With volatility clustering, large changes tend to follow large changes, and small changes tend to follow small changes. The changes from one period to the next are typically of unpredictable sign. Large disturbances, positive or negative, influence the magnitude of the realization of next period's disturbance through the variance term. In this way, large shocks can persist for several periods.

The GARCH model of errors however has some limitations. Although explicitly designed to model time-varying conditional variances, it fails to capture wild market fluctuations (for example, crashes and bubbles) and other unanticipated events leading to structural changes. For instance, time-varying volatility spillovers depending on an underlying state variable that tracks the state of the economy have been considered (Baele 2005). Furthermore, GARCH errors often fail to fully capture fat tails observed in asset returns (Creal, Koopman, and Lucas 2010).

\section{Empirical Results}

Maximum likelihood (ML) estimates of Model 1 for the US are presented in Table 2.1. The longrun unconditional mean of returns $\theta$ is estimated to be 12.044 percent per annum, although it is not statistically significantly different from zero. The unconditional mean of the time-varying coefficient on lagged returns $C$ is estimated to be -0.098 . The AR parameter $\rho$ driving this time-varying coefficient is 0.948 , but the standard deviation $\sqrt{Q^{\mathrm{US}}}$ of the signal shock $n_{\mathrm{t}}$ driving the AR process is essentially zero, suggesting no time-variation in this parameter. The GARCH parameter $a_{1}$ is estimated to be 0.911 and the $\mathrm{ARCH}$ parameter $a_{2}$ to be 0.08 , in line with values reported in numerous earlier studies. 
Table 2.1 also reports estimates of a restricted version of Model 1 for the US in column 3 with $a_{\mathrm{t}}^{\mathrm{US}}$ being constant (Model 2). Thus, the restricted specification in column 3 features no time-variation in the impact of lagged returns on current mean returns. The parameter estimates and their standard errors for Model 2 reported in column 3 are largely identical to those reported for Model 1. We compare Model 1 (the unrestricted model) with its restricted version using a likelihood ratio (LR) test. The test statistic is reported in the bottom row of Table 2.1. Testing Model 2 against Model 1 (test for no timevariation in $a_{\mathrm{t}}^{\mathrm{US}}$ ) results in an LR statistic of only 0.118 . Constancy of $a_{\mathrm{t}}^{\mathrm{US}}$ cannot be rejected even at large significance levels, using critical values from the $\chi^{2}$ distribution with two degrees of freedom. We proceed by testing Model 2 (the unrestricted model) for homoskedasticity. The resulting large test statistic of 728.437 (details not reported) overwhelmingly rejects in favor of time-varying volatility. Thus, results of the hypotheses tests indicate that the best-fitting model of US returns is the constant parameter restricted version of Model 1, referred to as Model 2 above (i.e., the GARCH model with constant $a_{\mathrm{t}}^{\mathrm{US}}$ ). In what follows, time-varying conditional variances of US returns estimated with this model are used to estimate Model 1 (and several restricted versions) using data on Frontier market returns.

Panel 1 in Figure 2.1 depicts observed returns for the US along with their one-step ahead predictions using the best-fitting Model 2. The figure clearly shows the unusually large fluctuations in returns observed during the global financial crisis around year 2009. The panels in Figure 2 plot US conditional volatility, as measured by the estimated standard deviation $\sqrt{H_{\mathrm{t}}^{\mathrm{US}}}$ in percent per annum, using Model 2 (along with the estimated conditional volatility for select Frontier countries to be discussed below). The conditional volatility ranges from a high of 1370 percent per annum in late 2008 to a low of 97 percent.

The parameter estimates and standard errors are reported in Table 2.2. The unconditional mean of returns $\theta^{\mathrm{K}}$ for seven countries are estimated to be higher than the US value reported in Table 2.1, with the highest value for Kazakhstan at 31 percent annualized. For seven countries, the estimated mean returns are negative, with the lowest for Sri Lanka at -10 percent annualized. Estimates of the parameter on lagged own country returns $a^{\mathrm{K}}$ is positive for all Frontier markets, except Bulgaria (0.067). The highest estimate is for Nigeria (0.443). These estimates are statistically significant for all but three countries. 
Estimates of the mean US return spillovers parameter $C$ are positive for 17 of the 21 countries. These estimates range from a high of 0.994 for Argentina to a low of -0.022 for Jordan. These estimates are however statistically significant for only 9 of the countries. Estimates of the AR parameter $\rho$ governing time variation in spillovers from the US to Frontier countries are positive for 13 countries. These range from a high of 0.813 for Pakistan to a low of -0.974 for Oman. These estimates are statistically significant for 10 countries. Estimates of the standard deviation of the signal shock $n_{\mathrm{t}}^{\mathrm{US}}$ driving the spillover process $a_{\mathrm{t}}^{\mathrm{US}}$, denoted by $\sqrt{Q^{\mathrm{US}}}$ is zero for 7 countries. Such a value essentially implies that, for these 7 countries, there is no time-variation in spillovers from the US. Except for Bulgaria, these are all countries in the Middle East (Bahrain, Jordan, Kuwait, Oman, Qatar, and S. Arabia).

Estimates of the GARCH parameter $b_{1}$ range from a high of 0.98 for Romania to a low of 0.55 for Bahrain. Estimates of the ARCH parameter $b_{2}$ range from a high of 0.21 for Mauritius to a low of 0.02 for Croatia. Estimates of the impact of current US volatility on Frontier markets volatility $b_{3}$ range from a high of 0.44 for Bahrain to a low of 0 for Slovenia, Nigeria, and Pakistan. Estimates of the impact of one-period lagged US volatility $b_{4}$ on all Frontier markets is essentially zero.

The various panels of Figure 2.1 plot observed returns for a few Frontier countries (selected in alphabetical order) along with their fitted values derived from Model 1. The figures show that for almost all countries (except Argentina and Nigeria), Model 1 captures only a small portion of the daily return fluctuations.

The various panels of Figure 2.2 plot estimates of the standard deviations $\sqrt{H_{\mathrm{t}}^{\mathrm{K}}}$ from Model 1. Each panel drawn for a selected Frontier country also shows plot of the standard deviation $\sqrt{H_{\mathrm{t}}^{\mathrm{K}}}$ from the best-fitting Model 2 for the US. The figures show that these volatilities are consistently higher for 10 Frontier countries than the US. Volatility in the US peaks in late 2008 and early 2009 coinciding with the turmoil in global financial markets. This is replicated and/or magnified for 11 of the Frontier countries. For some countries such as Nigeria and Pakistan, the peak in volatility clearly lags that for the US. For many Frontier markets, the volatility plots show numerous episodes of volatility clusters (with smaller peaks than around late 2008-early 2009) than is evident for the US. For these countries, we expect a lower degree of comovement of conditional volatilities with the US.

The various panels of Figure 2.3 plot time-varying US return spillovers parameter $a_{\mathrm{t}}^{\mathrm{US}}$. As indicated earlier, for 7 of the countries for which $\sqrt{Q^{\mathrm{US}}}$ is estimated to be zero, the plots show $a_{\mathrm{t}}^{\mathrm{US}}$ converging 
to a constant value. Because the algebraic sign of the estimate of the AR parameter $\rho$ is negative for these countries, the convergence is oscillatory. Except for Sri Lanka, for all the remaining countries, estimates of $\rho$ are positive. For UAE, the estimates of $a_{\mathrm{t}}^{\mathrm{US}}$ are essentially zero. Typically, the magnitude of spillovers $a_{\mathrm{t}}^{\mathrm{US}}$ ranges between -0.5 and 0.75 , with occasional spikes in both directions. Argentina is the only country with no estimated negative spillovers.

The various panels of Figure 2.4 plot the decomposition of Frontier country fitted returns into US and local market components. Quantitatively significant impact of US returns is found for 13 of the 21 markets. For 2 markets, Argentina and Kazakhstan, the effect of US returns is larger relative to that of lagged local returns. This implies that the evolution of returns in these countries is primarily governed by US market performance. For another set of countries, Bulgaria, Croatia, Estonia, Romania, Saudi Arabia, and Tunisia, the US component is about as important as local market component. On the other hand, returns for Jordan, Mauritius, Pakistan, Qatar, Slovenia, and Sri Lanka are dominated by the local market component. However, the impact of US returns remains strong. The remaining markets, Kenya, Kuwait, Lebanon, Nigeria, Oman, UAE, and Bahrain, are overwhelmingly dominated by the local component and the influence from US is minimal.

The various panels of Figure 2.5 plot the decomposition of Frontier country estimated conditional volatility into US and local market components. Quantitatively significant impact of US volatility is found for 18 of the 21 markets, the exceptions being Kenya, Pakistan, and Sri Lanka. This effect is strongest for Romania, for which the US volatility spillover component is about as strong as the local market volatility component. For 4 markets, Bahrain, Mauritius, Romania, and Slovenia, the US volatility component is relatively large, implying that conditional volatility in these countries is strongly influenced by US current and one-period lagged US volatility.

In summary, Model 1 estimated for Frontier countries captures only a small portion of their daily return fluctuations. Most Frontier markets display volatility that is greater both in magnitude and variability relative to the US. This is expected as developing markets are considered more risky and hence are expected to exhibit greater uncertainty. Time-varying spillovers are important in 13 of the 21 Frontier countries. Quantitatively significant impact of US returns is found for 13 of the 21 markets. Quantitatively significant impact of US conditional volatility is found for 18 of the 21 markets. 
In the next section, we formally test various restrictions on Model 1 that shed light on the economic importance of information flows emanating from the US market relative to local market feedback effects.

\section{II.IV Hypothesis Tests}

All tests are carried out by constructing the likelihood ratio (LR) test statistics. Model 1 estimated in section III is the most general (unrestricted) model in all the tests. The restricted model for each hypothesis is described in the subsections below. Each restricted model is obtained by imposing suitable restrictions on the parameters of Model 1. The LR test statistic is constructed as the difference $\Lambda=$ $L n L_{\mathrm{u}}-L n L_{\mathrm{r}}$, where $L n L_{\mathrm{u}}$ is the maximized log-likelihood value for the unrestricted model and $L n L_{\mathrm{r}}$ is the corresponding value under the restrictions imposed by the null hypothesis. The resulting test statistic $\Lambda$ has a $\chi^{2}$ distribution with degrees of freedom equal to the number of restrictions imposed. The null hypothesis is rejected if the value exceeds the appropriate critical value.

Test results are reported in Table 2.3. Values of LR test statistics are reported for each Frontier country for each hypothesis. All statistical inferences drawn below assume a five percent significance level. A summary of statistical inferences drawn is provided in Table 2.4. Parameter estimates for each of the restricted models in Tables A.1-A.4 and figures for selected countries are ploted in in Figures B1-B8. These figures provide a comparison of own-country lagged effects versus the effects from contemporaneous and lagged US shocks on both the mean and volatility of Frontier country returns.

\section{Test for no time-variation in spillovers in mean returns}

In this subsection we examine the significance of time-variability of US return spillovers. Because return spillovers transmit economic shocks, this clarifies whether the exposure of Frontier markets to economic shocks in the US fluctuates over time. The issue is studied by comparing a model restricting $a_{\mathrm{t}}^{\mathrm{US}}=$ constant with the general Model 1 estimated in Section III above. The specification under the null is denoted as Model 2 and can be written as follows:

$$
\begin{gathered}
R^{\mathrm{K}}=\theta^{\mathrm{K}}+a^{\mathrm{US}} R_{\mathrm{t}}^{\mathrm{US}}+a^{\mathrm{K}} R_{\mathrm{t}-1}^{\mathrm{K}}+u_{\mathrm{t}}^{\mathrm{K}} \\
u_{\mathrm{t}}^{\mathrm{K}} \sim N\left(0, H_{\mathrm{t}}^{\mathrm{K}}\right)
\end{gathered}
$$




$$
H_{\mathrm{t}}^{\mathrm{K}}=b_{0}+b_{1} H_{\mathrm{t}-1}^{\mathrm{K}}+b_{2} u_{\mathrm{t}-1}^{2 \mathrm{~K}}+b_{3} H_{\mathrm{t}}^{\mathrm{US}}+b_{4} H_{\mathrm{t}-1}^{\mathrm{US}}
$$

Estimates of Model 2 are presented in Table A.1. Estimates of the constant spillover parameter $a^{\mathrm{US}}$ are reported to be similar to the values of the unconditional expectation of return spillovers $c$ from Model 1 for Frontier countries reported earlier in Table 2.2. The estimated current and lagged volatility spillover parameters $b_{3}$ and $b_{4}$ are also similar to those obtained from Model 1. Thus, information flows transmitted through volatility spillovers are not significantly affected by the absence of time-variation in return spillovers.

Loglikelihood Ratio test statistics for the null hypothesis are reported in the second column of Table 2.3. Time-variability of $a_{\mathrm{t}}^{\mathrm{US}}$ is statistically significant (null hypothesis is rejected) for 13 countries. This indicates that time-variability of $a_{\mathrm{t}}^{\mathrm{US}}$ conveys economically important information that is not captured by the restricted model. Thus, changing sensitivity to US economic shocks is important. The null hypothesis of constant spillovers is not rejected for all the 7 Middle-Eastern countries in our sample as well as for Pakistan. For these countries, exposure of their returns to economic shocks originating in US is constant. This might be because some of the information transmitted through return spillovers is not relevant for these countries or is already captured by volatility spillovers and GARCH effects.

The various panels of Figure B.1 plot the US components of Frontier country returns estimated by Models 1 and 2. The contribution of US returns estimated from Model 1 is stronger for 5 countries, namely, Bahrain, Kuwait, Nigeria, Pakistan, and UAE. Thus, for this set of countries, time-variation in mean spillovers amplifies the estimated contribution of US effects on their mean returns. On the other hand, for Lebanon, Mauritius, and Slovenia, the US contribution to their mean returns is estimated to be larger from Model 2. For all other countries the US return components estimated by Models 1 and 2 are similar.

The contribution of US volatility to local market conditional volatility, estimated by Model 2 (Figure B.2) increases for 8 of the 21 markets. For the remaining 12 markets, shutting down time-variability in return spillovers results in no substantive change in the estimated impact of current and one-period lagged US volatility.

Test for no spillovers in volatility

Here we investigate the significance of US volatility spillovers to Frontier countries. As volatility is a measure of market uncertainty, this sheds light on whether economic unrest in US is transmitted to 
Frontier countries through spillovers in volatility. We compare Model 1 with a version restricting $b_{3}=$ $b_{4}=0$. Rejecting the null hypothesis highlights the importance of information flows through volatility spillovers (Baele 2005, Bekaert and Harvey 1997) and the dissemination of economic disturbances across countries through this channel. The specification under the null, denoted as Model 3 in what follows, can be written as:

$$
\begin{gathered}
R_{\mathrm{t}}^{\mathrm{K}}=\theta^{\mathrm{K}}+a_{\mathrm{t}}^{\mathrm{US}} R_{\mathrm{t}}^{\mathrm{US}}+a^{\mathrm{K}} R_{\mathrm{t}-1}^{\mathrm{K}}+u_{\mathrm{t}}^{\mathrm{K}} \\
u_{\mathrm{t}}^{\mathrm{K}} \sim N\left(0, H_{\mathrm{t}}^{\mathrm{K}}\right) \\
H_{\mathrm{t}}^{\mathrm{K}}=b_{0}+b_{1} H_{\mathrm{t}-1}^{\mathrm{K}}+b_{2} u_{\mathrm{t}-1}^{2 \mathrm{~K}} \\
a_{\mathrm{t}}^{\mathrm{K}}=c(1-\rho)+\rho a_{\mathrm{t}-1}^{\mathrm{US}}+n_{\mathrm{t}}^{\mathrm{US}} \\
n_{t}^{\mathrm{US}} \sim N\left(0, Q^{\mathrm{US}}\right) \\
E\left(u_{\mathrm{t}}^{K} n_{\mathrm{t}}^{\mathrm{US}}\right)=0
\end{gathered}
$$

Estimates of Model 3 are presented in Table A.2. Results indicate that the parameters $c, \rho$ and $\sqrt{Q^{\mathrm{US}}}$ remain largely unchanged for Slovenia. But, shutting down volatility spillovers causes the unconditional expectation of US return spillovers $c$ to increase for all Frontier countries, except Argentina, Kazakhstan, and Mauritius. The AR parameter $\rho$ correspondingly increases for 11 countries. Only for Mauritius, $c$ decreases while $\rho$ increases. Estimates of the standard deviation $\sqrt{Q^{\mathrm{US}}}$ of the signal shock $n_{\mathrm{t}}^{\mathrm{US}}$ increases for all Frontier countries, except Croatia and Romania.

LR test statistics for this hypothesis are presented in the third column of Table 2.3. The null hypothesis can be rejected for 14 of the 21 Frontier countries. For the 14 countries for which volatility spillovers are found to be important, information emanating from the US and transmitted through this channel may result in increased susceptibility of these Frontier country returns to US market distur- 
bances. For the remaining 7 countries, volatility spillovers do not represent an important channel of information flows. This could be because information transmitted through volatility spillovers is already captured by return spillovers and GARCH effects. Absence of volatility spillovers could potentially make these countries less vulnerable to turbulence originating in the US market.

The various panels of Figure B.3 plot the US components of Frontier country returns estimated by Models 1 and 3. The contribution of US returns estimated from Model 3 is stronger for 4 countries, namely, Kuwait, Oman, Pakistan, and Qatar. Thus, for this set of countries, shutting down volatility spillover effects from the US amplifies the estimated contribution of US effects on their mean returns. This shows that information flows transmitted through mean returns now capture some of the spillovers earlier transmitted through the volatility channel. On the other hand, for Mauritius and Nigeria, the US contribution to mean returns is estimated to be actually larger from Model 1. This means that for these two countries, shutting down volatility spillovers weakens mean returns spillovers as well. For all other countries, the US components estimated by both Models 1 and 3 are similar. This means that for the bulk of the Frontier countries, information flows being transmitted from the US through mean returns and their volatility are largely orthogonal.

The contribution of lagged own country effects to local market conditional volatility, estimated by Model 3 (Figure B.4), remains largely unchanged for all of the 21 markets.

Joint test for no spillovers in mean returns and no spillovers in volatility, or

Test for Complete Segmentation of US and Frontier Markets

Here, we investigate the possibility of complete segmentation of Frontier and US markets. This clarifies the significance of US economic shocks and related disturbances for local markets. The analysis is done by comparing the general Model 1 estimated in Section III above with a model featuring no impact from US returns. Rejecting the null hypothesis confirms the importance of information flows emanating from US and refutes the hypothesis of complete segmentation. The model under the null is denoted as Model 4 and can be written as:

$$
\begin{gathered}
R^{\mathrm{K}}=\theta^{\mathrm{K}}+a^{\mathrm{K}} R_{\mathrm{t}-1}^{\mathrm{K}}+u_{\mathrm{t}}^{\mathrm{K}} \\
u_{\mathrm{t}}^{\mathrm{K}} \sim N\left(0, H_{\mathrm{t}}^{\mathrm{K}}\right)
\end{gathered}
$$




$$
H_{\mathrm{t}}^{\mathrm{K}}=b_{0}+b_{1} H_{\mathrm{t}-1}^{\mathrm{K}}+b_{2} u_{\mathrm{t}-1}^{2 \mathrm{~K}}
$$

Model 4 estimates are reported in Table A.3. Estimates of $\theta^{\mathrm{K}}$ increase for 14 countries. The AR parameter $a^{\mathrm{K}}$ on own country lagged returns increases for 5 of these countries, as well as for 3 others. Estimates of the constant parameter in the volatility process $b_{0}$ increases for 7 countries, GARCH parameter $b_{1}$ increases for 12 countries, and the ARCH parameter $b_{2}$ increases for 14 countries.

The LR test statistics test are reported in Table 2.3, under the column heading 'Model 4'. The null hypothesis is strongly rejected for all Frontier countries. Rejecting the null confirms the importance of information flows from US and thus the impact of economic conditions there on Frontier country financial markets. This finding is in line with literature suggesting the importance of inter-market linkages. Inter-dependencies among countries is a factor of great importance for portfolio diversification. It is also important for determining the origin of economic crises and for designing relevant macroeconomic policies.

The various panels of Figure B.5 plot one-period lagged own market components of Frontier country returns estimated by Models 1 and 4. The contribution of own-country returns estimated from Model 4 is stronger only for Kazakhstan. On the other hand, for Argentina and Romania, own-country returns contribution surprisingly declines once US effects are shut down. For all other countries, own country lagged returns components estimated by Models 1 and 4 are similar, indicating orthogonality of US and lagged own-country effects on mean returns.

The contribution of local market conditional volatility, estimated by Model 4 remains largely unchanged for 19 of the 21 markets (Figure B.6). For Croatia and Romania, complete segmentation results in increased estimated impact of local markets volatility factors.

\section{Joint test for no impact of own market lagged information, or}

\section{Test for 'Complete Integration' of US and Frontier Markets}

Here we investigate whether local economic shocks remain significant, once disturbances from US are taken into account. The analysis is done by comparing the general Model 1 with a model featuring no impact of own market variables on either the mean or volatility of returns. Rejecting the null hypothesis confirms the importance of own market information flows and refutes the possibility of 'complete market integration'. The model under the null is denoted as Model 5 and can be written as: 


$$
\begin{gathered}
R_{\mathrm{t}}^{\mathrm{K}}=\theta^{\mathrm{K}}+a_{\mathrm{t}}^{\mathrm{US}} R_{\mathrm{t}}^{\mathrm{US}}+u_{\mathrm{t}}^{\mathrm{K}} \\
u_{\mathrm{t}}^{\mathrm{K}} \sim N\left(0, H_{\mathrm{t}}^{\mathrm{K}}\right) \\
H_{\mathrm{t}}^{\mathrm{K}}=b_{0}+b_{3} H_{\mathrm{t}}^{\mathrm{US}}+b_{4} H_{\mathrm{t}-1}^{\mathrm{US}} \\
a_{\mathrm{t}}^{\mathrm{US}}=c(1-\rho)+\rho a_{\mathrm{t}-1}^{\mathrm{US}}+n_{\mathrm{t}}^{\mathrm{US}} \\
n_{t}^{\mathrm{US}} \sim N\left(0, Q^{\mathrm{US}}\right) \\
E\left(u_{\mathrm{t}}^{K} n_{\mathrm{t}}^{\mathrm{US}}\right)=0
\end{gathered}
$$

Estimates of Model 5 are reported in Table A.4. Relative to Model 1, the unconditional expectation of US return spillovers $c$ increases for 5 countries. The AR parameter estimate $\rho$ increases for 11 countries. Estimates of the standard deviation $\sqrt{Q^{\mathrm{US}}}$ of the signal shock $n_{\mathrm{t}}^{\mathrm{US}}$ driving the spillover process $a_{\mathrm{t}}^{\mathrm{US}}$ increase for all countries except Romania.

Loglikelihood Ratio test statistics are reported in Table 2.3, under the column heading 'Model 5'. The null hypothesis is overwhelmingly rejected for all Frontier countries. This confirms the importance of local market feedback effects. The LR test results here, in conjunction with those reported in subsection II.IV above, clarify that Frontier markets are neither completely integrated nor completely segmented from the US. Such a finding is relevant for investment decisions because less than fully integrated markets lower the importance of financial markets as a path for transmitting economic shocks across countries.

The various panels of Figure B.7 plot the US components of Frontier country returns estimated by Models 1 and 5. The contribution of US returns estimated from Model 5 is now stronger for 3 countries, namely, Oman, Qatar, and UAE. On the other hand, for Pakistan, US returns contribution declines once own-country lagged effects are shut down. For all other countries, US contributions 
estimated from Models 1 and 5 are similar. This follows from the evidence on orthogonality of US and lagged own-country effects on mean returns of Frontier countries.

Shutting down local market effects results in significantly increased estimated impact of US current and one-period lagged volatility for all Frontier countries (Figure B.8). US volatility effects seem to be amplified in the absence of local market effects.

\section{Summary of hypotheses tests}

In this section, we investigated several statistical hypotheses of interest. First, we tested for no timevariability of US return spillovers to Frontier markets. Next, we tested for no spillovers in US volatility. This was followed by a test for complete market segmentation and, subsequently, for complete market integration. The statistical inferences from our tests for these hypotheses are summarized in Table 2.4.

Statistically significant time-variability of US return spillovers are found for 13 of the 21 frontier markets. However, the presence of time-variability amplifies the quantitative impact of US returns for only 5 countries as compared to a model with constant spillovers. But, it does not affect the quantitative impact of US returns for 13 countries. Introduction of constant return spillovers does not affect the estimated contribution of US market volatility in accounting for Frontier market returns volatility for 13 markets, but increases it for the remaining.

Exploring the assumption of no US volatility effects indicates statistically significant volatility spillovers to 14 Frontier markets. It follows that these countries are exposed to economic unrest in the US, while the remaining 7 are not as vulnerable. Shutting down volatility spillovers does not affect the contribution of US returns in accounting for Frontier country mean returns for 15 markets, but increases it for 4. The contribution of local components to Frontier market volatility remains largely unaffected.

Our results strongly reject the polar null hypotheses of complete market segmentation or complete market integration. This indicates that Frontier markets are characterized as neither completely segmented from US nor completely integrated with it. Shutting down US return and volatility spillover effects completely does not change the contribution of one-period lagged local returns in accounting for Frontier country mean returns for 18 countries, and increases it for only 1 country. The contribution of local volatility effects remains largely the same for 19 countries but increases for 2 . In testing for complete market integration, when all the effects from own-country returns are shut off, the contribution of US market returns in the estimated Frontier country mean returns remains largely unaffected for 17 of the 21 countries, but increases slightly for 3 countries. The absence of local market effects, however, 
results in a quantitatively important increase in the weight of US current and one-period lagged volatility in explaining the conditional volatilities of all markets. These results from the polar null hypotheses of complete market segmentation or complete market integration indicate possible orthogonality in the contributions of current US and lagged own-country returns on Frontier countries mean returns.

We also conducted separate hypotheses tests of homoskedasticity and of time-invariance of all estimated parameters in Model 1 (not reported for brevity). Both hypotheses are overwhelmingly rejected for all Frontier countries.

\section{II.V. DISCUSSION}

The finding of statistically significant financial market integration between the US and Frontier countries implies influence of US market returns and volatility on the mean and volatility of returns in Frontier countries. The greater the degree of integration, the greater the spillovers from US to Frontier markets, both in returns and volatility. Greater integration implies less country specific risk. However, this makes these countries vulnerable to recessions in the US.

Cross-border transmission of US economic shocks depends largely on the depth of economic and financial linkages between the US and Frontier countries. Establishing deeper and more liquid capital markets with diverse institutional investors may improve the ability of local economies to withstand shocks from abroad. Literature suggests several major ways of fostering robust financial markets (Kose 2003, Calvo, Izquierdo, and Mejia 2008, Reinhart 2009). Sound securities market infrastructure and institutions such as securities exchange and clearing systems, as well as implementation of regulatory reforms and international accounting standards, are also likely to be beneficial for developing healthy capital markets.

Structural features and country-specific fragility are also key factors affecting market vulnerability to shocks from abroad. For example, macroeconomic or financial weakness may increase susceptibility to shocks. Countries with both strong international financial and economic linkages, and high vulnerabilities are potentially more susceptible to spillovers. Domestic macroeconomic policies such as fiscal, monetary and exchange rate policies can additionally influence the impact of transmitted shocks. Higher current account and fiscal imbalances do little to insulate economies from transmission of turbulence. However, they may help dampen the impact on real economy. Last but not least, timely executed prudent economic policies may soften the impact of, and partly neutralize the effect of, US economic shocks. 


\section{II.VI. CONCLUSIONS}

In this study, we investigate whether financial stock index returns from the US have spillover effects on the stock index returns in 21 Frontier countries, using data from December 1st, 2005 through January 15th, 2010. We investigate spillovers from the US on both the mean and time-varying volatility of Frontier country returns. We entertain the possibility of time-variation in spillover effects in mean returns by considering a time-varying parameter (TVP) model. Spillover effects in volatility are modeled by augmenting a standard $\operatorname{GARCH}(1,1)$ model with volatility effects stemming from current period and one-period lagged US conditional volatility.

The model can be cast into a state space form. However, it is not time-invariant as the 'coefficient' multiplying the state variable (the TVP parameter) is current period US returns. The model is estimated by Kalman Filter. Several restricted versions of the general model are also estimated. Statistical tests on constancy of the mean spillovers parameter (i.e. a test for parameter constancy), tests for no spillover effects in mean returns and/or volatility, as well as other hypotheses of interest are performed. Relative contributions from US and own-country lagged effects on both mean returns and volatility of Frontier countries are explored.

Our analysis suggests that time-varying spillovers are statistically significant for a majority of the Frontier countries studied here. This implies time-varying exposure of these countries to US economic shocks. The presence of time-variability does not, however, affect the quantitative impact of US returns for most of these countries when compared with a model with constant spillover parameter. Most Frontier markets are found to display volatility that is greater both in magnitude and variability relative to the US. This is expected as developing markets are considered more risky and hence are expected to exhibit greater uncertainty. Our TVP model detects statistically significant volatility spillovers as well as quantitatively important impact of US conditional volatility for most of the Frontier markets. This indicates that Frontier countries are vulnerable to economic unrest in the US. However, we find the weight of US volatility factors in the conditional volatilities of most of the Frontier markets unaffected by forcing return spillovers to be constant.

Our results strongly reject the null hypotheses of complete market segmentation and complete market integration. This indicates that Frontier markets are characterized as neither completely segmented from the US nor completely integrated with it. In testing for complete market integration, when all the effects from own-country returns are shut off, the contribution of US market returns in the mean 
returns of most markets remains largely unaffected. However, the share of US current and one-period lagged volatility in the conditional volatilities of all markets increases. The results from the polar null hypotheses of complete market segmentation or complete market integration indicate possible orthogonality in the contribution of current US and lagged own-country returns on Frontier countries mean returns.

The hypotheses of homoskedasticity and time-invariance of all estimated parameters are both overwhelmingly rejected.

One line of extension of research presented in this article may be an explicit modeling of nonlinearities in the conditional mean and/or volatility relationship between US and Frontier market returns. For instance, there is literature suggesting increased spillovers during times of increased volatility (Ramchand and Susmel 1998). Also, the GARCH model could be modified to incorporate the leverage hypothesis. A second line of extension could be a multivariate investigation of time-varying spillovers and volatility. See, for example, Creal, Koopman, and Lucas (2010), for a recent illustration of this approach using the Student's t distribution that accounts for fat tails as well. Information contained in trading volume may also be useful in characterizing spillover effects. Geographic integration among groups of Frontier countries, such as the Middle Eastern countries, may be worth understanding (Baele 2005). An arguably more fruitful extension could be a theoretical exploration of the empirical relationships suggested by this study. 


\section{REFERENCES}

Aggarwal R, Inclan C, Leal R. Volatility in emerging stock markets. Journal of Financial and Quantitative Analysis. 1999; 34(1):33-55.

Baele L. Volatility spillover effects in European equity markets. Journal of Financial and Quantitative Analysis. 2005;40:373-401.

Baur, Dirk, Jung RC. Return and volatility linkages between the US and the German stock market. Journal of International Money and Finance 2006;25:598-613.

Beirne J, Caporale G, Schulze-Ghattas M, Spagnolo N. Volatility spillovers and contagion from mature to emerging stock markets. papers.ssrn.com. 2008.

Bekaert G, Harvey C. Time-varying world market integration. Journal of Finance. 1995;L(2):403444. 77.

Bekaert G, Harvey C. Emerging equity market volatility. Journal of Financial Economics. 1997;43:29-

Bialkowski J, Bohl M, Serwa D. Testing for financial spillovers in calm and turbulent periods. Quarterly Review of Economics and Finance. 2006;46(3):397-412.

Bouyé E. Financial Econometrics Kalman Filter: Some applications to finance. University of EvryMaster 2. Innovation. 2009:1-13.

Brooks RD, McKenzie M, Faff RW. Time-varying country risk: An assessment of alternative modelling techniques. European Journal of Finance. 2002;8(3):249-274.

Calvo G, Izquierdo A, Mejia L. Systemic sudden stops: the relevance of balance-sheet effects and financial integration. NBER Working Paper No. W14026. 2008.

Choudhry T, Wu H. Forecasting the Weekly time-varying beta of UK firms: GARCH models vs. Kalman filter method. European Journal of Finance. 2009;15(4):437-444.

Creal D., S.J. Koopman, and A. Lucas. A dynamic multi-variate heavy-tailed model for timevarying volatilities and correlations, Tinbergen Institute Discussion Paper, TI 2010-032/2.

Diebold F, Yilmaz K. Measuring financial asset return and volatility spillovers, with application to global equity markets. Economic Journal. 2009;119(534):158-171.

Dungey M, Fry R, González-Hermosillo B, Martin VL. Empirical modelling of contagion: a review of methodologies. Quantitative Finance. 2005;5(1):9-24.

Fama E. Market efficiency, long-term returns, and behavioral finance. Journal of Financial Economics. 1998;49(3):283-306.

Gebka B, Serwa D. Are financial spillovers stable across regimes? Evidence from the 1997 Asian crisis. Journal of International Financial Markets, Institutions and Money. 2006;16(4):301-317.

Hamao Y, Masulis R, Ng V. Correlations in price changes and volatility across international stock markets. Review of Financial Studies. 1990;3(2):281-307.

Hamilton J. Time series analysis. Princeton Univ Press; 1994. 
Harvey A. Forecasting, structural time series models and the Kalman filter. Cambridge University Press. 1989.

Harvey C. Predictable risk and returns in emerging markets. Review of Financial Studies. 1995;8(3):773-816.

Jochum C. Volatility spillovers and the price of risk: Evidence from the Swiss stock market. Empirical Economics. 1999;24(2):303-322.

Kaminsky G, Schmukler S. What triggers market jitters? A chronicle of the Asian crisis. Journal of International Money and Finance. 1999;18(4):537-560.

Kose M. Effects of Financial Globalization on Developing Countries: Some Empirical Evidence on Effects of Financial Globalization on Developing Countries. International Monetary Fund. 2003.

Lin W, Engle R, Ito T. Do bulls and bears move across borders? International transmission of stock returns and volatility. Review of Financial Studies. 1994;7(3):507-538.

Pasricha GK. Kalman filter and its economic applications. MPRA Paper. 2006:1-10.

Ramchand L. and R. Susmel. Volatility and cross correlation across major stock markets. Journal of Empirical Finance. 1998; 5: 397-416.

Reinhart C. The economic and fiscal consequences of financial crises. MPRA Paper. 2009;(13025).

Rockinger M, Urga G. A Time-varying parameter model to test for predictability and integration in stock markets of transition economies. Journal of Business and Economic Statistics. 2001; 19(1): 73-84.

Todorov G., Bidarkota P.V. On international financial spillovers to frontier markets. FIU Working Paper. 2010.

Wells C. Kalman filter in finance. Springer. 1995. 
Table 2.1. Parameter Estimates - US

The most general Model 1 given by: $R_{\mathrm{t}}^{\mathrm{US}}=\theta^{\mathrm{US}}+a_{\mathrm{t}}^{\mathrm{US}} R_{\mathrm{t}-1}^{\mathrm{US}}+u_{\mathrm{t}}^{\mathrm{US}}, u_{\mathrm{t}}^{\mathrm{US}} \sim \operatorname{iid} N\left(0, H_{\mathrm{t}}^{\mathrm{US}}\right), H_{\mathrm{t}}^{\mathrm{US}}=b_{0}+$ $b_{1} H_{\mathrm{t}-1}^{\mathrm{US}}+b_{2} u_{\mathrm{t}-1}^{2 \mathrm{US}}, a_{\mathrm{t}}^{\mathrm{US}}=c(1-\rho)+\rho a_{\mathrm{t}-1}^{\mathrm{US}}+n_{t}^{\mathrm{US}}, n_{\mathrm{t}}^{\mathrm{US}} \sim N\left(0, Q^{\mathrm{US}}\right)$. Model 2 is obtained by imposing $a_{\mathrm{t}}^{\mathrm{US}}=$ constant on Model 1. The sample spans from Nov. 15th 2005 to Jan 15th 2010. Standard errors are reported in parentheses below the parameter estimates. LR gives the value of the likelihood ratio test statistic.

Note:

\begin{tabular}{|c|c|c|}
\hline Parameters & Model 1 & Model 2 \\
$\theta$ & 12.044 & 12.041 \\
& $(7.069)$ & $(6.946)$ \\
\hline$c$ & -0.098 & -0.097 \\
& $(0.033)$ & $(0.0329)$ \\
\hline$\rho$ & 0.948 & \\
& $(0.23)$ & \\
\hline$\sqrt{Q^{\mathrm{US}}}$ & 0.000 & \\
& $(0.000)$ & \\
\hline$b_{0}$ & 884.449 & 883.868 \\
& $(264.64)$ & $(264.26)$ \\
\hline$b_{1}$ & 0.911 & 0.911 \\
& $(0.012)$ & $(0.012)$ \\
\hline$b_{2}$ & 0.08 & 0.08 \\
& $(0.012)$ & $(0.012)$ \\
\hline LogL & -7587.715 & -7587.775 \\
\hline$L R\left(a_{\mathrm{t}}^{\mathrm{US}}=\right.$ const. $)$ & \multicolumn{2}{|c}{} \\
\hline
\end{tabular}

1. $L R\left(a_{\mathrm{t}}^{\mathrm{US}}=\right.$ const. $)$ is a test for no time-variation in the $\mathrm{AR}(1)$ parameter. The $5 \% \chi_{2}^{2} \mathrm{p}$-value equals 5.99 . 
Table 2.2. Parameter Estimates for Model 1

Model 1 for Frontier countries:

$$
\begin{gathered}
R_{\mathrm{t}}^{\mathrm{K}}=\theta^{\mathrm{K}}+a_{\mathrm{t}}^{\mathrm{US}} R_{\mathrm{t}}^{\mathrm{US}}+a^{\mathrm{K}} R_{\mathrm{t}-1}^{\mathrm{K}}+u_{\mathrm{t}}^{\mathrm{K}}, u_{\mathrm{t}}^{\mathrm{K}} \sim N\left(0, H_{\mathrm{t}}^{\mathrm{K}}\right), H_{\mathrm{t}}^{\mathrm{K}}=b_{0}+b_{1} H_{\mathrm{t}-1}^{\mathrm{K}}+b_{2} u_{\mathrm{t}-1}^{2 \mathrm{~K}}+b_{3} H_{\mathrm{t}}^{\mathrm{US}}+b_{4} H_{\mathrm{t}-1}^{\mathrm{US}} \\
a_{\mathrm{t}}^{\mathrm{US}}=c(1-\rho)+\rho a_{\mathrm{t}-1}^{\mathrm{US}}+n_{\mathrm{t}}^{\mathrm{US}}, n_{t}^{\mathrm{US}} \sim N\left(0, Q^{\mathrm{US}}\right), E\left(u_{\mathrm{t}}^{\mathrm{K}} n_{\mathrm{t}}^{\mathrm{US}}\right)=0 .
\end{gathered}
$$

\begin{tabular}{|c|c|c|c|c|c|c|c|c|c|c|}
\hline Country & $\theta^{\mathrm{K}}$ & $c$ & $\rho$ & $\sqrt{Q^{\mathrm{US}}}$ & $a^{\mathrm{K}}$ & $b_{0}$ & $b_{1}$ & $b_{2}$ & $b_{3}$ & $b_{4}$ \\
\hline Argentina & $\begin{array}{c}10.5 \\
(10.5)\end{array}$ & $\begin{array}{c}0.99 \\
(0.04)\end{array}$ & $\begin{array}{c}0.67 \\
(0.12)\end{array}$ & $\begin{array}{c}0.21 \\
(0.06)\end{array}$ & $\begin{array}{c}0.11 \\
(0.03)\end{array}$ & $\begin{array}{c}0.68 \\
(0.00)\end{array}$ & $\begin{array}{c}0.80 \\
(0.04)\end{array}$ & $\begin{array}{c}0.14 \\
(0.03)\end{array}$ & $\begin{array}{c}0.11 \\
(0.05)\end{array}$ & $\begin{array}{c}0.00 \\
(0.00)\end{array}$ \\
\hline Bahrain & $\begin{array}{l}-6.01 \\
(7.81)\end{array}$ & $\begin{array}{c}0.00 \\
(0.01)\end{array}$ & $\begin{array}{l}-0.96 \\
(0.00)\end{array}$ & $\begin{array}{c}0.00 \\
(0.00)\end{array}$ & $\begin{array}{c}0.09 \\
(0.04)\end{array}$ & $\begin{array}{c}0.64 \\
(0.00)\end{array}$ & $\begin{array}{c}0.55 \\
(0.08)\end{array}$ & $\begin{array}{c}0.16 \\
(0.03)\end{array}$ & $\begin{array}{c}0.44 \\
(0.10)\end{array}$ & $\begin{array}{c}0.00 \\
(0.00)\end{array}$ \\
\hline Bulgaria & $\begin{array}{c}22.16 \\
(10.89)\end{array}$ & $\begin{array}{c}0.07 \\
(0.04)\end{array}$ & $\begin{array}{l}-0.93 \\
(0.00)\end{array}$ & $\begin{array}{c}0.00 \\
(0.00)\end{array}$ & $\begin{array}{l}-0.06 \\
(0.03)\end{array}$ & $\begin{array}{c}5.00 \\
(0.00)\end{array}$ & $\begin{array}{c}0.86 \\
(0.02)\end{array}$ & $\begin{array}{c}0.10 \\
(0.02)\end{array}$ & $\begin{array}{c}0.10 \\
(0.03)\end{array}$ & $\begin{array}{c}0.00 \\
(0.00) \\
\end{array}$ \\
\hline Croatia & $\begin{array}{c}14.48 \\
(11.48)\end{array}$ & $\begin{array}{c}0.14 \\
(0.03)\end{array}$ & $\begin{array}{c}0.30 \\
(0.21)\end{array}$ & $\begin{array}{c}0.50 \\
(0.08)\end{array}$ & $\begin{array}{c}0.12 \\
(0.03)\end{array}$ & $\begin{array}{c}1.49 \\
(7.07)\end{array}$ & $\begin{array}{c}0.96 \\
(0.00)\end{array}$ & $\begin{array}{c}0.02 \\
(0.00)\end{array}$ & $\begin{array}{c}0.01 \\
(0.00)\end{array}$ & $\begin{array}{c}0.00 \\
(0.00)\end{array}$ \\
\hline Estonia & $\begin{array}{l}-1.38 \\
(0.00)\end{array}$ & $\begin{array}{c}0.12 \\
(0.04)\end{array}$ & $\begin{array}{c}0.01 \\
(0.20)\end{array}$ & $\begin{array}{c}0.41 \\
(0.06)\end{array}$ & $\begin{array}{c}0.12 \\
(0.03)\end{array}$ & $\begin{array}{c}0.56 \\
(0.00)\end{array}$ & $\begin{array}{c}0.89 \\
(0.01)\end{array}$ & $\begin{array}{c}0.07 \\
(0.01)\end{array}$ & $\begin{array}{c}0.05 \\
(0.02)\end{array}$ & $\begin{array}{c}0.00 \\
(0.00)\end{array}$ \\
\hline Jordan & $\begin{array}{l}-5.61 \\
(7.83)\end{array}$ & $\begin{array}{l}-0.02 \\
(0.02)\end{array}$ & $\begin{array}{l}-0.78 \\
(0.00)\end{array}$ & $\begin{array}{c}0.00 \\
(0.00)\end{array}$ & $\begin{array}{c}0.04 \\
(0.03)\end{array}$ & $\begin{array}{c}0.71 \\
(0.00)\end{array}$ & $\begin{array}{c}0.93 \\
(0.01)\end{array}$ & $\begin{array}{c}0.06 \\
(0.01)\end{array}$ & $\begin{array}{c}0.01 \\
(0.00)\end{array}$ & $\begin{array}{r}0.00 \\
(0.00)\end{array}$ \\
\hline Kazakhst. & $\begin{array}{c}30.97 \\
(16.62)\end{array}$ & $\begin{array}{c}0.25 \\
(0.05)\end{array}$ & $\begin{array}{c}0.07 \\
(0.41)\end{array}$ & $\begin{array}{c}0.36 \\
(0.06)\end{array}$ & $\begin{array}{c}0.00 \\
(0.03)\end{array}$ & $\begin{array}{c}0.74 \\
(7.12)\end{array}$ & $\begin{array}{c}0.94 \\
(0.01)\end{array}$ & $\begin{array}{c}0.04 \\
(0.01)\end{array}$ & $\begin{array}{c}0.02 \\
(0.01)\end{array}$ & $\begin{array}{c}0.00 \\
(0.00)\end{array}$ \\
\hline Kenya & $\begin{array}{c}3.67 \\
(8.20)\end{array}$ & $\begin{array}{c}0.02 \\
(0.03)\end{array}$ & $\begin{array}{c}0.22 \\
(0.16)\end{array}$ & $\begin{array}{c}0.38 \\
(0.05)\end{array}$ & $\begin{array}{c}0.34 \\
(0.03)\end{array}$ & $\begin{array}{c}0.84 \\
(0.00)\end{array}$ & $\begin{array}{c}0.93 \\
(0.00)\end{array}$ & $\begin{array}{c}0.06 \\
(0.01)\end{array}$ & $\begin{array}{c}0.00 \\
(0.00)\end{array}$ & $\begin{array}{c}0.00 \\
(0.01)\end{array}$ \\
\hline Kuwait & $\begin{array}{l}10.06 \\
(9.90)\end{array}$ & $\begin{array}{c}0.00 \\
(0.03)\end{array}$ & $\begin{array}{l}-0.92 \\
(0.00)\end{array}$ & $\begin{array}{c}0.00 \\
(0.00)\end{array}$ & $\begin{array}{c}0.07 \\
(0.03)\end{array}$ & $\begin{array}{c}0.81 \\
(3.67)\end{array}$ & $\begin{array}{c}0.93 \\
(0.01)\end{array}$ & $\begin{array}{c}0.05 \\
(0.00)\end{array}$ & $\begin{array}{c}0.02 \\
(0.01)\end{array}$ & $\begin{array}{c}0.00 \\
(0.00)\end{array}$ \\
\hline Lebanon & $\begin{array}{c}5.73 \\
(26.15)\end{array}$ & $\begin{array}{l}-0.02 \\
(0.03)\end{array}$ & $\begin{array}{c}0.07 \\
(1.28)\end{array}$ & $\begin{array}{c}0.28 \\
(0.12)\end{array}$ & $\begin{array}{c}0.13 \\
(0.04)\end{array}$ & $\begin{array}{c}0.65 \\
(2.07)\end{array}$ & $\begin{array}{c}0.73 \\
(0.04)\end{array}$ & $\begin{array}{c}0.25 \\
(0.05)\end{array}$ & $\begin{array}{c}0.14 \\
(0.03)\end{array}$ & $\begin{array}{c}0.00 \\
(0.00)\end{array}$ \\
\hline Mauritius & $\begin{array}{l}29.28 \\
(8.67)\end{array}$ & $\begin{array}{c}0.06 \\
(0.03)\end{array}$ & $\begin{array}{c}0.08 \\
(0.19)\end{array}$ & $\begin{array}{c}0.63 \\
(0.06)\end{array}$ & $\begin{array}{c}0.23 \\
(0.04)\end{array}$ & $\begin{array}{c}0.64 \\
(3.21)\end{array}$ & $\begin{array}{c}0.57 \\
(0.07)\end{array}$ & $\begin{array}{c}0.21 \\
(0.06)\end{array}$ & $\begin{array}{c}0.24 \\
(0.05)\end{array}$ & $\begin{array}{c}0.00 \\
(0.00)\end{array}$ \\
\hline Nigeria & $\begin{array}{c}9.58 \\
(7.67)\end{array}$ & $\begin{array}{l}-0.01 \\
(0.02)\end{array}$ & $\begin{array}{l}-0.64 \\
(0.12)\end{array}$ & $\begin{array}{c}0.24 \\
(0.05)\end{array}$ & $\begin{array}{c}0.44 \\
(0.03)\end{array}$ & $\begin{array}{c}0.76 \\
(0.00)\end{array}$ & $\begin{array}{c}0.89 \\
(0.01)\end{array}$ & $\begin{array}{c}0.08 \\
(0.01)\end{array}$ & $\begin{array}{c}0.00 \\
(0.00)\end{array}$ & $\begin{array}{c}0.01 \\
(0.03)\end{array}$ \\
\hline Oman & $\begin{array}{c}9.10 \\
(8.84)\end{array}$ & $\begin{array}{c}0.01 \\
(0.03)\end{array}$ & $\begin{array}{l}-0.97 \\
(0.07)\end{array}$ & $\begin{array}{c}0.00 \\
(0.00)\end{array}$ & $\begin{array}{c}0.10 \\
(0.03)\end{array}$ & $\begin{array}{c}0.66 \\
(0.00)\end{array}$ & $\begin{array}{c}0.84 \\
(0.02)\end{array}$ & $\begin{array}{c}0.11 \\
(0.01)\end{array}$ & $\begin{array}{c}0.07 \\
(0.02)\end{array}$ & $\begin{array}{c}0.00 \\
(0.02)\end{array}$ \\
\hline Pakistan & $\begin{array}{c}1.07 \\
(3.88)\end{array}$ & $\begin{array}{c}0.02 \\
(0.03)\end{array}$ & $\begin{array}{c}0.81 \\
(0.19)\end{array}$ & $\begin{array}{c}0.15 \\
(0.11)\end{array}$ & $\begin{array}{c}0.10 \\
(0.03)\end{array}$ & $\begin{array}{c}0.57 \\
(1.69)\end{array}$ & $\begin{array}{c}0.89 \\
(0.02)\end{array}$ & $\begin{array}{c}0.10 \\
(0.02)\end{array}$ & $\begin{array}{c}0.00 \\
(0.00)\end{array}$ & $\begin{array}{c}0.04 \\
(0.01)\end{array}$ \\
\hline Qatar & $\begin{array}{c}-9.35 \\
(12.36)\end{array}$ & $\begin{array}{l}-0.01 \\
(0.04)\end{array}$ & $\begin{array}{l}-0.95 \\
(0.39)\end{array}$ & $\begin{array}{c}0.00 \\
(0.00)\end{array}$ & $\begin{array}{c}0.09 \\
(0.03)\end{array}$ & $\begin{array}{c}0.83 \\
(0.00)\end{array}$ & $\begin{array}{c}0.87 \\
(0.02)\end{array}$ & $\begin{array}{c}0.09 \\
(0.01)\end{array}$ & $\begin{array}{c}0.09 \\
(0.02)\end{array}$ & $\begin{array}{r}0.00 \\
(0.00)\end{array}$ \\
\hline Rom & $\begin{array}{c}13.72 \\
(15.42)\end{array}$ & $\begin{array}{l}0.29 \\
(0.1)\end{array}$ & $\begin{array}{c}0.16 \\
(1.00)\end{array}$ & $\begin{array}{c}0.45 \\
(0.08)\end{array}$ & $\begin{array}{c}0.07 \\
(0.03)\end{array}$ & $\begin{array}{c}2.17 \\
(14.3)\end{array}$ & $\begin{array}{c}0.97 \\
(0.00)\end{array}$ & $\begin{array}{c}0.01 \\
(0.00)\end{array}$ & $\begin{array}{c}0.04 \\
(0.01)\end{array}$ & $\begin{array}{c}0.00 \\
(0.00)\end{array}$ \\
\hline S.Arabia & $\begin{array}{l}-0.45 \\
(0.00)\end{array}$ & $\begin{array}{c}0.13 \\
(0.04)\end{array}$ & $\begin{array}{l}-0.92 \\
(0.33)\end{array}$ & $\begin{array}{c}0.00 \\
(0.00)\end{array}$ & $\begin{array}{c}0.04 \\
(0.03)\end{array}$ & $\begin{array}{c}0.61 \\
(0.00)\end{array}$ & $\begin{array}{c}0.93 \\
(0.00)\end{array}$ & $\begin{array}{c}0.06 \\
(0.01)\end{array}$ & $\begin{array}{c}0.02 \\
(0.01)\end{array}$ & $\begin{array}{r}0.00 \\
(0.00)\end{array}$ \\
\hline Slovenia & $\begin{array}{l}19.69 \\
(9.49)\end{array}$ & $\begin{array}{c}0.16 \\
(0.04)\end{array}$ & $\begin{array}{c}0.49 \\
(0.34)\end{array}$ & $\begin{array}{c}0.28 \\
(0.11)\end{array}$ & $\begin{array}{c}0.17 \\
(0.03)\end{array}$ & $\begin{array}{c}1.11 \\
(0.00)\end{array}$ & $\begin{array}{c}0.94 \\
(0.01)\end{array}$ & $\begin{array}{c}0.05 \\
(0.01)\end{array}$ & $\begin{array}{c}0.00 \\
(0.00)\end{array}$ & $\begin{array}{c}0.00 \\
(0.00)\end{array}$ \\
\hline S. Lanka & $\begin{array}{l}-9.71 \\
(7.00)\end{array}$ & $\begin{array}{c}0.06 \\
(0.02)\end{array}$ & $\begin{array}{l}-0.31 \\
(0.11)\end{array}$ & $\begin{array}{c}0.49 \\
(0.05)\end{array}$ & $\begin{array}{c}0.24 \\
(0.03)\end{array}$ & $\begin{array}{c}0.77 \\
(0.00)\end{array}$ & $\begin{array}{c}0.94 \\
(0.01)\end{array}$ & $\begin{array}{c}0.04 \\
(0.00)\end{array}$ & $\begin{array}{c}0.00 \\
(0.01)\end{array}$ & $\begin{array}{c}0.00 \\
(0.07)\end{array}$ \\
\hline Tunisia & $\begin{array}{l}17.18 \\
(7.14)\end{array}$ & $\begin{array}{c}0.06 \\
(0.02)\end{array}$ & $\begin{array}{c}0.11 \\
(0.18)\end{array}$ & $\begin{array}{c}0.39 \\
(0.06)\end{array}$ & $\begin{array}{c}0.08 \\
(0.03)\end{array}$ & $\begin{array}{c}0.66 \\
(3.82)\end{array}$ & $\begin{array}{c}0.92 \\
(0.02)\end{array}$ & $\begin{array}{c}0.06 \\
(0.02)\end{array}$ & $\begin{array}{c}0.01 \\
(0.02)\end{array}$ & $\begin{array}{c}0.01 \\
(0.02)\end{array}$ \\
\hline UAE & $\begin{array}{l}-0.56 \\
(1.91)\end{array}$ & $\begin{array}{c}0.00 \\
(0.05)\end{array}$ & $\begin{array}{c}0.50 \\
(0.97)\end{array}$ & $\begin{array}{c}0.00 \\
(0.04)\end{array}$ & $\begin{array}{c}0.13 \\
(0.03)\end{array}$ & $\begin{array}{c}0.48 \\
(1.26)\end{array}$ & $\begin{array}{c}0.91 \\
(0.01)\end{array}$ & $\begin{array}{c}0.07 \\
(0.01)\end{array}$ & $\begin{array}{c}0.06 \\
(0.02)\end{array}$ & $\begin{array}{c}0.00 \\
(0.00)\end{array}$ \\
\hline
\end{tabular}

Standard errors are reported in parentheses below the parameter estimates. 
Table 2.3. Hypothesis Tests

The table presents values of the test statistics derived from LR tests performed to examine restricted versions of Model 1 for Frontier market returns. The LR-statistic is approximately chi-squared. It has 2 degrees of freedom for Models $2 \&$ 3, 5 for Model 4, and 3 for Model 5. All tests are performed at the 5\% significance level. Respective critical values are as follows: 5.99 with 2 d.f.; 7.82 with 3 d.f.; 9.49 with 4 d.f.; and 11.07 with 5 d.f.

\begin{tabular}{|c|c|c|c|c|}
\hline & \multicolumn{4}{|c|}{ Model under $H_{0}$} \\
\hline Country & Model 2 & Model 3 & Model 4 & Model 5 \\
\hline Argentina & 9.572 & 5.09 & 343.551 & 131.576 \\
\hline Bahrain & 0.021 & 152.778 & 475.823 & 26.8611 \\
\hline Bulgaria & 12.697 & 58.501 & 60.97 & 51.632 \\
\hline Croatia & 35.169 & 4.647 & 23.116 & 226.451 \\
\hline Estonia & 11.073 & 13.343 & 38.209 & 128.63 \\
\hline Jordan & 0.006 & 3.862 & 13.702 & 476.146 \\
\hline Kazakhstan & 9.816 & 4.045 & 19.216 & 556.142 \\
\hline Kenya & 16.128 & 3.234 & 17.901 & 351.252 \\
\hline Kuwait & 0.001 & 18.421 & 18.568 & 440.989 \\
\hline Lebanon & 2.928 & 51.504 & 76.22 & 467.694 \\
\hline Mauritius & 18.814 & 27.678 & 60.366 & 106.388 \\
\hline Nigeria & 13.227 & 21.108 & 42.086 & 374.232 \\
\hline Oman & 0.007 & 5.515 & 19.402 & 205.541 \\
\hline Pakistan & 3.226 & 16.877 & 72.413 & 315.625 \\
\hline Qatar & 0.007 & 61.008 & 71.592 & 162.438 \\
\hline Romania & 45.93 & 54.212 & 124.653 & 35.837 \\
\hline S.Arabia & 0.007 & 8.895 & 30.472 & 839.083 \\
\hline Slovenia & 6.371 & 52.75 & 76.391 & 114.68 \\
\hline Sri Lanka & 52.489 & 0.997 & 77.202 & 350.446 \\
\hline Tunisia & 36.571 & 31.739 & 52.207 & 226.96 \\
\hline UAE & 0.000 & 22.839 & 23.083 & 494.803 \\
\hline & & & &
\end{tabular}


Table 2.4. Summary of Hypothesis Tests

The table presents a summary of the statistical inferences reached on hypotheses tests reported in Table 3. The model under the null hypothesis in each of the columns 2-5 below corresponds to that in the corresponding columns of Table 3. The restriction being tested under each null hypothesis is noted in the header for columns 2-5. In all cases, the alternative hypothesis is Model 1.

\begin{tabular}{|c|c|c|c|c|}
\hline Country & $\begin{array}{c}\text { Presence of time-variable } \\
\text { return spillovers }\end{array}$ & $\begin{array}{c}\text { Presence of } \\
\text { volatility spillovers }\end{array}$ & $\begin{array}{c}\text { Complete } \\
\text { Segmentation }\end{array}$ & $\begin{array}{c}\text { Complete } \\
\text { Integration }\end{array}$ \\
\hline Argentina & yes & no & no & no \\
\hline Bahrain & no & yes & no & no \\
\hline Bulgaria & yes & yes & no & no \\
\hline Croatia & yes & yes & no & no \\
\hline Estonia & yes & no & no & no \\
\hline Jordan & no & no & no & no \\
\hline Kazakhstan & yes & no & no & no \\
\hline Kenya & yes & yes & no & no \\
\hline Kuwait & no & yes & no & no \\
\hline Lebanon & no & yes & no & no \\
\hline Mauritius & yes & no & no & no \\
\hline Nigeria & yes & yes & no & no \\
\hline Oman & no & yes & no & no \\
\hline Pakistan & yes & yes & no & no \\
\hline Qatar & no & yes & no & no \\
\hline Romania & yes & yes & no & no \\
\hline S.Arabia & no & no & no & no \\
\hline Slovenia & yes & yes & no & no \\
\hline Sri Lanka & yes & yes & no & \\
\hline Tunisia & & no & no & \\
\hline UAE & & & no & no \\
\hline
\end{tabular}


Table A.1. Parameter Estimates for Model 2

$R^{\mathrm{K}}=\theta^{\mathrm{K}}+a^{\mathrm{US}} R_{\mathrm{t}}^{\mathrm{US}}+a^{\mathrm{K}} R_{\mathrm{t}-1}^{\mathrm{K}}+u_{\mathrm{t}}^{\mathrm{K}}, u_{\mathrm{t}}^{\mathrm{K}} \sim N\left(0, H_{\mathrm{t}}^{\mathrm{K}}\right), H_{\mathrm{t}}^{\mathrm{K}}=b_{0}+b_{1} H_{\mathrm{t}-1}^{\mathrm{K}}+b_{2} u_{\mathrm{t}-1}^{2 \mathrm{~K}}+b_{3} H_{\mathrm{t}}^{\mathrm{US}}+b_{4} H_{\mathrm{t}-1}^{\mathrm{US}}$ Standard errors are reported in parentheses below the parameter estimates.

\begin{tabular}{|c|c|c|c|c|c|c|c|c|}
\hline Country & $\theta^{\mathrm{k}}$ & $a^{\mathrm{US}}$ & $a^{\mathrm{K}}$ & $b_{0}$ & $b_{1}$ & $b_{2}$ & $b_{3}$ & $b_{4}$ \\
\hline Argentina & $\begin{array}{l}5.122 \\
(25.4)\end{array}$ & $\begin{array}{c}0.998 \\
(0.008)\end{array}$ & $\begin{array}{c}0.11 \\
(0.028)\end{array}$ & $\begin{array}{c}1.736 \\
(17.353)\end{array}$ & $\begin{array}{c}0.812 \\
(0.035)\end{array}$ & $\begin{array}{c}0.184 \\
(0.036)\end{array}$ & $\begin{array}{c}0.077 \\
(0.034)\end{array}$ & $\begin{array}{c}0.000 \\
(0.000)\end{array}$ \\
\hline Bahrain & $\begin{array}{l}-5.982 \\
(7.642)\end{array}$ & $\begin{array}{l}-0.006 \\
(0.036)\end{array}$ & $\begin{array}{c}0.091 \\
(0.045)\end{array}$ & $\begin{array}{c}0.632 \\
(0.000)\end{array}$ & $\begin{array}{c}0.552 \\
(0.083)\end{array}$ & $\begin{array}{c}0.167 \\
(0.033)\end{array}$ & $\begin{array}{c}0.444 \\
(0.103)\end{array}$ & $\begin{array}{c}0.000 \\
(0.000)\end{array}$ \\
\hline Bulgaria & $\begin{array}{c}22.325 \\
(10.917)\end{array}$ & $\begin{array}{c}0.077 \\
(0.045)\end{array}$ & $\begin{array}{l}-0.067 \\
(0.035)\end{array}$ & $\begin{array}{c}0.583 \\
(2.636)\end{array}$ & $\begin{array}{c}0.806 \\
(0.047)\end{array}$ & $\begin{array}{c}0.1 \\
(0.022)\end{array}$ & $\begin{array}{c}0.229 \\
(0.087)\end{array}$ & $\begin{array}{c}0.000 \\
(0.000)\end{array}$ \\
\hline Croatia & $\begin{array}{c}27.781 \\
(11.059)\end{array}$ & $\begin{array}{c}0.155 \\
(0.037)\end{array}$ & $\begin{array}{c}0.135 \\
(0.033)\end{array}$ & $\begin{array}{c}1.421 \\
(13.098)\end{array}$ & $\begin{array}{c}0.945 \\
(0.011)\end{array}$ & $\begin{array}{c}0.052 \\
(0.012)\end{array}$ & $\begin{array}{c}0.012 \\
(0.006)\end{array}$ & $\begin{array}{c}0.000 \\
(0.000)\end{array}$ \\
\hline Est & $\begin{array}{c}-2.055 \\
(10.633)\end{array}$ & $\begin{array}{l}0.112 \\
(0.04)\end{array}$ & $\begin{array}{c}0.124 \\
(0.033)\end{array}$ & $\begin{array}{c}0.555 \\
(1.663)\end{array}$ & $\begin{array}{c}0.858 \\
(0.021)\end{array}$ & $\begin{array}{c}0.125 \\
(0.019)\end{array}$ & $\begin{array}{c}0.067 \\
(0.023)\end{array}$ & $\begin{array}{c}0.000 \\
(0.000)\end{array}$ \\
\hline Jordan & $\begin{array}{c}-5.758 \\
(10.341)\end{array}$ & $\begin{array}{l}-0.022 \\
(0.028)\end{array}$ & $\begin{array}{c}0.043 \\
(0.032)\end{array}$ & $\begin{array}{c}0.714 \\
(0.000)\end{array}$ & $\begin{array}{c}0.934 \\
(0.011)\end{array}$ & $\begin{array}{c}0.063 \\
(0.012)\end{array}$ & $\begin{array}{c}0.008 \\
(0.003)\end{array}$ & $\begin{array}{c}0.000 \\
(0.000)\end{array}$ \\
\hline Kaza & $\begin{array}{c}36.639 \\
(16.929)\end{array}$ & $\begin{array}{c}0.246 \\
(0.059)\end{array}$ & $\begin{array}{c}0.002 \\
(0.033)\end{array}$ & $\begin{array}{c}0.667 \\
(2.002)\end{array}$ & $\begin{array}{c}0.921 \\
(0.014)\end{array}$ & $\begin{array}{c}0.076 \\
(0.015)\end{array}$ & $\begin{array}{l}0.036 \\
(0.02)\end{array}$ & $\begin{array}{c}0.000 \\
(0.000)\end{array}$ \\
\hline Kenya & $\begin{array}{c}4.355 \\
(7.488)\end{array}$ & $\begin{array}{c}0.027 \\
(0.027)\end{array}$ & $\begin{array}{c}0.313 \\
(0.032)\end{array}$ & $\begin{array}{l}0.594 \\
(1.52)\end{array}$ & $\begin{array}{c}0.91 \\
(0.008)\end{array}$ & $\begin{array}{c}0.094 \\
(0.011)\end{array}$ & $\begin{array}{c}0.007 \\
(0.012)\end{array}$ & $\begin{array}{c}0.001 \\
(0.011)\end{array}$ \\
\hline Kuv & $\begin{array}{c}10.085 \\
(10.199)\end{array}$ & $\begin{array}{c}0.000 \\
(0.034)\end{array}$ & & $\begin{array}{c}0.81 \\
(17.477)\end{array}$ & $\begin{array}{c}0.936 \\
(0.009)\end{array}$ & $\begin{array}{c}0.054 \\
(0.009)\end{array}$ & $\begin{array}{c}0.021 \\
(0.051)\end{array}$ & $\begin{array}{c}0.001 \\
(0.051)\end{array}$ \\
\hline $\mathrm{Le}$ & $\begin{array}{c}4.301 \\
(11.166)\end{array}$ & $\begin{array}{l}-0.025 \\
(0.034)\end{array}$ & $\begin{array}{c}0.134 \\
(0.038)\end{array}$ & $\begin{array}{c}0.803 \\
(0.000)\end{array}$ & $\begin{array}{l}0.733 \\
(0.03)\end{array}$ & $\begin{array}{c}0.3 \\
(0.045)\end{array}$ & $\begin{array}{c}0.113 \\
(0.024)\end{array}$ & $\begin{array}{c}0.000 \\
(0.000)\end{array}$ \\
\hline $\mathrm{M}$ & $\begin{array}{l}27.388 \\
(7.45)\end{array}$ & $\begin{array}{c}0.071 \\
(0.031)\end{array}$ & $\begin{array}{l}0.204 \\
(0.04)\end{array}$ & $\begin{array}{c}0.573 \\
(0.000)\end{array}$ & $\begin{array}{c}0.275 \\
(0.042)\end{array}$ & $\begin{array}{c}0.714 \\
(0.094)\end{array}$ & $\begin{array}{c}0.456 \\
(0.015)\end{array}$ & $\begin{array}{c}0.000 \\
(0.000)\end{array}$ \\
\hline & $\begin{array}{c}6.074 \\
(6.095)\end{array}$ & $\begin{array}{c}-0.011 \\
(0.021)\end{array}$ & $\begin{array}{c}0.442 \\
(0.031)\end{array}$ & $\begin{array}{c}0.617 \\
(0.000)\end{array}$ & & $\begin{array}{c}0.129 \\
(0.021)\end{array}$ & $\begin{array}{c}0.000 \\
(0.000)\end{array}$ & $\begin{array}{c}0.011 \\
(0.004)\end{array}$ \\
\hline C & $\begin{array}{c}9.101 \\
(8.222)\end{array}$ & $\begin{array}{c}0.008 \\
(0.031)\end{array}$ & $\begin{array}{c}0.106 \\
(0.036)\end{array}$ & $\begin{array}{c}0.646 \\
(0.000)\end{array}$ & $\begin{array}{c}0.844 \\
(0.022)\end{array}$ & $\begin{array}{c}0.112 \\
(0.019)\end{array}$ & $\begin{array}{c}0.072 \\
(0.018)\end{array}$ & $\begin{array}{c}0.000 \\
(0.002)\end{array}$ \\
\hline $\mathrm{P}$ & $\begin{array}{c}8.329 \\
(12.787)\end{array}$ & $\begin{array}{c}0.021 \\
(0.023)\end{array}$ & $\begin{array}{c}0.106 \\
(0.034)\end{array}$ & $\begin{array}{l}1.177 \\
(3.21)\end{array}$ & $\begin{array}{c}0.873 \\
(0.016)\end{array}$ & $\begin{array}{c}0.142 \\
(0.023)\end{array}$ & $\begin{array}{c}0.000 \\
(0.000)\end{array}$ & $\begin{array}{c}0.007 \\
(0.003)\end{array}$ \\
\hline $\mathrm{Qa}$ & $\begin{array}{c}-9.394 \\
(11.611)\end{array}$ & $\begin{array}{c}-0.011 \\
(0.042)\end{array}$ & $\begin{array}{c}0.091 \\
(0.036)\end{array}$ & $\begin{array}{c}0.821 \\
(2.846)\end{array}$ & $\begin{array}{c}0.877 \\
(0.018)\end{array}$ & $\begin{array}{c}0.093 \\
(0.017)\end{array}$ & $\begin{array}{c}0.096 \\
(0.022)\end{array}$ & $\begin{array}{c}0.000 \\
(0.000)\end{array}$ \\
\hline Rom & $\begin{array}{c}16.395 \\
(15.722)\end{array}$ & $\begin{array}{c}0.344 \\
(0.059)\end{array}$ & $\begin{array}{c}0.042 \\
(0.031)\end{array}$ & $\begin{array}{c}2.261 \\
(0.000)\end{array}$ & $\begin{array}{c}0.968 \\
(0.006)\end{array}$ & $\begin{array}{c}0.023 \\
(0.005)\end{array}$ & $\begin{array}{c}0.031 \\
(0.011)\end{array}$ & $\begin{array}{c}0.000 \\
(0.000)\end{array}$ \\
\hline S.A & $\begin{array}{l}-1.576 \\
(2.838)\end{array}$ & $\begin{array}{c}0.13 \\
(0.041)\end{array}$ & $\begin{array}{c}0.04 \\
(0.034)\end{array}$ & $\begin{array}{c}0.957 \\
(0.000)\end{array}$ & $\begin{array}{c}0.937 \\
(0.000)\end{array}$ & $\begin{array}{c}0.064 \\
(0.004)\end{array}$ & $\begin{array}{c}0.012 \\
(0.005)\end{array}$ & $\begin{array}{c}0.000 \\
(0.000)\end{array}$ \\
\hline Slov & $\begin{array}{l}20.797 \\
(9.296)\end{array}$ & $\begin{array}{c}0.136 \\
(0.036)\end{array}$ & $\begin{array}{c}0.189 \\
(0.033)\end{array}$ & $\begin{array}{c}0.526 \\
(3.167)\end{array}$ & $\begin{array}{c}0.854 \\
(0.046)\end{array}$ & $\begin{array}{c}0.111 \\
(0.033)\end{array}$ & $\begin{array}{c}0.000 \\
(0.008)\end{array}$ & $\begin{array}{c}0.032 \\
(0.018)\end{array}$ \\
\hline Sri Lanka & $\begin{array}{l}-10.784 \\
(9.021) \\
\end{array}$ & $\begin{array}{c}0.063 \\
(0.026)\end{array}$ & $\begin{array}{c}0.237 \\
(0.036)\end{array}$ & $\begin{array}{c}0.946 \\
(3.426)\end{array}$ & $\begin{array}{c}0.801 \\
(0.048)\end{array}$ & $\begin{array}{c}0.183 \\
(0.043)\end{array}$ & $\begin{array}{c}0.061 \\
(0.026)\end{array}$ & $\begin{array}{c}0.000 \\
(0.002)\end{array}$ \\
\hline Tunisia & $\begin{array}{l}14.425 \\
(7.108)\end{array}$ & $\begin{array}{c}0.051 \\
(0.022)\end{array}$ & $\begin{array}{c}0.092 \\
(0.035)\end{array}$ & $\begin{array}{c}0.643 \\
(0.000)\end{array}$ & $\begin{array}{c}0.856 \\
(0.029)\end{array}$ & $\begin{array}{c}0.158 \\
(0.036)\end{array}$ & $\begin{array}{c}0.002 \\
(0.000)\end{array}$ & $\begin{array}{c}0.007 \\
(0.000)\end{array}$ \\
\hline UAE & $\begin{array}{c}-2.5 \\
(0.000)\end{array}$ & $\begin{array}{c}0.000 \\
(0.047)\end{array}$ & $\begin{array}{c}0.13 \\
(0.034)\end{array}$ & $\begin{array}{c}0.668 \\
(0.000)\end{array}$ & $\begin{array}{c}0.915 \\
(0.012)\end{array}$ & $\begin{array}{c}0.078 \\
(0.012)\end{array}$ & $\begin{array}{c}0.042 \\
(0.015)\end{array}$ & $\begin{array}{c}0.000 \\
(0.000)\end{array}$ \\
\hline
\end{tabular}


Table A.2. Parameter Estimates for Model 3

$R_{\mathrm{t}}^{\mathrm{K}}=\theta^{\mathrm{K}}+a_{\mathrm{t}}^{\mathrm{US}} R_{\mathrm{t}}^{\mathrm{US}}+a^{\mathrm{K}} R_{\mathrm{t}-1}^{\mathrm{K}}+u_{\mathrm{t}}^{\mathrm{K}}, u_{\mathrm{t}}^{\mathrm{K}} \sim N\left(0, H_{\mathrm{t}}^{\mathrm{K}}\right), H_{\mathrm{t}}^{\mathrm{K}}=b_{0}+b_{1} H_{\mathrm{t}-1}^{\mathrm{K}}+b_{2} u_{\mathrm{t}-1}^{2 \mathrm{~K}}$, $a_{\mathrm{t}}^{\mathrm{K}}=c(1-\rho)+\rho a_{\mathrm{t}-1}^{\mathrm{US}}+n_{\mathrm{t}}^{\mathrm{US}}, n_{t}^{\mathrm{US}} \sim N\left(0, Q^{\mathrm{US}}\right), E\left(u_{\mathrm{t}}^{K} n_{\mathrm{t}}^{\mathrm{US}}\right)=0$

Standard errors are reported in parentheses below the parameter estimates.

\begin{tabular}{|c|c|c|c|c|c|c|c|c|}
\hline Country & $\theta^{\mathrm{k}}$ & $c$ & $\rho$ & $\sqrt{Q^{\mathrm{US}}}$ & $a^{\mathrm{K}}$ & $b_{0}$ & $b_{1}$ & $b_{2}$ \\
\hline \multirow[t]{2}{*}{ Argentina } & 0.241 & 0.966 & 0.661 & 0.252 & 0.101 & 0.501 & 0.931 & 0.062 \\
\hline & $(5.22)$ & $(0.047)$ & $(0.125)$ & (0.058) & $(0.031)$ & (3.006) & $(0.016)$ & $0.018)$ \\
\hline \multirow[t]{2}{*}{ Bahrain } & -13.236 & 0.284 & 0.824 & 0.433 & 0.04 & 0.109 & 0.749 & 0.377 \\
\hline & $(5.272)$ & $(0.038)$ & $(0.031)$ & $(0.056)$ & $(0.047)$ & $(0.000)$ & $(0.019)$ & $(0.048)$ \\
\hline \multirow[t]{2}{*}{ Bulgaria } & 22.042 & 0.079 & -0.988 & 0.000 & -0.078 & 0.052 & 0.919 & 0.094 \\
\hline & (11.917) & $(0.048)$ & $(0.02)$ & $(0.000)$ & $(0.034)$ & $(0.366)$ & $(0.017)$ & $(0.023)$ \\
\hline \multirow[t]{2}{*}{ Croatia } & 14.795 & 0.153 & 0.397 & 0.458 & 0.126 & 1.177 & 0.972 & 0.022 \\
\hline & $(15.71)$ & $(0.035)$ & $(0.183)$ & $(0.097)$ & $(0.037)$ & 15.331) & $(0.005)$ & $(0.006)$ \\
\hline \multirow[t]{2}{*}{ Estonia } & 0.533 & 0.138 & -0.017 & 0.437 & 0.12 & 0.789 & 0.924 & 0.071 \\
\hline & $(0.000)$ & $(0.04)$ & $(0.186)$ & $(0.071)$ & $(0.036)$ & $(0.000)$ & $(0.012)$ & $(0.016)$ \\
\hline \multirow[t]{2}{*}{ Jordan } & -5.514 & -0.02 & -0.802 & 0.000 & 0.044 & 0.556 & 0.944 & 0.061 \\
\hline & 5.749) & $(0.029)$ & $(0.000)$ & $(0.000)$ & $(0.032)$ & (5.131) & $(0.008)$ & $(0.011)$ \\
\hline \multirow[t]{2}{*}{ Kazakhstan } & 33.111 & 0.254 & 0.033 & 0.358 & -0.001 & 1.198 & 0.947 & 0.049 \\
\hline & 7.472) & $(0.059)$ & $(0.309)$ & $(0.068)$ & $(0.035)$ & $(0.000)$ & $(0.009)$ & $(0.011)$ \\
\hline \multirow[t]{2}{*}{ Kenya } & 0.236 & 0.021 & 0.204 & 0.388 & 0.353 & 0.672 & 0.934 & 0.063 \\
\hline & (0.000) & $(0.026)$ & $(0.152)$ & $(0.058)$ & $(0.036)$ & $(0.000)$ & $(0.008)$ & $(0.011)$ \\
\hline \multirow[t]{2}{*}{ Kuwait } & 10.957 & 0.009 & 0.142 & 0.000 & 0.078 & 0.998 & 0.948 & 0.06 \\
\hline & (9.666) & $(0.034)$ & (3.847) & $(0.001)$ & $(0.034)$ & $(0.000)$ & $(0.006)$ & $(0.008)$ \\
\hline \multirow[t]{2}{*}{ Lebanon } & 0.208 & 0.023 & 0.192 & 0.542 & 0.119 & 0.501 & 0.935 & 0.065 \\
\hline & (0.000) & $(0.034)$ & $(0.083)$ & $(0.061)$ & $(0.041)$ & (1.959) & $(0.007)$ & $(0.012)$ \\
\hline \multirow[t]{2}{*}{ Mauritius } & 18.781 & 0.042 & 0.161 & 0.793 & 0.293 & 0.821 & 0.987 & 0.006 \\
\hline & $0.011)$ & (0.033) & $(0.088)$ & $(0.051)$ & (0.049) & (3.956) & $(0.002)$ & $(0.001)$ \\
\hline \multirow[t]{2}{*}{ Nigeria } & 8.784 & -0.01 & 0.424 & 0.309 & 0.431 & 0.441 & 0.9 & 0.098 \\
\hline & (8.09) & $(0.023)$ & $(0.158)$ & $(0.054)$ & $(0.032)$ & $(0.000)$ & $(0.012)$ & $(0.017)$ \\
\hline \multirow[t]{2}{*}{ Oman } & 12.445 & 0.025 & -0.985 & $\overline{0.000}$ & 0.094 & 0.003 & 0.91 & 0.116 \\
\hline & $.013)$ & $(0.031)$ & $(0.045)$ & $0.000)$ & (0.036) & $.121)$ & $(0.011)$ & (0.019) \\
\hline \multirow[t]{2}{*}{ Pakistan } & 0.296 & 0.048 & -0.222 & 0.453 & 0.123 & 0.861 & 0.96 & 0.031 \\
\hline & 332) & 033) & $(0.429)$ & $0.067)$ & $(0.036)$ & t.016) & $(0.005)$ & $(0.005)$ \\
\hline \multirow[t]{2}{*}{ Qatar } & 0.369 & 0.041 & 0.65 & 0.179 & 0.081 & 0.23 & 0.971 & 0.03 \\
\hline & 1.766) & 045) & $(0.277)$ & $(0.071)$ & $(0.036)$ & 1.594) & $(0.004)$ & $(0.005)$ \\
\hline \multirow[t]{2}{*}{ Romania } & 0.422 & 0.3 & 0.543 & 0.422 & 0.075 & 0.473 & 0.982 & 0.014 \\
\hline & $(0.000)$ & $0.066)$ & $(0.135)$ & $0.059)$ & $(0.039)$ & $(0.076)$ & $(0.002)$ & $(0.002)$ \\
\hline \multirow[t]{2}{*}{ S.Arabia } & 0.115 & 0.14 & -0.215 & 0.001 & 0.042 & 1.003 & 0.942 & 0.066 \\
\hline & 000) & $(0.042)$ & $(2.988)$ & $(0.000)$ & (0.034) & (5.301) & $(0.005)$ & $(0.008)$ \\
\hline \multirow[t]{2}{*}{ Slovenia } & 19.753 & 0.159 & 0.495 & 0.285 & 0.179 & 1.802 & 0.941 & 0.059 \\
\hline & 409) & $(0.035)$ & $(0.21)$ & (0.079) & (0.034) & (0.000) & (0.009) & $(0.012)$ \\
\hline \multirow[t]{2}{*}{ Sri Lanka } & -10.107 & 0.068 & -0.32 & 0.503 & 0.248 & 1.154 & 0.946 & 0.046 \\
\hline & & & $.101)$ & $(0.048)$ & $(0.039)$ & $0.000)$ & $(0.006)$ & $(0.008)$ \\
\hline \multirow[t]{2}{*}{ Tunisia } & 16.362 & 0.064 & 0.102 & 0.402 & 0.087 & 0.418 & 0.941 & 0.056 \\
\hline & & & & $0.064)$ & $(0.037)$ & $0.000)$ & $(0.015)$ & $(0.017)$ \\
\hline \multirow[t]{2}{*}{ UAE } & 1.624 & 0.027 & 0.788 & 0.002 & 0.129 & 2.501 & 0.935 & 0.079 \\
\hline & (3.514) & $(0.049)$ & $(0.000)$ & $(0.041)$ & $(0.034)$ & (5.335) & (0.007) & $(0.011$ \\
\hline
\end{tabular}


Table A.3 Parameter Estimates for Model 4

$R^{\mathrm{K}}=\theta^{\mathrm{K}}+a^{\mathrm{K}} R_{\mathrm{t}-1}^{\mathrm{K}}+u_{\mathrm{t}}^{\mathrm{K}}, u_{\mathrm{t}}^{\mathrm{K}} \sim N\left(0, H_{\mathrm{t}}^{\mathrm{K}}\right), H_{\mathrm{t}}^{\mathrm{K}}=b_{0}+b_{1} H_{\mathrm{t}-1}^{\mathrm{K}}+b_{2} u_{\mathrm{t}-1}^{2 \mathrm{~K}}$

Standard errors are reported in parentheses below the parameter estimates.

\begin{tabular}{|c|c|c|c|c|c|}
\hline Country & $\theta^{\mathrm{k}}$ & $a^{\mathrm{K}}$ & $b_{0}$ & $b_{1}$ & $b_{2}$ \\
\hline \multirow[t]{2}{*}{ Argentina } & 18.43 & -0.004 & 0.616 & 0.944 & 0.061 \\
\hline & (16.224) & (0.032) & $(0.000)$ & (0.007) & (0.009) \\
\hline \multirow[t]{2}{*}{ Bahrain } & 8.602 & 0.102 & 0.007 & 0.972 & 0.033 \\
\hline & (8.798) & (0.034) & $(0.000)$ & $(0.003)$ & (0.004) \\
\hline \multirow[t]{2}{*}{ Bulgaria } & 21.468 & -0.081 & 2.852 & 0.915 & 0.099 \\
\hline & (11.112) & (0.034) & $(0.000)$ & $(0.017)$ & $(0.023)$ \\
\hline \multirow[t]{2}{*}{ Croatia } & 31.151 & 0.128 & 2.324 & 0.945 & 0.945 \\
\hline & (11.088) & $(0.032)$ & $(0.000)$ & $(0.009)$ & $(0.012)$ \\
\hline \multirow[t]{2}{*}{ Estonia } & -6.304 & 0.115 & 0.335 & 0.898 & 0.121 \\
\hline & (11.593) & $(0.033)$ & (1.264) & $(0.011)$ & $(0.017)$ \\
\hline \multirow[t]{2}{*}{ Jordan } & 0.161 & 0.045 & 0.966 & 0.944 & 0.061 \\
\hline & $(0.000)$ & (0.033) & $(0.000)$ & (0.008) & $(0.011)$ \\
\hline \multirow[t]{2}{*}{ Kazakhstan } & 39.083 & -0.018 & 0.005 & 0.933 & 0.074 \\
\hline & (16.794) & (0.033) & $(0.000)$ & (0.009) & $(0.012)$ \\
\hline \multirow[t]{2}{*}{ Kenya } & 4.457 & 0.315 & 0.009 & 0.914 & 0.101 \\
\hline & $(6.565)$ & $(0.032)$ & $(0.126)$ & (0.007) & (0.011) \\
\hline \multirow[t]{2}{*}{ Kuwait } & 10.897 & 0.077 & 0.416 & 0.948 & 0.06 \\
\hline & (10.401) & (0.034) & (1.442) & $(0.006)$ & (0.008) \\
\hline \multirow[t]{2}{*}{ Lebanon } & -0.328 & 0.148 & 1.229 & 0.894 & 0.149 \\
\hline & (1.692) & $(0.035)$ & $(0.000)$ & $(0.008)$ & (0.016) \\
\hline \multirow[t]{2}{*}{ Mauritius } & 28.788 & 0.162 & 0.000 & 0.944 & 0.069 \\
\hline & (12.472) & $(0.033)$ & $(0.000)$ & $(0.005)$ & (0.008) \\
\hline \multirow[t]{2}{*}{ Nigeria } & 12.722 & 0.432 & 1.449 & 0.886 & 0.135 \\
\hline & (8.256) & $(0.031)$ & (4.651) & $(0.015)$ & $(0.022)$ \\
\hline \multirow[t]{2}{*}{ Oman } & 21.477 & -0.081 & 0.581 & 0.915 & 0.099 \\
\hline & (11.432) & (0.034) & $(0.000)$ & $(0.017)$ & $(0.023)$ \\
\hline \multirow[t]{2}{*}{ Pakistan } & 0.725 & 0.111 & 0.001 & 0.949 & 0.055 \\
\hline & (1.664) & $(0.031)$ & $(0.006)$ & $(0.004)$ & $(0.005)$ \\
\hline \multirow[t]{2}{*}{ Qatar } & 0.225 & 0.079 & 0.148 & 0.962 & 0.043 \\
\hline & (0.000) & (0.034) & (1.174) & (0.006) & (0.008) \\
\hline \multirow[t]{2}{*}{ Romania } & 18.168 & 0.035 & 0.000 & 0.976 & 0.024 \\
\hline & (18.807) & $(0.032)$ & $(0.000)$ & $(0.003)$ & $(0.003)$ \\
\hline \multirow[t]{2}{*}{ S.Arabia } & 3.685 & 0.037 & 1.623 & 0.943 & 0.066 \\
\hline & $(29.195)$ & (0.034) & (6.081) & $(0.005)$ & (0.008) \\
\hline \multirow[t]{2}{*}{ Slovenia } & 24.909 & 0.174 & 0.491 & 0.926 & 0.085 \\
\hline & (9.664) & $(0.032)$ & $(2.264)$ & (0.009) & $(0.013)$ \\
\hline \multirow{2}{*}{ Sri Lanka } & -5.257 & 0.23 & 0.000 & 0.92 & 0.102 \\
\hline & (7.427) & (0.034) & $(0.000)$ & $(0.01)$ & (0.016) \\
\hline \multirow[t]{2}{*}{ Tunisia } & 15.446 & 0.089 & 0.338 & 0.898 & 0.124 \\
\hline & (7.107) & (0.034) & $(1.751)$ & $(0.024)$ & $(0.035)$ \\
\hline \multirow[t]{2}{*}{ UAE } & -0.997 & 0.128 & 0.564 & 0.935 & 0.078 \\
\hline & (1.109) & $(0.034)$ & $(0.000)$ & $(0.007)$ & $(0.011)$ \\
\hline
\end{tabular}


Table A.4 Parameter Estimates for Model 5 $R_{\mathrm{t}}^{\mathrm{K}}=\theta^{\mathrm{K}}+a_{\mathrm{t}}^{\mathrm{US}} R_{\mathrm{t}}^{\mathrm{US}}+u_{\mathrm{t}}^{\mathrm{K}}, u_{\mathrm{t}}^{\mathrm{K}} \sim N\left(0, H_{\mathrm{t}}^{\mathrm{K}}\right), H_{\mathrm{t}}^{\mathrm{K}}=b_{0}+b_{3} H_{\mathrm{t}}^{\mathrm{US}}+b_{4} H_{\mathrm{t}-1}^{\mathrm{US}}$,
$a_{\mathrm{t}}^{\mathrm{US}}=c(1-\rho)+\rho a_{\mathrm{t}-1}^{\mathrm{US}}+n_{\mathrm{t}}^{\mathrm{US}}, n_{t}^{\mathrm{US}} \sim N\left(0, Q^{\mathrm{US}}\right), E\left(u_{\mathrm{t}}^{K} n_{\mathrm{t}}^{\mathrm{US}}\right)=0$

Standard errors are reported in parentheses below the parameter estimates.

\begin{tabular}{|c|c|c|c|c|c|c|c|}
\hline Country & $\theta^{\mathrm{k}}$ & $c$ & $\rho$ & $\sqrt{Q^{\mathrm{US}}}$ & $b_{0}$ & $b_{3}$ & $b_{4}$ \\
\hline \multirow[t]{2}{*}{ Argentina } & 21.819 & 1.059 & 0.379 & 0.432 & 0.546 & 2.252 & 0.000 \\
\hline & (11.94) & $(0.051)$ & $(0.204)$ & $(0.058)$ & $(0.000)$ & $(0.135)$ & $(0.000)$ \\
\hline \multirow[t]{2}{*}{ Bahrain } & -8.409 & 0.001 & -0.554 & 0.282 & 0.561 & 0.195 & 1.109 \\
\hline & (7.355) & $(0.036)$ & $(0.307)$ & $(0.081)$ & $(0.000)$ & $(0.127)$ & $(0.137)$ \\
\hline \multirow[t]{2}{*}{ Bulgaria } & 30.37 & 0.14 & 0.979 & 0.053 & 0.528 & 2.191 & 0.000 \\
\hline & $(0.081)$ & $(0.081)$ & $(0.018)$ & $(0.031)$ & $(0.000)$ & $(0.101)$ & $(0.000)$ \\
\hline \multirow[t]{2}{*}{ Croatia } & 28.498 & 0.134 & 0.013 & 0.744 & 0.568 & 1.408 & 0.000 \\
\hline & (9.983) & $(0.041)$ & $(0.12)$ & $(0.051)$ & $(0.000)$ & $(0.086)$ & $(0.000)$ \\
\hline \multirow[t]{2}{*}{ Estonia } & 10.399 & 0.149 & 0.143 & 0.668 & 0.538 & 1.732 & 0.000 \\
\hline & (10.407) & $(0.046)$ & $(0.124)$ & $(0.048)$ & (1.606) & $(0.101)$ & $(0.000)$ \\
\hline \multirow[t]{2}{*}{ Jordan } & -14.362 & -0.016 & -0.291 & 0.319 & 0.567 & 0.563 & 1.147 \\
\hline & (9.971) & $(0.041)$ & $(0.333)$ & $(0.043)$ & (1.204) & $(0.404)$ & $(0.407)$ \\
\hline \multirow[t]{2}{*}{ Kazakhstan } & 0.107 & 0.249 & -0.057 & 0.648 & 0.5 & 0.381 & 6.132 \\
\hline & (7.556) & $(0.087)$ & $(0.229)$ & $(0.051)$ & (2.816) & (1.355) & (1.37) \\
\hline \multirow{2}{*}{ Kenya } & 17.223 & -0.004 & 0.013 & 0.633 & 0.589 & 0.997 & 0.224 \\
\hline & (8.353) & $(0.038)$ & $(0.205)$ & $(0.047)$ & $(0.000)$ & $(0.000)$ & $(0.066)$ \\
\hline \multirow[t]{2}{*}{ Kuwait } & -0.053 & -0.009 & 0.227 & 0.241 & 0.503 & 0.972 & 0.983 \\
\hline & $(0.529)$ & $(0.044)$ & $(0.311)$ & $(0.043)$ & $(0.000)$ & $(0.000)$ & $(0.000)$ \\
\hline \multirow[t]{2}{*}{ Lebanon } & -10.213 & -0.007 & -0.033 & 0.995 & 0.581 & 0.026 & 1.865 \\
\hline & (11.621) & $(0.048)$ & (0.133) & $(0.081)$ & (1.51) & (0.069) & $(0.147)$ \\
\hline \multirow[t]{2}{*}{ Mauritius } & -10.213 & -0.007 & -0.033 & 0.995 & 0.581 & 0.026 & 1.865 \\
\hline & (11.621) & $(0.048)$ & $(0.133)$ & $(0.081)$ & (1.51) & (0.069) & $(0.147)$ \\
\hline \multirow[t]{2}{*}{ Nigeria } & 9.852 & -0.012 & 0.308 & 0.662 & 0.607 & 0.000 & 1.147 \\
\hline & (8.112) & $(0.042)$ & $(0.175)$ & (0.049) & $(0.000)$ & $(0.000)$ & $(0.066)$ \\
\hline \multirow[t]{2}{*}{ Oman } & 0.214 & -0.011 & -0.304 & 0.247 & 0.501 & 0.058 & 1.262 \\
\hline & (2.557) & $(0.036)$ & $(0.574)$ & $(0.068)$ & (2.063) & $(0.065)$ & $(0.088)$ \\
\hline \multirow[t]{2}{*}{ Pakistan } & 21.018 & 0.098 & -0.208 & 0.643 & 0.598 & 2.124 & 0.001 \\
\hline & (11.81) & $(0.052)$ & $(0.185)$ & $(0.046)$ & $(0.000)$ & $(0.123)$ & $(0.000)$ \\
\hline \multirow[t]{2}{*}{ Qatar } & -16.963 & -0.044 & 0.163 & 0.354 & 0.56 & 2.557 & 0.000 \\
\hline & (12.343) & $(0.051)$ & $(0.431)$ & $(0.047)$ & (0.409) & $(0.121)$ & $(0.000)$ \\
\hline \multirow[t]{2}{*}{ Romania } & 25.161 & 0.289 & 0.621 & 0.323 & 0.535 & 3.33 & 0.513 \\
\hline & (15.104) & $(0.063)$ & $(0.153)$ & $(0.067)$ & (1.168) & $(0.866)$ & $(0.831)$ \\
\hline \multirow[t]{2}{*}{ S.Arabia } & -37.559 & 0.027 & 0.114 & 0.361 & 0.601 & 4.835 & 0.000 \\
\hline & (16.571) & $(0.069)$ & $(0.53)$ & $(0.042)$ & (3.89) & $(0.219)$ & $(0.000)$ \\
\hline \multirow[t]{2}{*}{ Slovenia } & 41.454 & 0.079 & -0.039 & 0.57 & 0.578 & 1.306 & 0.000 \\
\hline & (8.691) & $(0.038)$ & (0.169) & $0.065)$ & 5.288) & (0.085) & $(0.000)$ \\
\hline \multirow[t]{2}{*}{ Sri Lanka } & 0.256 & 0.034 & 0.135 & 0.691 & 0.501 & 0.226 & 0.848 \\
\hline & (1.865) & $(0.035)$ & $(0.13)$ & (0.063) & $(0.000)$ & $(0.361)$ & $(0.343)$ \\
\hline \multirow[t]{2}{*}{ Tunisia } & 27.861 & 0.022 & -0.142 & 0.578 & 0.66 & 0.344 & 0.505 \\
\hline & (7.172) & $(0.031)$ & $(0.162)$ & $(0.051)$ & (0.000) & $(0.311)$ & $(0.307)$ \\
\hline \multirow[t]{2}{*}{ UAE } & -19.252 & 0.016 & -0.057 & 0.271 & 0.553 & 4.343 & 0.000 \\
\hline & (15.134) & $(0.065)$ & $(0.495)$ & $(0.041)$ & $(0.000)$ & (0.198) & $(0.000)$ \\
\hline
\end{tabular}


Figure 2.1.

Estimated Returns from Model 1

Panel 0: USA

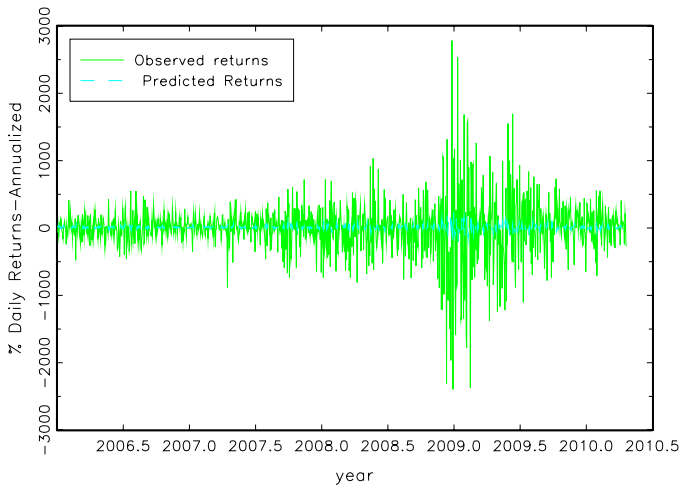

Panel 2: Bahrain

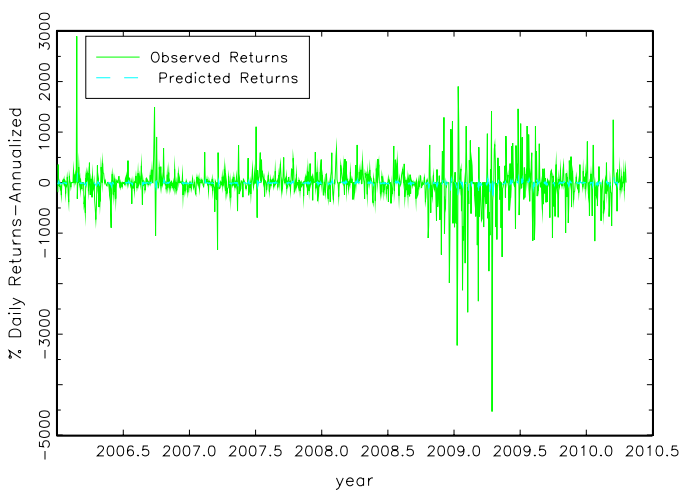

Panel 4: Croatia

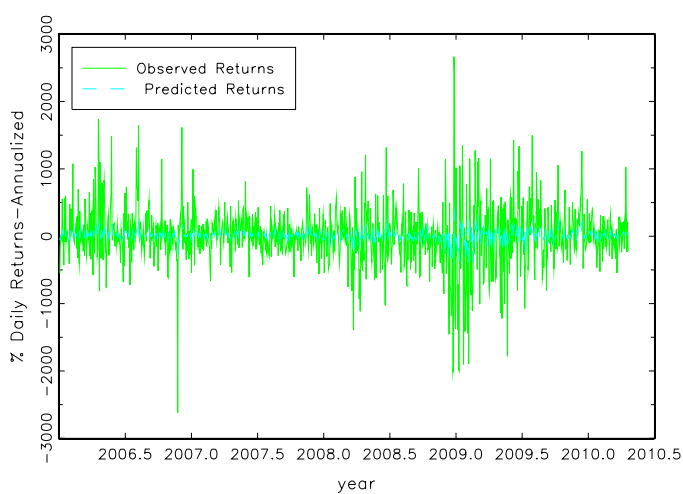

Panel 1: Argentina

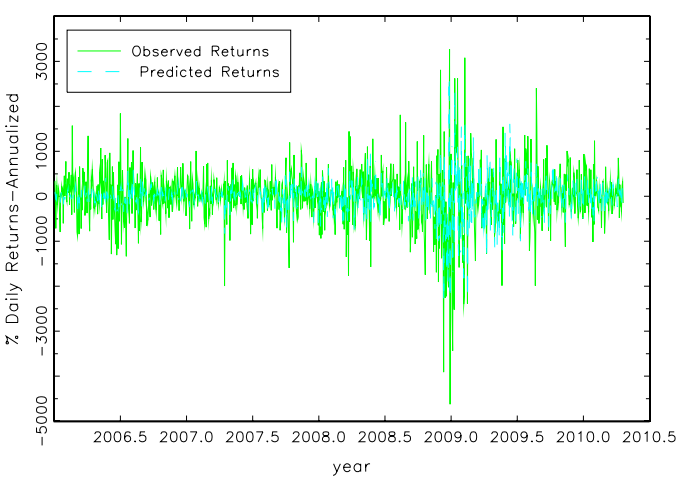

Panel 3: Bulgaria

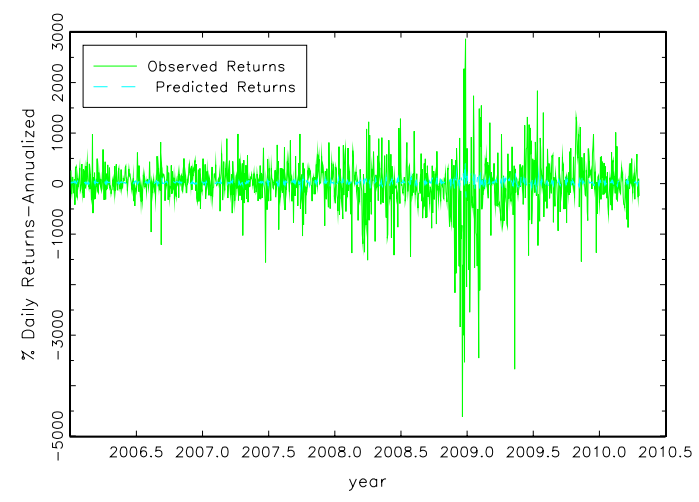

Panel 5: Estonio

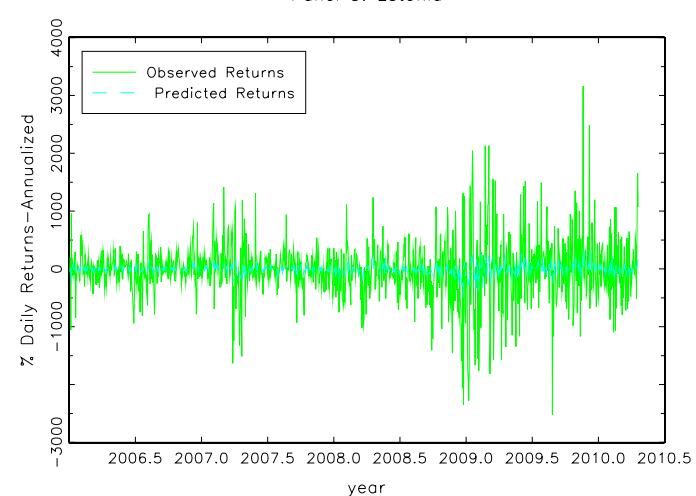


Figure 2.2.

Plots of Time-Variable Volatility

Estimates of volatility for Frontier markets are derived from Model 1 and from best-fitting Model 2 for the US.
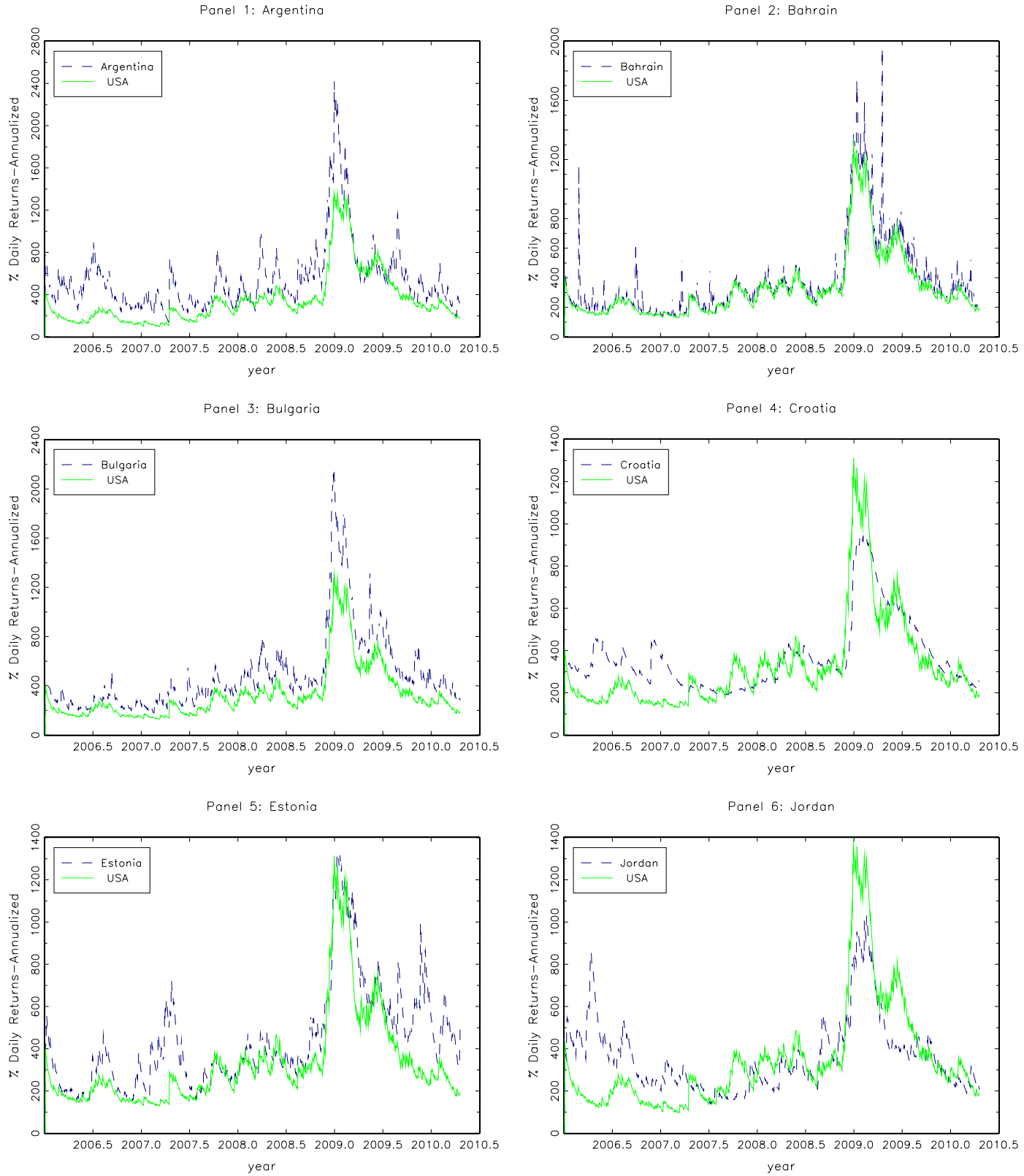
Figure 2.3.

Time-Variable Return Spillover Parameter Estimated by Model 1 for Frontier Countries
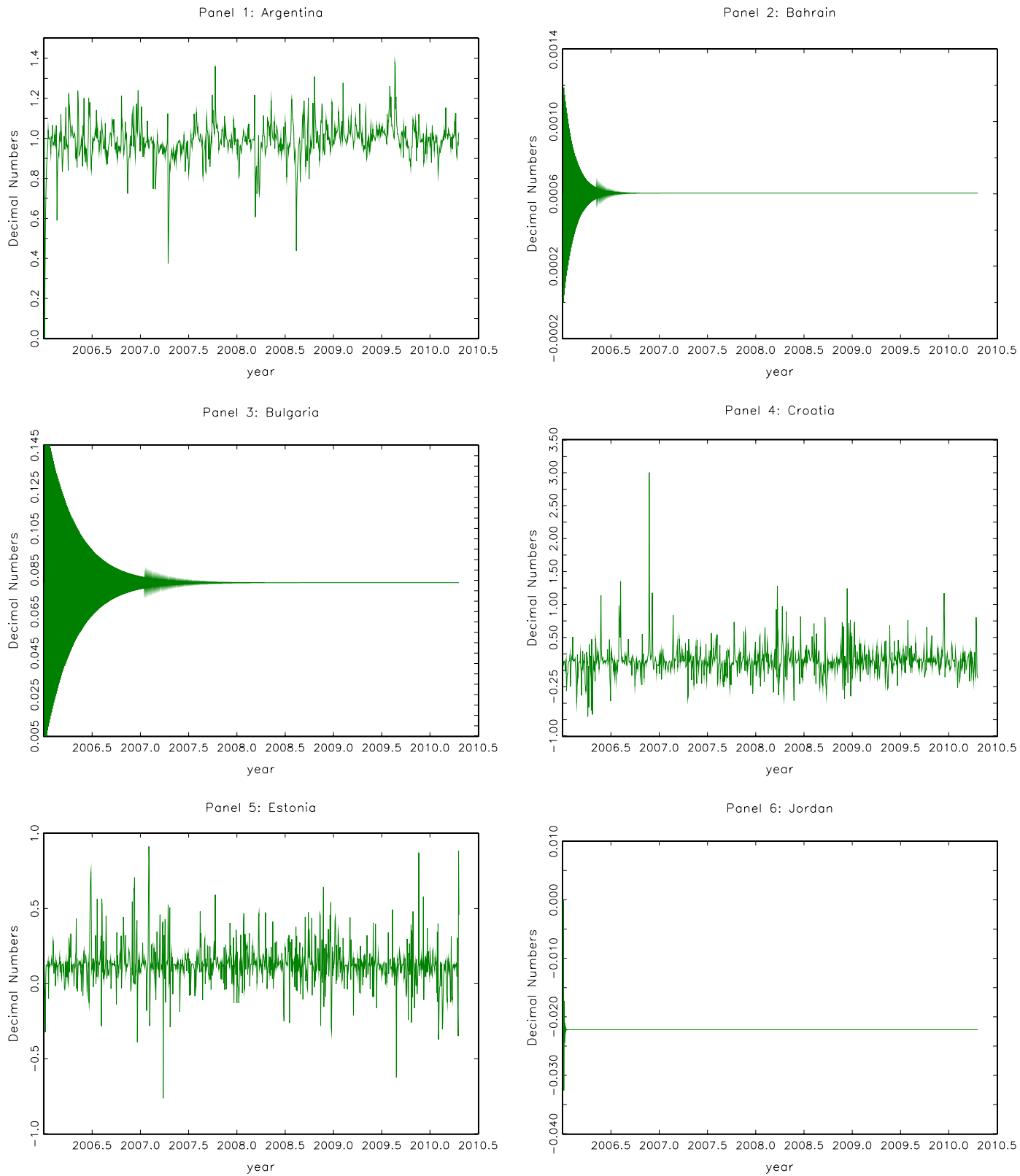
Figure 2.4.

US and Own-Country Lagged Components of Returns Estimated by Model 1
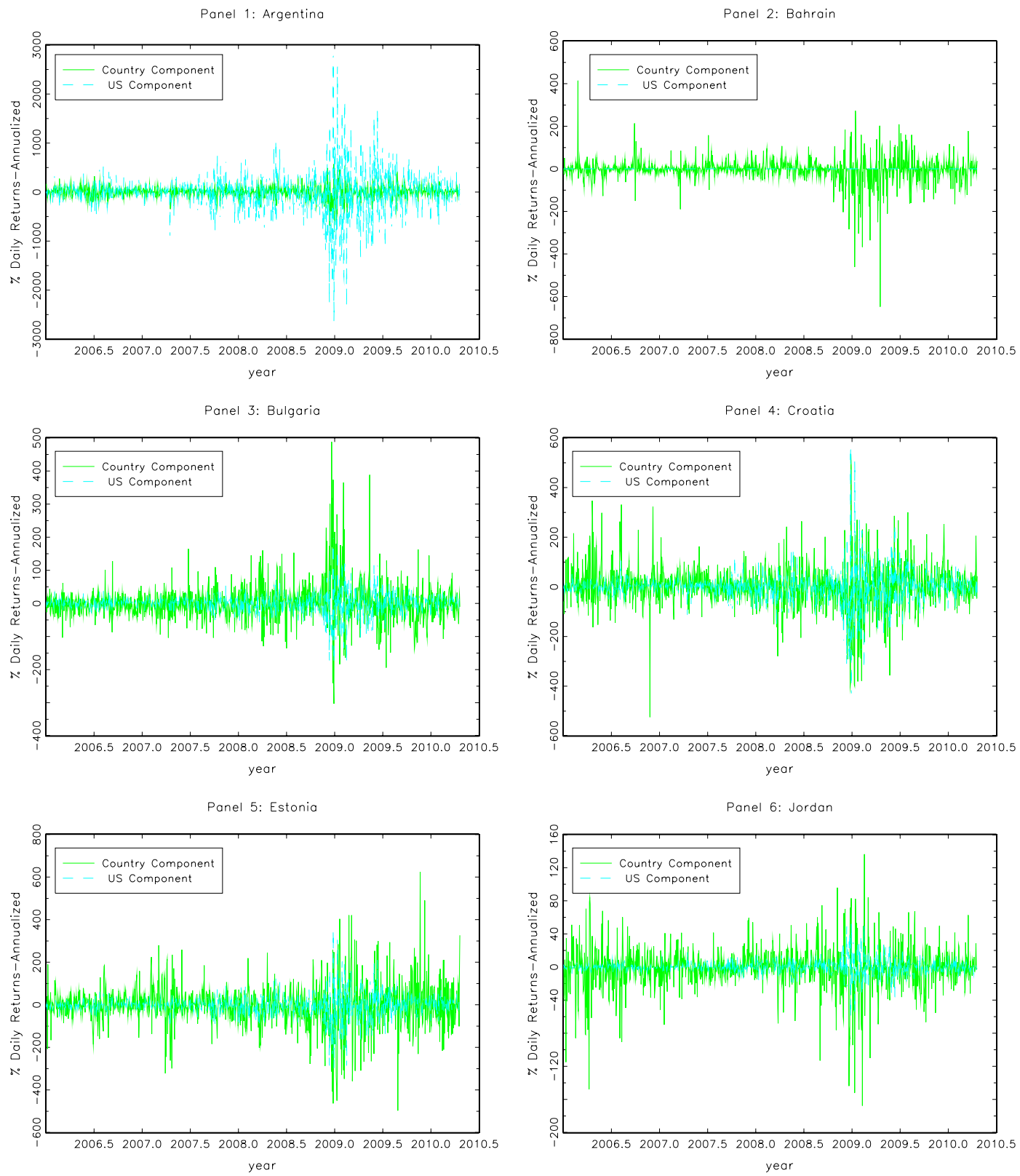
Figure 2.5

Conditional Volatility Components from Model 1
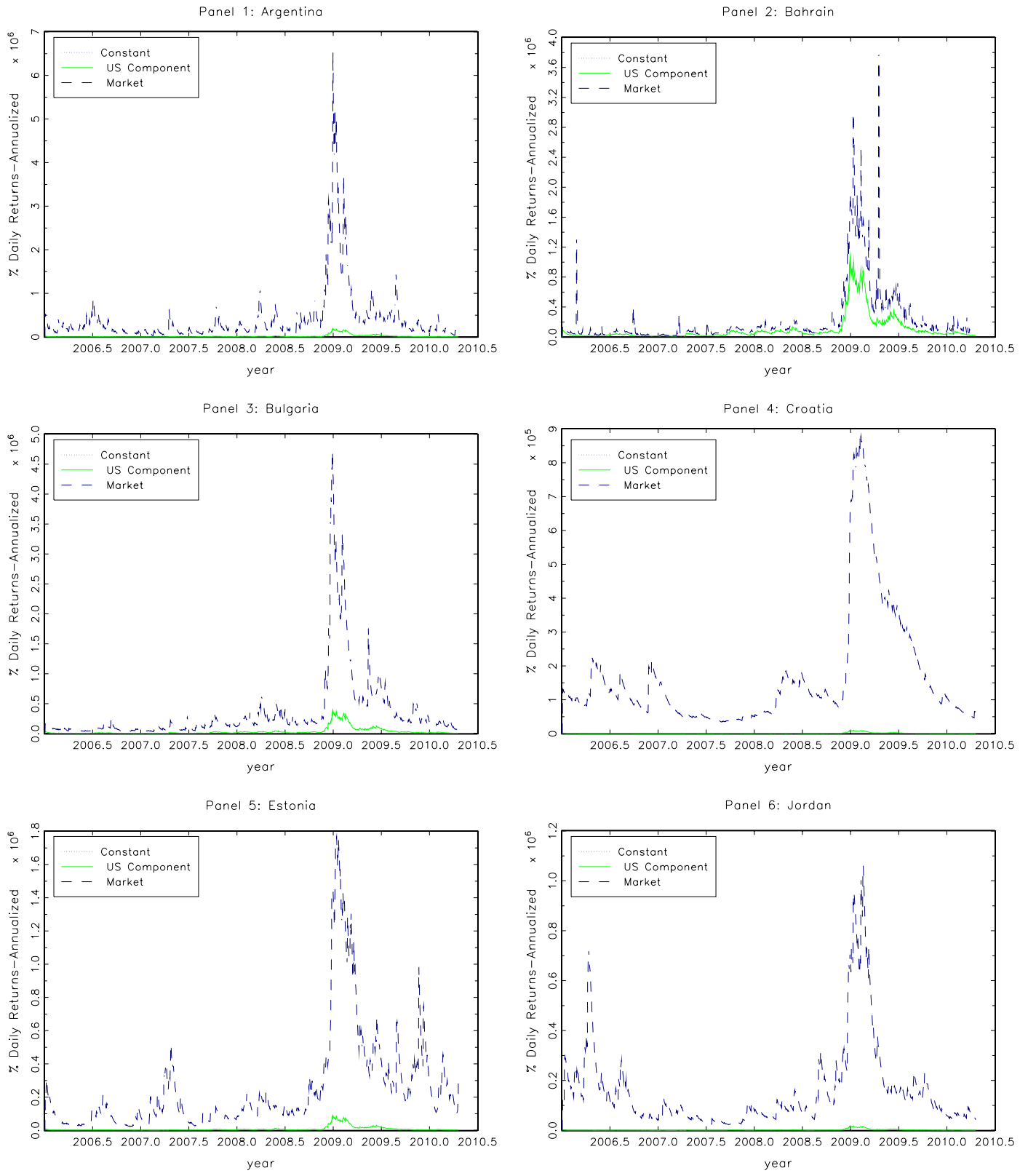
Figure B.1.

US Components of Frontier Country Returns Estimated by Model 1 and Model 2
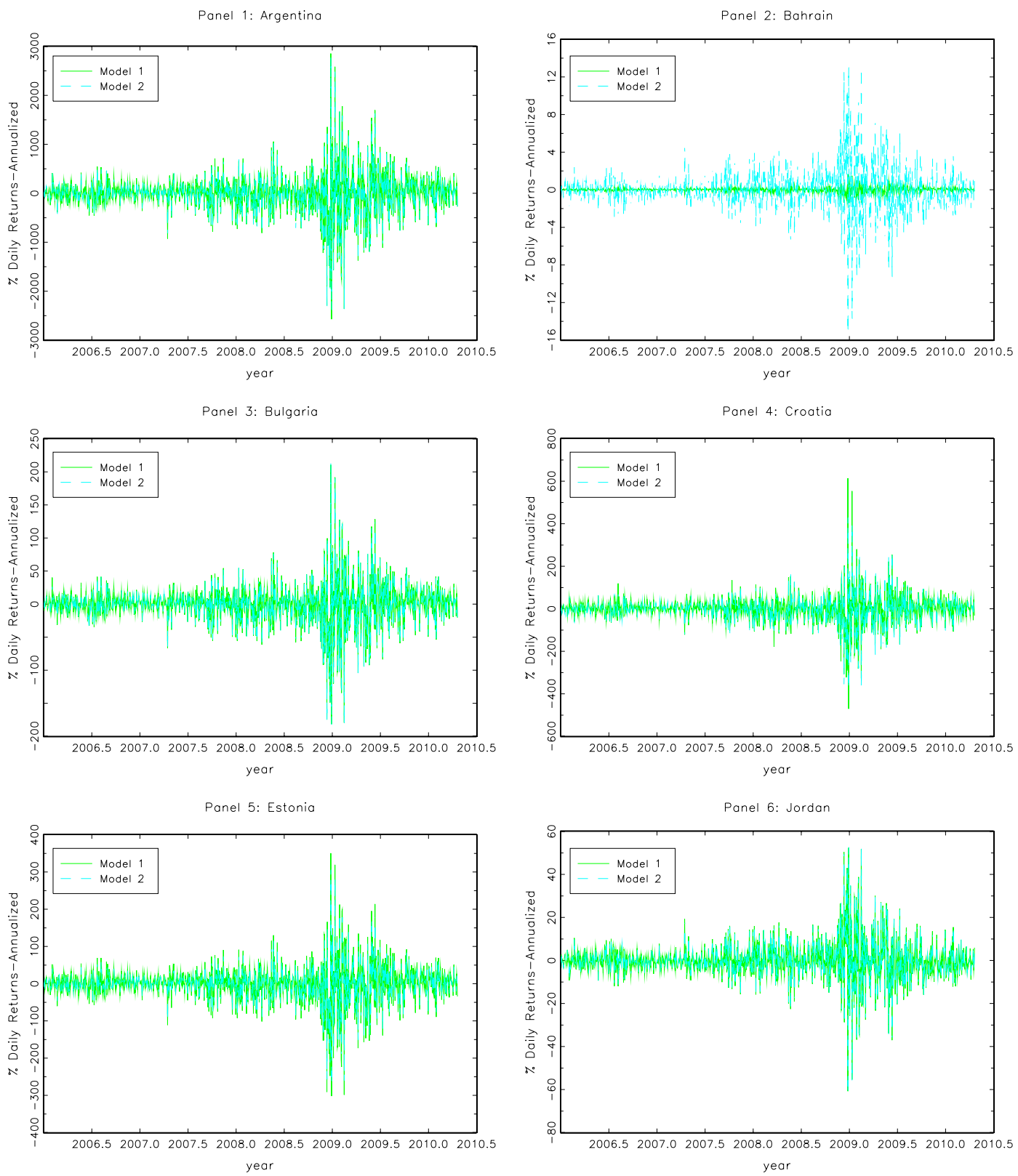
Figure B.2.

US Components of Frontier Country Conditional Volatility Estimated by Model 1 and Model 2
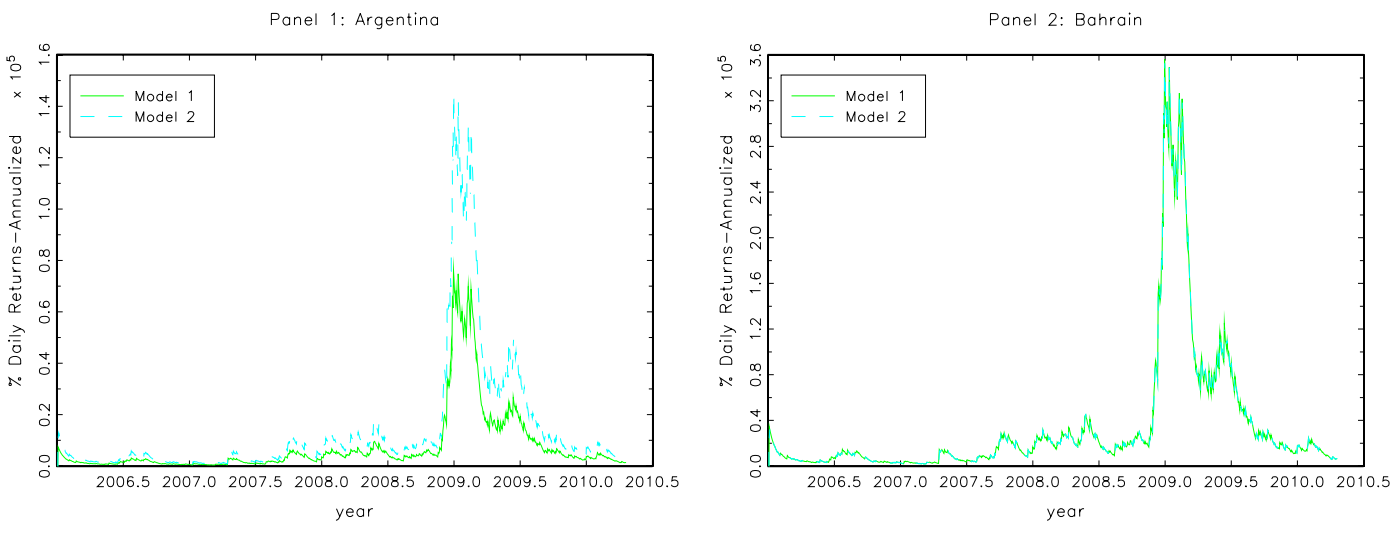

Panel 3: Bulgaria

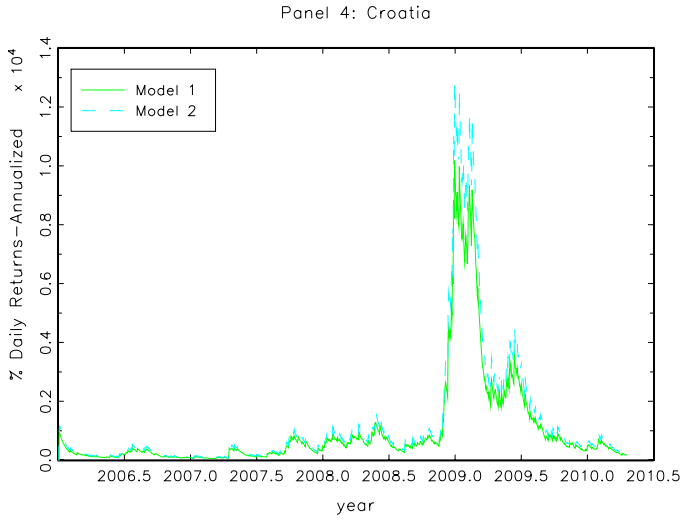

Ponel 5: Estonia
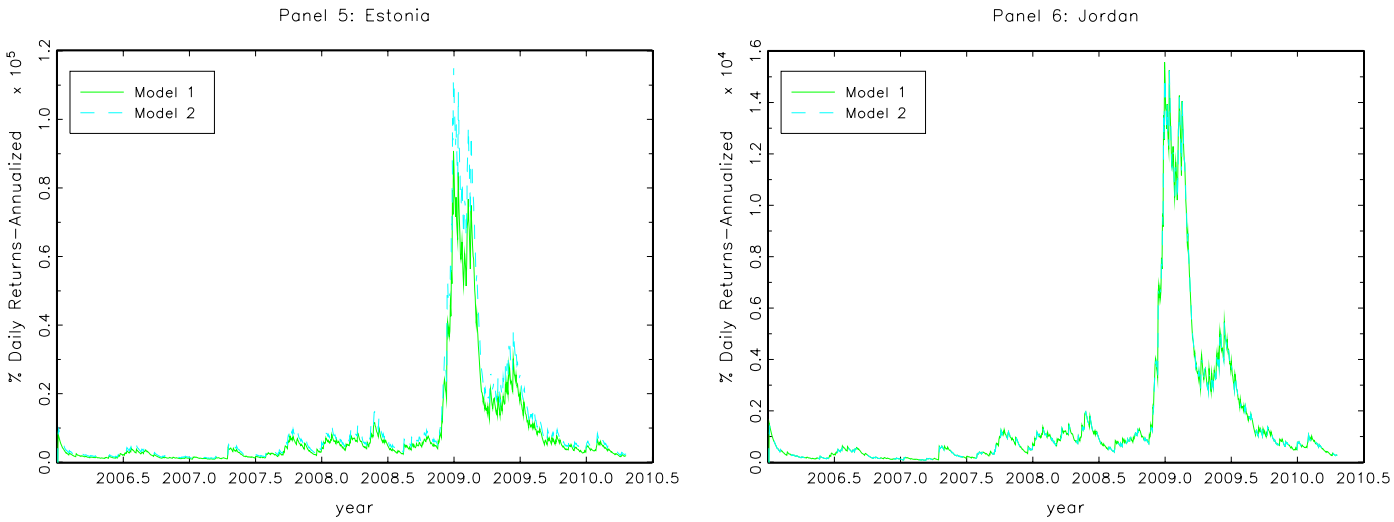
Figure B.3

US Components of Frontier Country Returns Estimated by Model 1 and Model 3
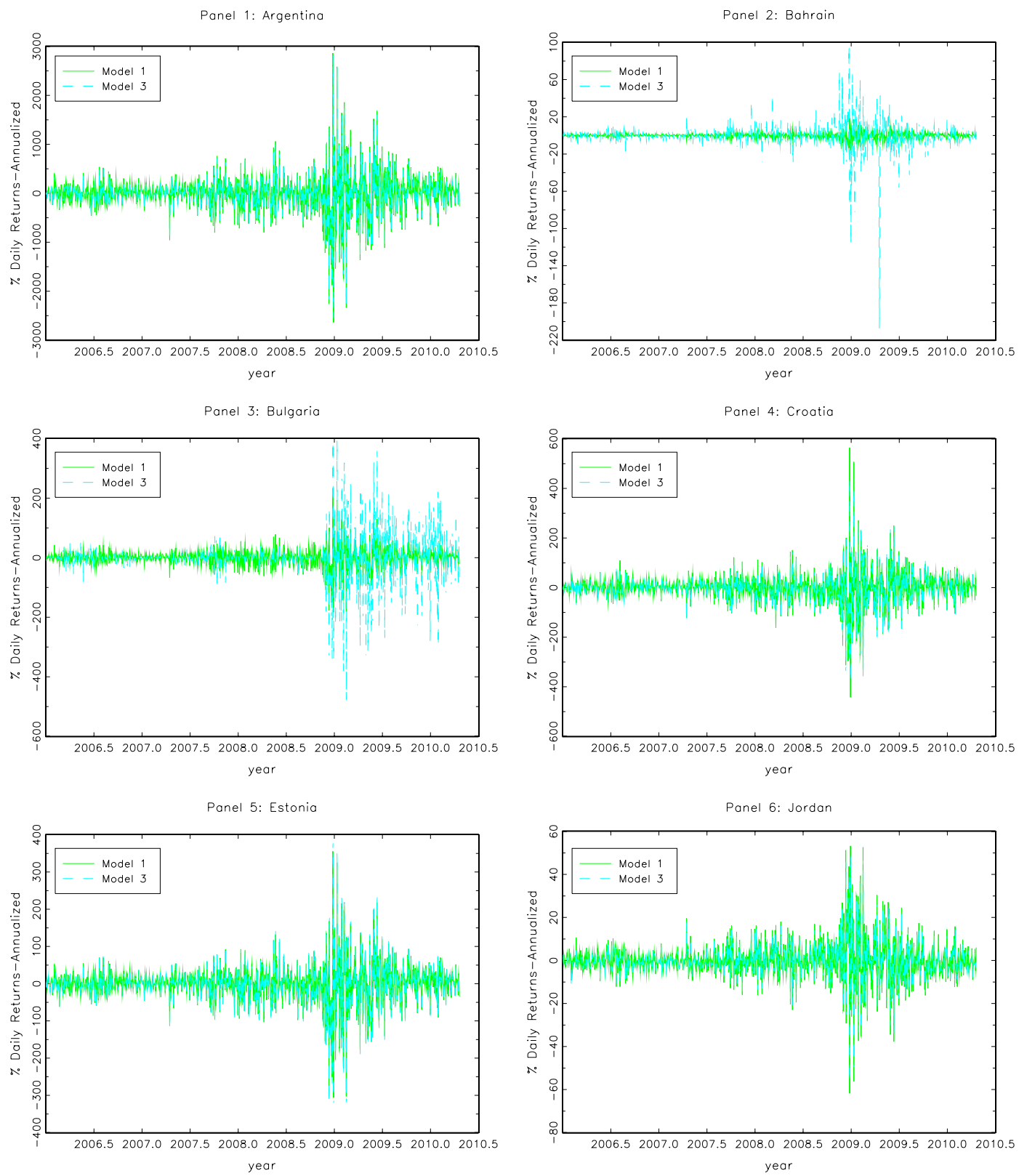
Figure B.4.

US Components of Frontier Country Conditional Volatility Estimated by Model 1 and Model 3
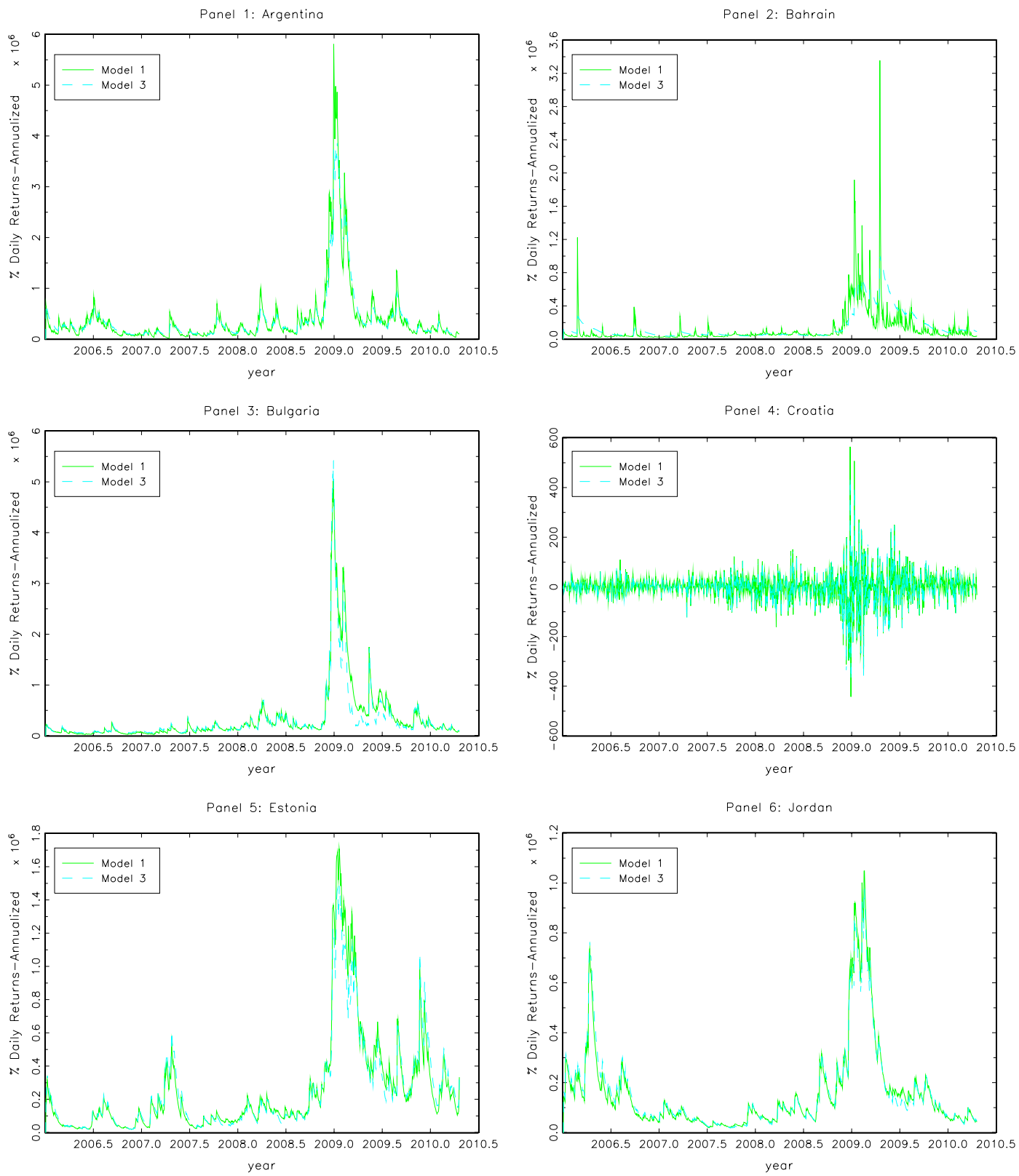
Figure B.5.

Own-Country Lagged Components of Frontier Country Returns Estimated by Model 1 and Model 4
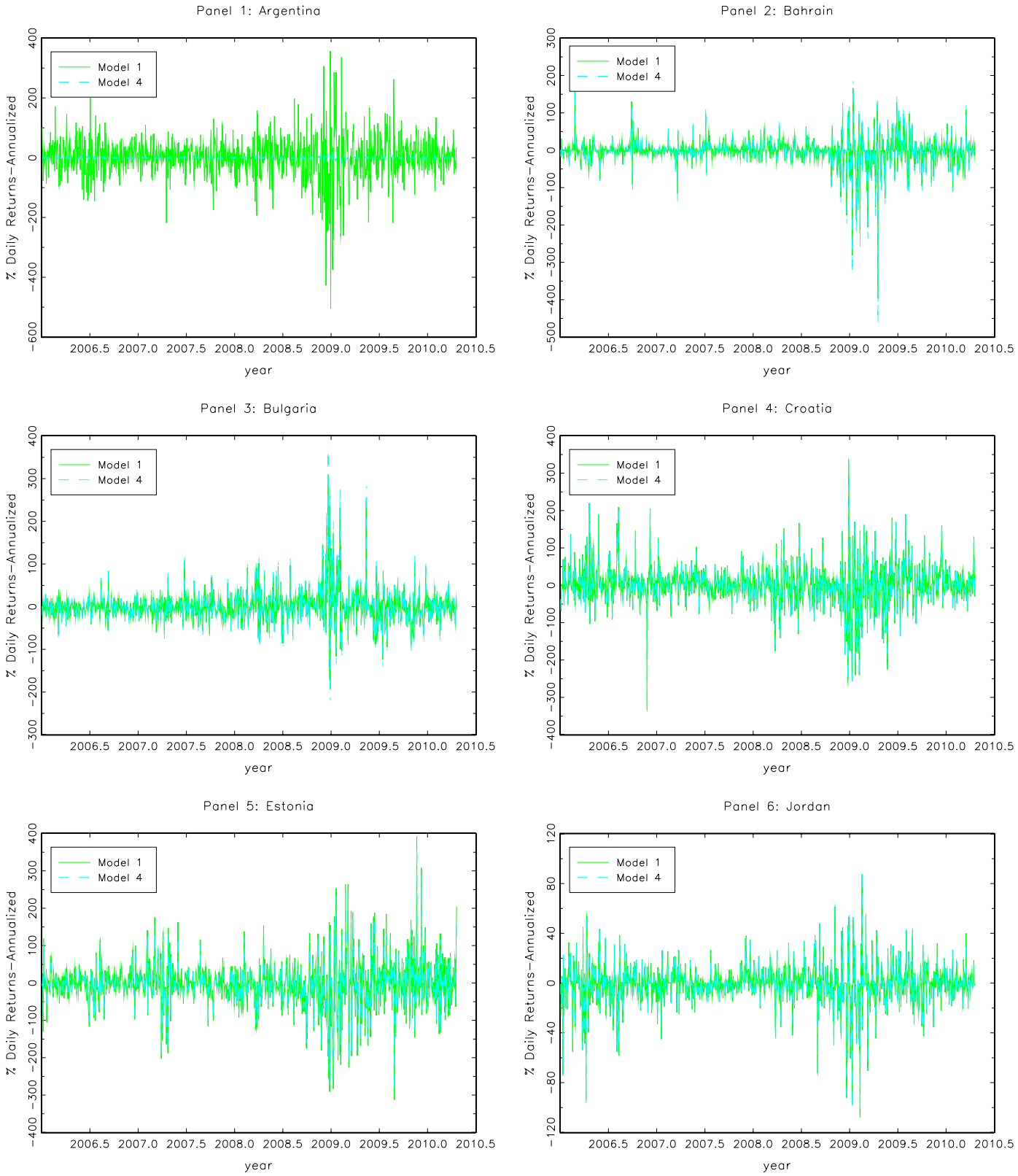
Figure B.6.

Own-Country Components of Frontier Country Conditional Volatility Estimated by Model 1 and Model 4
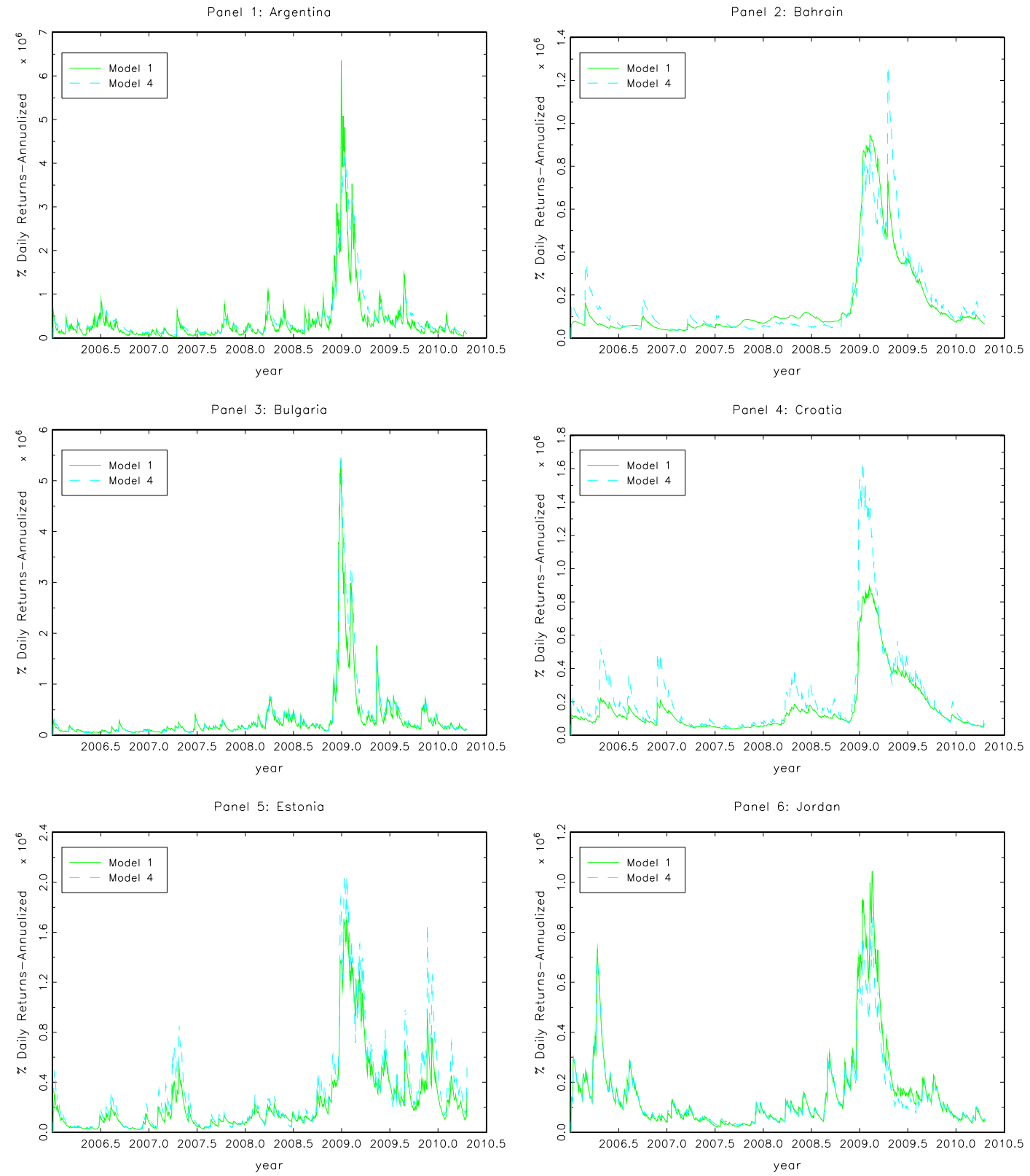
Figure B.7.

US Components of Frontier Country Returns Estimated by Model 1 and Model 5
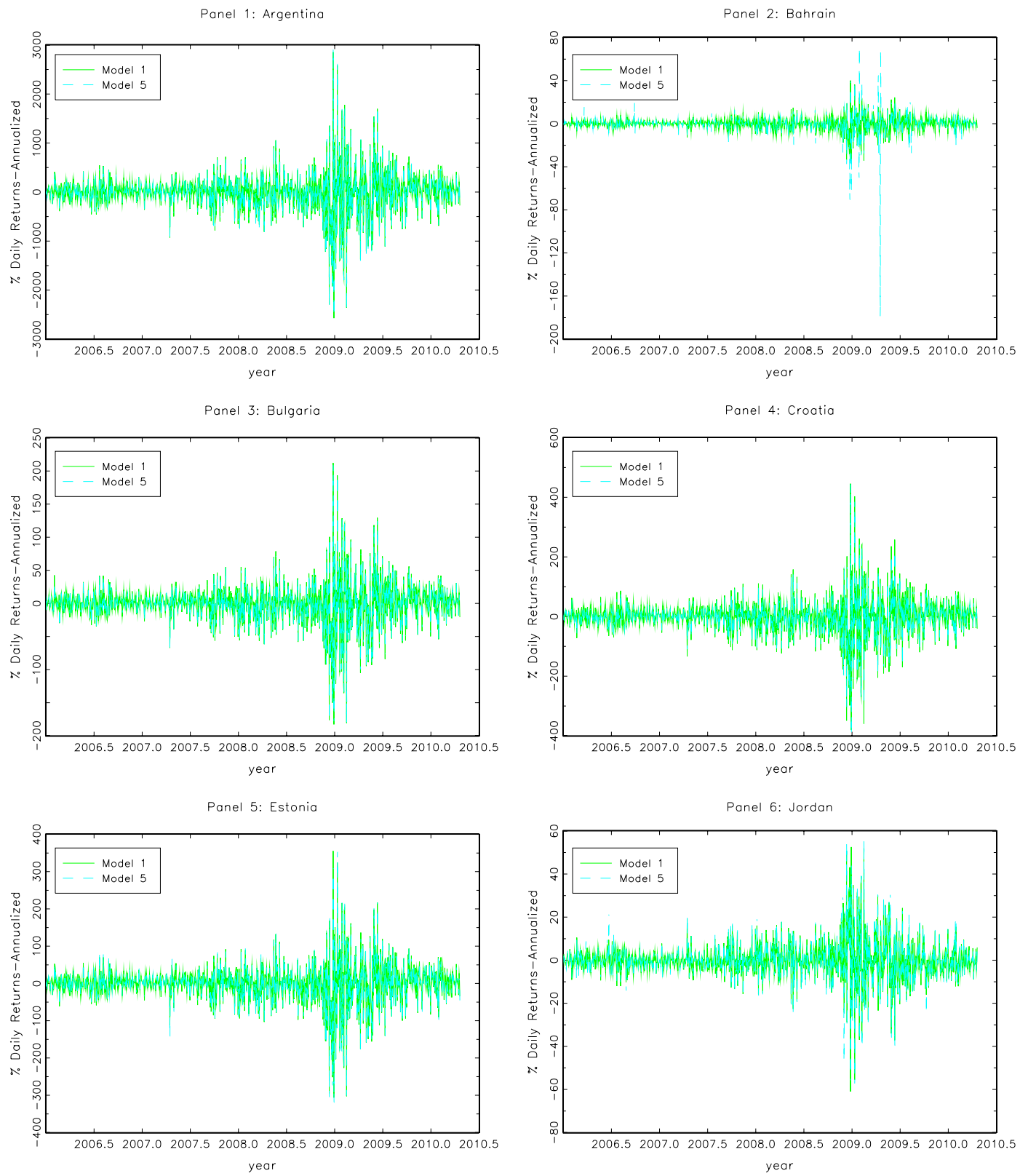
Figure B.8.

US Components of Frontier Country Conditional Volatility Estimated by Model 1 and Model 5
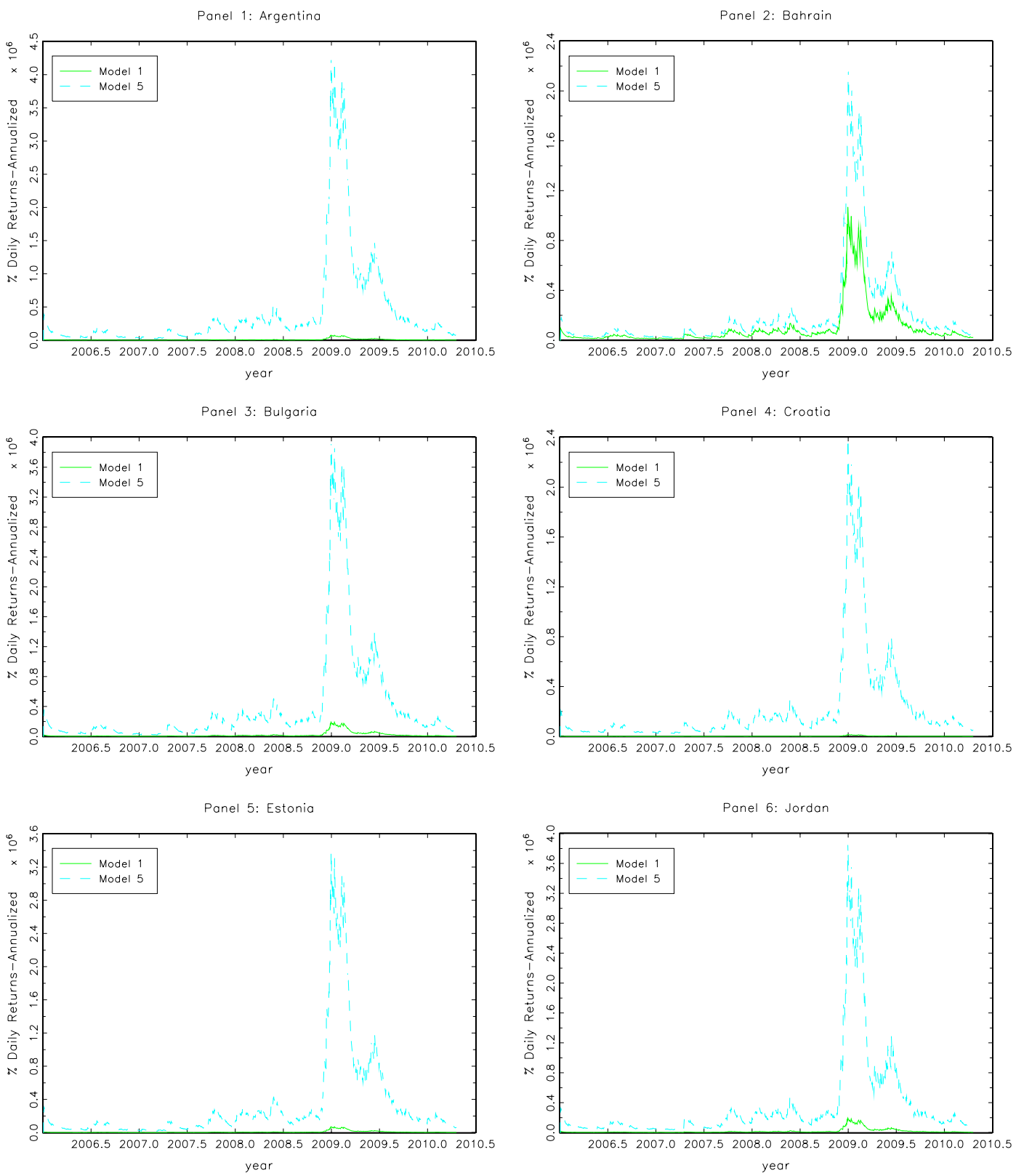


\section{III.TIME-VARYING RISK AND RISK PREMIUMS IN FRONTIER MARKETS}

\section{III.I. Introduction}

Cross-country correlations between financial market returns depend on financial openness of countries, as well as on the nature of cross-country economic and financial linkages. The more financially open a stock market is, the more synchronized its returns are expected to be with foreign markets; thus the greater the scope for high correlations. Low correlations among national stock markets, however, are key for international portfolio diversification. Hedging strategies depend on shocks to stock markets being relatively isolated. However, if stock markets are highly correlated, diversification benefits may be undermined. International asset allocation decisions and risk assessment are largely based on cross-country correlations as well.

Asset pricing studies frequently assume constant correlations between returns on different markets. Such an assumption is primarily motivated by convenience. However, in a dynamically changing economic environment, this assumption may not be realistic. For example, markets under study may be undergoing structural changes during the period of interest, or they may be experiencing macroeconomic reforms. Assuming constancy of correlations could be particularly inappropriate when Frontier markets are in consideration.

In this article, we study the risk-return relationship in twenty Frontier markets by setting up an international version of the intertemporal capital asset pricing model (International ICAPM) of Merton (1973). The systematic risk in this model comes from covariance of Frontier market returns with world returns (see Solnik 1974 and Stulz 1982). Our model allows for this covariance risk to be timevarying. Time-varying correlations are captured by utilizing the Dynamic Conditional Correlations (DCC) model of Engle (2002). The risk premium per unit of covariance risk (or, the price of covariance risk) is allowed to vary over time as well. Thus, both the risk and risk premium on Frontier country market returns are time-varying in our model.

Our model of Frontier market returns can be considered a time-varying parameter (TVP) model. Thus, it can be cast into a state space form. However, it is not time-invariant as the "coefficient" multiplying the state variable (the TVP parameter) is current period conditional covariance between Frontier market returns and world returns. Nonetheless, the TVP model can be estimated via the Kalman Filter. 
Our study is motivated by a desire to explore potential diversification benefits to US investors from investing in these Frontier markets. Therefore, we use returns on US stock markets to proxy for world market returns (see Karolyi and Stulz, 2002).

The rest of the paper is organized as follows. Section III.II briefly reviews relevant literature on time-varying conditional correlations and their application in the international finance literature. We review some specific applications of the DCC model. We also briefly review the related international ICAPM literature. In section III.III we present data and some of its descriptive statistics. In section III.IV we outline the DCC and International ICAPM models. In section III.V we present results on estimation of dynamic conditional correlations and the International ICAPM model. Section 6 offers concluding remarks and prospects for future research.

\section{III.II. Literature Review}

A detailed description of Dynamic Conditional Correlations (DCCs), introduced by Engle (2002), is given in Section III.IV. Here, in this section, we review its recent applications in the international finance literature. We also briefly review the extensive literature on international intertemporal capital asset pricing model (International ICAPM).

Dynamic Conditional Correlations have been used, in conjunction with some version of the domestic ICAPM model, to investigate risk-return relationships in the US equity market. For instance, Bali and Engle (2010) study risk-return relations on individual stocks in the Dow Jones Industrial Average (DJIA) index using time-varying covariances, modeled through DCCs, with the market returns. They find that risk premia induced by time-varying conditional covariation of individual stock returns with the market portfolio returns remain positive and significant, even after controlling for risk premia induced by conditional covariation with macroeconomic, financial, and volatility factors.

An international version of Merton's (1973) intertemporal capital asset pricing model (International ICAPM) was originally developed by Solnik (1974) and Stulz (1982), and applied extensively in the international finance literature by Harvey (1991) and others. Bali and Wu (2010) apply International ICAPM model to analyze international stock market returns and find that the risk premiums are positive and highly dependent on currency denominations. In a recent paper, You and Daigler (2010) utilize DCCs to explore scope for international portfolio diversification using emerging stock markets. They find little or no benefits for US investors from diversification beyond the S\&P 500 stock index portfolio. On the other hand, Berger, Pukthuanthong and Yang (2011) report that frontier markets have low inte- 
gration with the world market, thereby offering potentially significant diversification benefits. Cheng, Jahan-Parvar and Rothman (2010) use a Markov switching version of an International ICAPM to investigate Middle Eastern and North African (MENA region) countries and find presence of significant portfolio diversification opportunities.

Yiu, Ho and Jin (2010) use DCCs to explore correlations of Asian and Latin American stock markets with the US. They find modest time-varying correlations suggesting little diversification benefits. The correlations moreover increase significantly between 2007 and 2009, further reducing these benefits during the global financial turmoil. Syriopoulos and Roumpis (2009) employ DCCs to investigate time-varying comovement of South Eastern European developing markets with leading mature equity markets. Their study reports modest time-varying correlations, with no trend, indicating potential opportunities for portfolio diversification. Guesmi and Nguyen (2011) utilize DCCs within an International ICAPM model to examine integration of emerging market regions with the world market. They report positive local and world market risk premiums. Local market risk is found more important for emerging markets than world market risk, implying presence of some diversification benefits.

To summarize, the predominant opinion in current literature on international portfolio diversification is that there exist some diversification benefits from investing in developing countries. The literature, however, is inconclusive about the significance of these benefits.

\section{III.III. Data}

Daily MSCI Barra index closing prices are used for US and 20 Frontier stock markets for the period between December 1st, 2005 and June 30th, 2011. Daily percentage annualized returns for each country are calculated as follows:

$$
R_{\mathrm{it}}=252 * \ln \left(P_{\mathrm{it}} / P_{\mathrm{i}(\mathrm{t}-1)}\right) * 100
$$

where $P_{i t}$ is each country's closing price index at time $t$.

We choose daily data since it better accounts for stock market dynamics and provides greater insight into cross-market interactions. The countries included are: Argentina, Bahrain, Bulgaria, Croatia, Estonia, Jordan, Kazakhstan, Kenya, Kuwait, Lebanon, Mauritius, Nigeria, Oman, Pakistan, Qatar, Romania, Slovenia, Sri Lanka, Tunisia, and United Arab Emirates. These are chosen on the basis of MSCI classification as of July 1st, 2011. Lithuania, Serbia, Ukraine, Bangladesh, Vietnam, Trinidad 
and Tobago, Jamaica, Botswana and Ghana are also defined as Frontier markets, but are not included here becuase of the lack of data for a sufficiently long period.

Morgan Stanley Composite Indices are established consistently across countries and thus provide an adequate ground for exploration of cross-market relations. They are value-weighted and calculated with dividends reinvested. In order to avoid double counting, stock prices of companies set up abroad are not included. All indices are in US dollars, which provides additional comparability across markets and implicitly takes care of currency market effects.

Descriptive statistics for US and the Frontier markets are reported in Table 3.1. The first four columns report the first four moments of returns. The last two columns present results from the JarqueBera test for normality and the mean-to-standard deviation (Sharpe ratios) for each country.

The first column of Table 3.1 shows that half the countries in our sample display positive annualized mean returns. These range from $18.631 \%$ for Mauritius to $-26.617 \%$ for UAE ( $0.943 \%$ for the US). The annualized standard deviation of returns range from $727.337 \%$ for Kazakhstan to $284.556 \%$ for Tunisia (373.153\% for the US). The third column shows that half the countries exhibit positive skewness. The null hypothesis for no skewness is rejected at 5\% significance level for Estonia, Kazakhstan, Kenya, and Mauritius. The fourth column provides values of the fourth moment of returns indicating high and statistically significant positive excess kurtosis for all countries. The second to last column reports the Jarque-Bera test statistics. The null hypothesis of normal distribution of index returns is strongly rejected at the 5\% significance level for all countires. Thus, when examining potential benefits of diversification, we need to consider the third and fourth moments as well, as emphasized by You and Daigler (2010).

The last column of Table 3.1 provides the mean-to-standard deviation (Sharpe ratio) for all markets. It is positive for half of the countries. The highest value is 0.005 for Mauritius and the lowest is -0.068 for Bahrain (0.003 for US). Further comparison of individual country mean-to-standard deviation ratios with US shows a relatively high return-standard deviation benefit for Argentina, Croatia, Kazakhstan, Mauritius, Sri Lanka, and Tunisia over the US index. Therefore, for US investors, diversification benefits from investing in these markets may be worthwhile if one assumes a normal distribution for returns. 
In the next section we describe the methodology used to analyze dynamic conditional covariances between US and Frontier country returns, as well as time-variation in the payoff per unit of country risk exposure.

\section{III.IV. Methodology}

\section{Dynamic Conditional Correlations}

Cross-country diversification studies typically employ constant correlations to evaluate diversification benefits. This restrictive approach, however, ignores the possibility of correlations being timevarying. In the present study we utilize time-varying conditional correlations in order to evaluate international diversification potential between Frontier countries and the US stock markets. In particular, we explore the Dynamic Conditional Correlation (DCC) model introduced by Engle (2002).

The time-varying correlation between two zero mean variables $r_{\mathrm{i}}$ and $r_{\mathrm{j}}$ at period $t$ is conditioned on known information at period $t-1$, and is defined as:

$$
\rho_{\mathrm{ij}, \mathrm{t}}=\frac{q_{\mathrm{ij}, \mathrm{t}}}{\sqrt{q_{\mathrm{ii}, \mathrm{t}} q_{\mathrm{jj}, \mathrm{t}}}}=\frac{E_{\mathrm{t}-1}\left[r_{\mathrm{i}, \mathrm{t}} r_{\mathrm{j}, \mathrm{t}}\right]}{\sqrt{E_{\mathrm{t}-1}\left[r_{\mathrm{i}, \mathrm{t}}^{2}\right] E_{\mathrm{t}-1}\left[r_{\mathrm{j}, \mathrm{t}}^{2}\right]}}
$$

For convenience, we can write the variables as the product of the conditional standard deviation and the standardized disturbance:

$$
r_{\mathrm{i}, \mathrm{t}}=\sqrt{h_{\mathrm{i}, \mathrm{t}}} U_{\mathrm{i}, \mathrm{t}}, \quad i=i, j
$$

where $U_{\mathrm{i}, \mathrm{t}}$ is a standardized disturbance with zero mean and variance one for each series and $h_{\mathrm{i}, \mathrm{t}}$ is the conditional variance of $r_{\mathrm{i}, \mathrm{t}}$ estimated from the following univariate $\mathrm{GARCH}(1,1)$ model:

$$
\begin{gathered}
r_{i, \mathrm{t}}=\gamma_{0}+\gamma_{1} r_{\mathrm{i}, \mathrm{t}-1}+\varepsilon_{\mathrm{i}, \mathrm{t}} \\
\varepsilon_{\mathrm{i}, \mathrm{t}}=\sqrt{h_{\mathrm{i}, \mathrm{t}}} z_{\mathrm{t}}
\end{gathered}
$$$$
z_{\mathrm{t}} \sim \operatorname{iidN}(0,1)
$$ 


$$
h_{\mathrm{i}, \mathrm{t}}=b_{0}+b_{1} h_{\mathrm{i}, \mathrm{t}-1}+b_{2} \varepsilon_{\mathrm{t}-1}^{2}
$$

Substituting (2) in (1) allows the conditional correlation to be expressed as:

$$
\rho_{\mathrm{ij}, \mathrm{t}}=E_{\mathrm{t}-1}\left[U_{\mathrm{i}, \mathrm{t}} U_{\mathrm{j}, \mathrm{t}}\right]
$$

It follows, the conditional correlation between two variables is the same as the conditional covariance between the standardized disturbances.

To account for the dynamics of stock return correlations, Engle (2002) builds on Bollerslev's (1990) constant conditional correlation (CCC) model to allow conditional correlations to vary over time. In Engle's (2002) dynamic conditional correlation (DCC) model, the variance-covariance matrix of $i$ assets is given by:

$$
H_{\mathrm{t}}=D_{\mathrm{t}} \Omega_{\mathrm{t}} D_{\mathrm{t}}
$$

where $D_{\mathrm{t}}=\operatorname{diag}\left\{\sqrt{h_{\mathrm{ij}, \mathrm{t}}}\right\}$ is the $(N x N)$ diagonal matrix of time-varying standard deviations from univariate GARCH models with $\sqrt{h_{\mathrm{ii}, \mathrm{t}}}$ on the $i-t h$ diagonal and $\Omega_{\mathrm{t}}=\left\{\rho_{\mathrm{ij}}\right\}$ is the $(N x N)$ time-varying conditional correlation matrix. The estimation of the DCC model involves two stages. In the first stage univariate volatility models are fitted for each variable and estimates of $\sqrt{h_{\mathrm{ii}, \mathrm{t}}}$ are obtained. In the second stage, the residuals are transformed by their estimated standard deviations from the first stage. That is $U_{t}=D_{\mathrm{t}}^{-1} \varepsilon_{\mathrm{t}} \cdot U_{\mathrm{t}}$ is then employed to develop the DCC specification as follows:

$$
Q_{\mathrm{t}}=S\left(1-\alpha_{1}-\alpha_{2}\right)+\alpha_{1}\left(U_{\mathrm{t}-1} U_{\mathrm{t}-1}^{\prime}\right)+\alpha_{2} Q_{\mathrm{t}-1}
$$

and

$$
\Omega_{t}=Q_{\mathrm{t}}^{*-1} Q_{\mathrm{t}} Q_{\mathrm{t}}^{*}
$$

where $Q_{\mathrm{t}}=\left\{q_{\mathrm{ij}, \mathrm{t}}\right\}$ is the covariance matrix of the standardized residuals $U_{\mathrm{t}}, S=\left\{\bar{q}_{\mathrm{ij}, \mathrm{t}}\right\}$ is the $(N x N)$ unconditional covariance of $U_{\mathrm{t}}$, and $Q_{\mathrm{t}}^{*}=\left(\operatorname{diag}\left(Q_{\mathrm{t}}\right)\right)^{-1 / 2}$ is a diagonal matrix composed of the squared roots of the diagonal elements of $Q_{\mathrm{t}}$. 
In (8) $\alpha_{1}$ and $\alpha_{2}$ capture the effects of previous shocks and previous dynamic correlations on the current dynamic correlation. The two parameters are nonnegative, with the usual GARCH restriction of $\alpha_{1}+\alpha_{2}<1, \quad\left(\alpha_{1}, \alpha_{2} \geq 0\right)$ to guarantee $Q_{\mathrm{t}}$ is positive and mean reverting. The restriction implies, that after a shock occurs, the correlation between the underlying variables will return to the long run unconditional level. When $\alpha_{1}=\alpha_{2}=0$, the DCC model is reduced to the Bollerslev (1990) CCC model. A typical element of the correlation matrix $\Omega_{\mathrm{t}}$ now has the following form:

$$
\rho_{\mathrm{ij}, \mathrm{t}}=\frac{q_{\mathrm{ij}, \mathrm{t}}}{\sqrt{q_{\mathrm{ii}, \mathrm{t}}} \sqrt{q_{\mathrm{jj}, \mathrm{t}}}} \quad \text { for } i, j=1,2 \ldots n \quad \text { and } i \neq j
$$

The DCC model is estimated by maximization of the following log-likelihood function:

$$
L=-\frac{1}{2} \sum_{\mathrm{T}=1}^{\mathrm{T}}\left(n L O G(2 \pi)+2 L O G\left|D_{\mathrm{t}}\right|+L O G\left|\Omega_{\mathrm{t}}\right|+U_{\mathrm{t}}^{\prime} \Omega_{\mathrm{t}}^{-1} U_{\mathrm{t}}\right)
$$

Engle (2002) suggests estimating the DCC in a two-stage procedure. See Engle (2002) for details on estimation.

The standard DCC model provides a parsimonious parametrization of conditional correlations. That, however, comes with some limitations. One such limitation is the weakness of the model in capturing asymmetric effects of positive and negative shocks on conditional correlations. To account for any potential asymmetry, Cappiello et al. (2006) introduce the scalar asymmetric DCC (ADCC) model. The model allows conditional correlations to increase more when both returns are falling than when both are rising. Another limitation is the assumption that all correlations are driven by the same dynamic pattern which is hard to justify as the number of assets increases. Hafner and Franses (2003) address this issue by generalizing the DCC model by replacing the common $\alpha_{1}$ and $\alpha_{2}$ parameters with asset specific $\alpha_{1, \mathrm{i}}$ and $\alpha_{2, \mathrm{i}}$ parameters.

Time-Varying Intertemporal Relation Between Expected Returns and Risk

An international version of Merton's (1973) ICAPM and work by Bekaert and Harvey (1995) motivates the following specification for Frontier country risk and expected returns:

$$
R_{\mathrm{k}, \mathrm{t}}=\theta_{\mathrm{k}}+\beta \sigma_{\mathrm{us}, \mathrm{k}, \mathrm{t}}+\delta_{\mathrm{k}} \sigma_{\mathrm{k}, \mathrm{t}}^{2}+u_{\mathrm{k}, \mathrm{t}}
$$

where $R_{\mathrm{k}, \mathrm{t}}$ denotes expected returns for country $k ; \sigma_{\mathrm{us}, \mathrm{k}, \mathrm{t}}$ denotes conditional covariance between US and country $k$ returns, and $\sigma_{\mathrm{k}, \mathrm{t}}^{2}$ represents local market conditional volatility. The parameter $\beta$ reflects 
compensation (return) a representative investor must receive per unit of covariance risk exposure to US markets, and the parameter $\delta_{\mathrm{k}}$ represents compensation per unit of local market risk (variance). Equation (12) states that investors in Frontier markets are compensated, in terms of expected returns, for bearing covariance risk with US markets and for bearing own-country risk. The error term $u_{\mathrm{k}, \mathrm{t}}$ captures other factors affecting country returns, like regional integration and political risk. Such a model has recently been used to investigate whether world market risk and country-specific total risk are priced in international stock markets by Bali and Cakici (2010).

An important issue is whether investors' expected returns per unit covariance risk with US is constant. In the context of mature, industrial economies, such an assumption may be acceptable. However, it may be too strong when emerging markets are involved. Emerging economies often experience shifting industrial structure that will induce variation in investors' perception of risk exposure. To address the possibility of time-variation of expected premium per unit of covariance risk, we entertain a time-variable parameter (TVP) version of Eq. (12), ICAPM-TVP. Our model is specified as follows:

$$
\begin{gathered}
R_{\mathrm{k}, \mathrm{t}}=\theta_{\mathrm{k}}+\beta_{\mathrm{t}} \sigma_{\mathrm{us}, \mathrm{k}, \mathrm{t}}+\delta_{\mathrm{k}} \sigma_{\mathrm{k}, \mathrm{t}}^{2}+u_{\mathrm{k}, \mathrm{t}} \\
u_{\mathrm{k}, \mathrm{t}} \sim N\left(0, H_{\mathrm{k}}\right) \\
\beta_{\mathrm{t}}=c(1-\rho)+\rho \beta_{\mathrm{t}-1}+n_{\mathrm{t}} \\
n_{t} \sim N(0, Q) \\
E\left(u_{\mathrm{k}, \mathrm{t}} n_{\mathrm{t}}\right)=0
\end{gathered}
$$

where the expected time-variable payoff per unit of covariance risk is captured by the parameter $\beta_{\mathrm{t}}$.

Using the terminology of state space models, Eq. (13) is the measurement equation. It relates the observed (explained) variable $R_{\mathrm{k}, \mathrm{t}}$ to the state variable (time-varying parameter) $\beta_{\mathrm{t}}$. The "coefficient" $\sigma_{\mathrm{us}, \mathrm{k}, \mathrm{t}}$, multiplying the state variable is the current period conditional covariance between US and Fron- 
tier country $K$ (country risk). The parameter $\delta_{\mathrm{k}}$ captures the impact of current period own-market risk (return variance) $\sigma_{\mathrm{k}, \mathrm{t}}^{2}$ and is assumed to be fixed rather than time-varying for simplicity. Both the dynamic conditional covariances $\sigma_{\mathrm{us}, \mathrm{k}, \mathrm{t}}$ and local market variances $\sigma_{\mathrm{k}, \mathrm{t}}^{2}$ are estimated in a first step from the DCC model described earlier. Eq. (14) is the state equation describing the evolution of $\beta_{\mathrm{t}}$ as an AR(1) process. Detailed exposition of such state space models, along with their estimation via the Kalman filter, can be found in Harvey (1989) and Hamilton (1994).

In the next section we present results from estimation of the DCC and ICAPM-TVP models for each frontier country.

\section{III.V. Empirical Results}

\section{Dynamic Conditional Correlations}

The results from the estimation of the DCC model are presented in Table 3.2. The first column of Table 3.2 presents the estimated values for the constant term $\gamma_{0}$ in Eq.(3). The estimated parameter is statistically significant for 8 Frontier markets. For the US and the remaining markets, the term is found to bear no statistical importance. The AR(1) term, $\gamma_{1}$, is presented in the second column of Table 3.2. The estimates are statistically significant and positive for the US and 12 Frontier markets, while statistically significant and negative only for Bulgaria. For 6 countries, the AR(1) coefficient is not statistically significant. The constant term $b_{0}$ of Eq. (5) is offered in the third column of Table 3.2. The estimates are statistically significant for all countries, but the US, Argentina, and Mauritius. The GARCH and ARCH parameters $b_{1}$ and $b_{2}$ are presented in columns 4 and 5 respectively. Both parameters are statistically significant for all countries.

The last two columns of Table 3.2 report the estimates of the DCC parameters $\alpha_{1}$ and $\alpha_{2}$ in Eq. (8). The two parameters capture the effects of previous dynamics in covariances and shocks to the US and Frontier market returns. The estimates of $\alpha_{1}$ are statistically significant for all Frontier markets but Jordan, Lebanon, and Romania; the $\alpha_{2}$ values are not significant only for Jordan. The statistical significance of the parameters for most countries reveals a substantial time-variation of conditional covariances. The closer the sum of $\alpha_{1}$ and $\alpha_{2}$ to one, the greater the covariance persistence.

Descriptive statistics of estimated dynamic conditional correlations (DCCs) for each Frontier country are reported in Table 3.3. The first column reports unconditional constant correlations between Frontier countries and US market returns. The second and third columns report maximum and minimum values of the DCCs for each country over the sample time span investigated. The next four 
columns present the first four moments of the DCCs. The last two columns report results from the Jarque-Bera test for normality and the Ljung-Box test for autocorrelation in the DCCs.

Fifteen countries exhibit positive correlation with the US. Argentina is most highly correlated, with correlation coefficient equal to 0.563 . For most of the remaining 14 markets, constant correlations are below 0.20 , suggesting potential diversification benefits based on non-time varying correlations. Five countries display low negative correlations. These are Bahrain, Jordan, Nigeria, Oman, and Qatar. Negative correlations also suggest diversification opportunities from investing in these Frontier countries.

Dynamic Conditional Correlations for majority of the countries have a range lower than 0.25 . A high value of 0.891 is reached between US and Argentina. Their standard deviations range from 0.145 for Bulgaria to essentially 0 for Nigeria. 15 countries exhibit negative skewness, implying the predominant expectation of investors for most countries is for positive correlation. The null hypothesis of no skewness is rejected at 5\% significance level for Bulgaria, Lebanon, Nigeria, Qatar, and Sri Lanka. High and statistically significant positive excess kurtosis is found for 17 markets. This implies, that the variance of DCCs is largely due to infrequent extreme deviations from the mean, rather than modestly sized deviations. Skewness and excess kurtosis in DCCs suggest that their distributions are possibly non-normal, indicating the presence of extreme values. This is further suggested by the results from the Jarque-Bera normality tests. The null hypothesis for normal distribution of index returns is strongly rejected at the 5\% significance level for all countries except Estonia. Ljung-Box test shows that DCCs for 12 countries are highly serially correlated at 6 lags, suggesting possible predictability of correlations. No statistically significant autocorrelation is exhibited by the DCCs for Bahrain, Jordan, Mauritius, Nigeria, Pakistan, Slovenia, Tunisia, and UAE.

The DCCs, as well as the constant unconditional correlations are plotted in Fig. 3.1. Typically, DCCs range between -0.2 and 0.2. The greatest magnitude is displayed for DCCs between US and Argentina, about 0.9 in 2007, and between US and Bahrain, about 0.5 in 2009. Several countries display very low DCCs. Such countries, like Jordan and Kuwait, exhibit almost no correlation with US throughout the sample period. Most volatile DCCs are found for Argentina, Bahrain, and Kazakhstan. No significant time-variability in DCCs are found in Mauritius, Nigeria, Pakistan and Slovenia. DCCs exhibit a slightly positive trend over our sample period for 6 frontier markets. Such a trend illustrates decrease over time in diversification benefits between US and these markets. 
The relatively low cross-country correlations and the absence of a significant time trend or pattern in them suggest that increasing globalization over the past years did not significantly affect correlations between US and Frontier markets. This may be a result of industry mixes within each country being sufficiently different from US to induce low correlations, or business cycles in US and Frontier countries being out of phase.

In summary, our results indicate modest DCCs, providing substantial diversification benefits from investing in Frontier markets. We show that correlations of many Frontier markets with US do in fact vary over time and are non-normally distributed, suggesting the presence of extreme values. They display largely no trend, suggesting no diminishing of diversification benefits over time. We detect a significant level of autocorrelation, suggesting that correlation patterns may be predictable. Our findings imply that portfolio diversification based solely on constant correlations could lead to inaccurate estimates of its benefits. Thus, investors need to take time-variation of correlations into account in order to fully evaluate the efficacy of their diversification strategies.

\section{ICAPM-TVP Estimates for Frontier Markets}

This subsection reports estimates of the ICAPM-TVP model for 20 Frontier countries, applied to MSCI data for the period between December 1st, 2005 and June 30th, 2011. Maximum likelihood parameter estimates and standard errors are reported in Table 3.4. Tests of hypothesis related to important restricted versions of the ICAPM-TVP model are presented in Table 3.5.

Estimates in Table 3.4 show that Frontier countries are vastly different from each other in terms of magnitude and signs of estimated parameters. This finding is to be expected as these countries/ markets may be at different levels of development, or at different stages of the business cycle during the less than 6-year sample period considered here. The first column reports estimates of unconditional mean returns $\theta_{\mathrm{k}}$. The largest recorded value is 150.3 daily percent annualized returns for Pakistan. For four countries, estimated mean returns are negative, with the lowest for Sri Lanka at -101.4 percent annualized. These estimates, however, are statistically significant for only four countries. Estimates of the price of own country market variance risk $\delta_{\mathrm{k}}$ are reported in the second column. The highest estimate is for Sri Lanka (0.203) and the lowest for Pakistan (-0.46). The estimates are positive for only six Frontier markets. These estimates are statistically significant for all but three countries.

Negative risk-return relationships have been well-documented in the literature using both aggregate country level and firm level data. See, for example, Whitelaw (1994) and Ang et al (2006). The 
predominantly negative estimates of local market risk prices imply the possibility of sizeable hedging and discount rate news components in Frontier market risk (Gou and Whitelaw (2006), Brandt, Jin, and Wang, (2009)). Gou and Whitelaw (2006) investigate the possibility of a negative market risk premium. They find that sizeable market risk hedging component may induce negative risk-return relationship. Brandt, Jin, and Wang (2009) break the conditional variance of US market returns into components associated with cash flow news and discount rate news. They find that sizeable discount rate news component, in addition to the hedging component, may also induce negative risk premia.

Estimates of mean covariance risk premium with US markets, represented by parameter $C$ in Eq. (14), are reported in column 4. These risk premia are positive for 13 countries, and range from a high of 635.55 for Oman to a low of -835.2 for Slovenia. These values are, however, statistically significant for only 5 countries. Estimated values of the AR parameter $\rho$ governing time-variation in covariance risk premium $\beta_{\mathrm{t}}$ are presented in column 5. The estimates are positive for 18 countries, and range from a high of 0.999 for Jordan to a low of -0.819 for Bulgaria. These values are statistically significant for 18 countries. The last column of Table 3.5 reports the estimates of the standard deviation $\sqrt{Q}$ of shocks $n_{\mathrm{t}}$, driving time variation in these premia. The estimated values are statistically significant for all countries. Statistically significant estimates of $\rho$ and $\sqrt{Q}$ imply some predictability of covariance risk premia.

The various panels of Figure 3.2 plot the fitted and observed Frontier market returns, while the panels of Figure 3.3 present the decomposition of Frontier country fitted returns into US and local market components. Quantitatively significant impact of US market risk is found only for Argentina. For all other countries, the US component is very small relative to the local market component. The latter implies that evolution of returns in these countries is governed primarily by local market factors and not by US market covariance risk. This finding is in line with results reported in Bali and Cakici (2010).

Table 3.5 reports results from hypothesis tests performed to test restricted versions of the ICAPMTVP model. Statistical significance of estimated parameters is tested via the LR test. Test statistics for the null hypothesis $\left(H_{0}: \beta_{\mathrm{t}}=0\right)$ for each Frontier market are reported in the first column of Table 3.5. The LR test detects statistically significant impact of the covariance risk (null hypothesis is rejected) for 14 of the 20 Frontier markets at the 5\% significance level and for additional 2 countries at $10 \%$. 
Loglikelihood Ratio test statistics for the null hypothesis of no time-variation in covariance risk premia $\left(H_{0}: \beta_{\mathrm{t}}=\right.$ constant $)$ are reported in the second column of Table 3.5. Time-variability of $\beta_{\mathrm{t}}$ is statistically significant (null hypothesis is rejected) for 14 countries at the 5\% significance level and for additional 2 countries at $10 \%$. These countries are the same as the countries for which the null hypothesis for no impact of the covariance risk is rejected. The results indicate that if risk premium exists, then it is time-variabe. Understanding the factors that may contribute to such time-variability would be a worthwhile exercise.

The second to last column of Table 3.5 reports the test statistics from exploring the null hypothesis of no impact of US covariance risk $\left(H_{0}: \beta_{\mathrm{t}}=0\right)$, when the alternative model features constant risk premia $\left(H_{1}: \beta_{\mathrm{t}}=\right.$ constant $)$. The results indicate statistically significant impact of covariance risk (null hypothesis is rejected) for only 4 of the 20 Frontier markets at the $5 \%$ significance level. These are Nigeria, Qatar, Romania, and UAE. At the 10\% significance level, the null hypothesis is rejected for Mauritius as well. The outcomes from this hypothesis test further emphasize the importance of timevariability of covariance risk prices. The results indicate that if time-variability in covariance risk prices is not taken into account, the impact of US covariance risk may erroneously be found to be statistically insignificant and easily omitted.

The last column of Table 3.5 presents test statistics from exploring the null hypothesis of no impact of local Frontier market risk $\left(H_{0}: \delta_{k}=0\right)$. The LR test detects statistically significant impact of local Frontier market risk (null hypothesis is rejected) for all Frontier markets, except Argentina and Croatia.

In summary, the ICAPM-TVP estimation detects statistically significant impact of US covariance risk and local market risk for most Frontier markets. We detect statistically significant and often predictable time-variation in covariance risk premia for most countries. Our results emphasize the importance of accounting for time-variability of the price of US covariance risk in understanding time variation in Frontier market stock returns.

\section{III.VI. Conclusion}

We study the risk-return relationship in twenty Frontier markets by setting up an international version of the intertemporal capital asset pricing model (International ICAPM). The systematic risk in this model comes from covariance of Frontier market returns with world returns, proxied by US stock index returns. We also incorporate own country variances as additional determinants of Frontier country returns. Our model allows for the covariance risk to be time-varying. Time-varying correlations are 
captured by utilizing the Dynamic Conditional Correlations (DCC) model of Engle (2002). The risk premium on covariance risk is allowed to vary over time as well, using a time-varying parameter (TVP). Thus, both the risk and risk premium on Frontier country market returns are time-varying in our model.

The International ICAPM-TVP model can be cast into a state space form. However, it is not time-invariant as the "coefficient" multiplying the state variable (the TVP parameter) is (time-varying) current period conditional covariance between US and Frontier markets. The model nonetheless can be estimated by the Kalman Filter.

Results from estimation of the DCC model indicate modest average conditional correlations, suggestive of substantial diversification benefits from investing in Frontier markets. Correlations between most Frontier markets and US do in fact vary over time and are non-normally distributed due to presence of extreme values. They display largely no time trend, suggesting that diversification benefits have not diminished despite recent globalization. We detect a significant level of autocorrelation in these correlations, indicating predictability. Results from ICAPM-TVP estimation suggest that Frontier markets differ significantly from each other. We detect statistically significant impact of both US covariance risk and own country variance risk in explaining Frontier country returns. Time-variation in the price of covariance risk is also found to be statistically significant for most Frontier market returns. However, own country variance risk is found to be quantitatively more important.

Overall, results from our study show that international stock market diversification benefits might still hold, despite recent increased globalization and integration of financial markets. For accurate estimation of portfolio diversification benefits, investors must consider time-variation in conditional correlations of stock market returns as well as in country covariance risk prices. A logical extension of research presented in this article is understanding of factors that may contribute to time-variation and predictability in covariance risk premia. Exploration of portfolio diversification benefits further by constructing investment opportunity sets, calculating mean Sharpe ratios, and considering higher moments of returns to capture downside risk and possibility of large shocks to stock returns is also worthwhile. This can be done by comparing the above quantities with and without including Frontier market indexes in the investment portfolio. 


\section{REFERENCES}

Ang, A., R.J. Hodrick, Y. Xing, and X. Zhang. The Cross-Section of Volatility and Expected Returns. The Journal of Finance. 2006; 61(1):259-299.

Bali TG, Cakici N. World market risk, country-specific risk and expected returns in international stock markets. Journal of Banking and Finance. 2010; 34, 1152-1165.

Bali TG, Engle RF. The intertemporal capital asset pricing model with dynamic conditional correlations. Journal of Monetary Economics. 2010;57(4):377-390.

Bali TG, Wu L. The role of exchange rates in intertemporal risk-return relations. Journal of International Money and Finance. 2010;29(8):1670-1686.

Bekaert, G., Harvey, C. Time-varying world market integration. The Journal of Finance. 1995; 50(2):403-444.

Berger D, Pukthuanthong K, Jimmy Yang J. International diversification with frontier markets. Journal of Financial Economics. 2011;101(1):227-242.

Bollerslev, T. Modelling the coherence in short-run nominal exchange rates: A multivariate generalized ARCH model. The Review of Economics and Statistics. 1990; 72(3):498-505.

Brandt M, Jin X, Wang L. Cash-flow risk, discount-rate risk, and the time-varying market risk premium. Duke Working Paper.2009.

Cappiello, L., Engle, R.F., Sheppard, K. Asymmetric dynamics in the correlations of global equity and bond return. Journal of Financial Econometrics.2006; 4(4), 537-572.

Cheng A-R, Jahan-Parvar MR, Rothman P. An empirical investigation of stock market behavior in the Middle East and North Africa. Journal of Empirical Finance. 2010;17(3):413-427.

Engle R. Dynamic conditional correlation. Journal of Business and Economic Statistics. 2002;20(3):339350 .

Guesmi K, Nguen DK. How strong is the global integration of emerging market regions? An empirical assessment. Université de Paris Ouest Nanterre La Défense working paper. 2011.

Guo H, Whitelaw RF. Uncovering the risk-return relation in the stock market. The Journal of Finance. 2006;61(3):1433-1463.

Hafner M., Franses F. A generalized dynamic conditional correlation model for many asset returns. Econometric Institute Report EI. 2003-18

Hamilton J. Time series analysis. Princeton Univ Press. 1994.

Harvey A. Forecasting, structural time series models and the Kalman filter. Cambridge University Press. 1989.

Harvey CR. The world price of covariance risk. The Journal of Finance. 1991;46(1):111-157.

Harvey CR. Predictable risk and returns in emerging markets. Review of Financial Studies. 1995;8(3):773-816.

Karolyi GA, Stulz RM. Are financial assets priced locally or globally? NBER Working Paper No. 8994. 2002. 
Merton RC. An Intertemporal capital asset pricing model. Econometrica.1973; 41(5):867-887.

Solnik, B. The International Pricing of Risk: An Empirical Investigation of the World Capital Market Structure. The Journal of Finance. 1974;29(2):365-378.

Stulz, R. A Model of International Asset Pricing. Journal of Financial Economics, 1981;9(4), 383406.

Syriopoulos T, Roumpis E. Dynamic correlations and volatility effects in the Balkan equity markets. Journal of International Financial Markets, Institutions and Money. 2009;19(4):565-587.

Todorov G., Bidarkota P.V. Time-varying financial spillovers from the US to Frontier markets. FIU Working Paper. 2011.

Whitelaw, R.F. Time variations and covariations in the expectation and volatility of stock market returns. The Journal of Finance, 1994;49(2):515-541.

Yiu M, Ho A, Jin L. Dynamic correlation analysis of financial spillover to Asian and Latin American markets in global financial turmoil. Hong Kong Monetary Authority, working paper. 2010:1-22.

You L, Daigler RT. Is international diversification really beneficial? Journal of Banking \& Finance. 2010;34(1):163-173. 
Table 3.1. Distributional Characteristics of Annualized Daily Percentage Logarithmic Returns. The table provides mean, standard deviation, skewness, kurtosis, Jarque-Bera test statistic, and mean-to standard deviation (Sharpe) ratio for each frontier market and US.

\begin{tabular}{|l|l|l|l|c|c|c|}
\hline Country & Mean & St.Dev & Skewness & Kurtosis & Jarque-Bera & Mean/St.Dev \\
\hline Argentina & 9.38 & 592.93 & -0.626 & 10.84 & 3827.41 & 0.016 \\
\hline Bahrain & -24.3 & 356.44 & -3.596 & 64.67 & 233902.71 & -0.068 \\
\hline Bulgaria & -14.7 & 504.67 & -1.589 & 16.401 & 11508.027 & -0.029 \\
\hline Croatia & 9.86 & 418.53 & -0.156 & 9.438 & 2520.702 & 0.024 \\
\hline Estonia & -6.68 & 511.29 & $0.13^{*}$ & 7.127 & 1037.792 & -0.013 \\
\hline Jordan & -19.7 & 343.70 & -0.787 & 11.254 & 4283.52 & -0.057 \\
\hline Kazakhstan & 13.98 & 727.33 & $0.315^{*}$ & 10.095 & 3078.657 & 0.019 \\
\hline Kenya & 2.14 & 360.31 & $0.378^{*}$ & 13.306 & 6479.127 & 0.006 \\
\hline Kuwait & -7.68 & 410.17 & -1.114 & 11.906 & 5113.558 & -0.019 \\
\hline Lebanon & 2.52 & 417.12 & -0.126 & 17.766 & 13263.225 & 0.006 \\
\hline Mauritius & 18.63 & 365.83 & $0.181 *$ & 12.81 & 5846.367 & 0.051 \\
\hline Nigeria & 0.60 & 387.45 & -0.258 & 6.067 & 587.032 & 0.002 \\
\hline Oman & -3.61 & 374.72 & -1.576 & 27.798 & 37910.577 & -0.009 \\
\hline Pakistan & -5.98 & 450.35 & -0.608 & 6.512 & 838.552 & -0.013 \\
\hline Qatar & -4.94 & 449.67 & -0.704 & 12.831 & 5983.325 & -0.011 \\
\hline Romania & -2.9 & 643.75 & -1.456 & 21.302 & 20836.586 & -0.005 \\
\hline Slovenia & 2.34 & 396.66 & -0.361 & 9.713 & 2765.997 & 0.006 \\
\hline Sri Lanka & 9.37 & 363.65 & 1.931 & 24.674 & 29404.741 & 0.026 \\
\hline Tunisia & 9.59 & 284.55 & 0.094 & 9.046 & 2220.283 & 0.033 \\
\hline UAE & -26.6 & 546.43 & -0.633 & 14.334 & 7891.139 & -0.05 \\
\hline USA & 0.94 & 373.15 & -0.268 & -2397.46 & 5758.433 & 0.003 \\
\hline
\end{tabular}

Note: The statistics are based on 1456 daily observations of country returns between December 1st, 2005 and June 30th, 2011 as given by MSCI Barra country indices. All country indices are in US currency. The null hypothesis of no kurtosis is rejected for all countries and * indicates the null hypothesis for no skewness is rejected at 5\% level. The distribution of the Jarque-Bera test statistic is approximates $\chi^{2}(2)$, with 5.99 critical value at the $5 \%$ level. 
Table 3.2. Estimation results from DCC-GARCH models

GARCH models: $R_{i, \mathrm{t}}=\gamma_{0}+\gamma_{1} R_{\mathrm{i}, \mathrm{t}-1}+\varepsilon_{\mathrm{i}, \mathrm{t}}, \varepsilon_{\mathrm{i}, \mathrm{t}}=\sqrt{h_{\mathrm{i}, \mathrm{t}}} z_{\mathrm{t}}, z_{\mathrm{t}} \sim \operatorname{iidN}(0,1), h_{\mathrm{i}, \mathrm{t}}=b_{0}+b_{1} h_{\mathrm{i}, \mathrm{t}-1}+b_{2} \varepsilon_{\mathrm{t}-1}^{2}, i=$ $1,2 \ldots .21$.

DCC equations: $Q_{\mathrm{t}}=S\left(1-\alpha_{1}-\alpha_{2}\right)+\alpha_{1}\left(U_{\mathrm{t}-1} U_{\mathrm{t}-1}^{\prime}\right)+\alpha_{2} Q_{\mathrm{t}-1}, R_{t}=Q_{\mathrm{t}}^{*-1} Q_{\mathrm{t}} Q_{\mathrm{t}}^{*-1}$

\begin{tabular}{|c|c|c|c|c|c|c|c|}
\hline 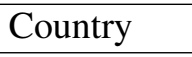 & $\gamma_{0}$ & $\gamma_{1}$ & $b_{0}$ & $b_{1}$ & $b_{2}$ & $\alpha_{1}$ & $\alpha_{2}$ \\
\hline USA & $\begin{array}{l}10.995 \\
(6.0744)\end{array}$ & $\begin{array}{l}-0.081 \\
(0.028)\end{array}$ & $\begin{array}{l}0.00 \\
(0.000)\end{array}$ & $\begin{array}{c}0.927 \\
(0.007)\end{array}$ & $\begin{array}{l}0.082 \\
(0.01)\end{array}$ & & \\
\hline Arge & $\begin{array}{c}31.24 \\
12.109)\end{array}$ & $\begin{array}{l}0.046 \\
(0.028)\end{array}$ & $\begin{array}{l}6.53 \\
38.23)\end{array}$ & $\begin{array}{l}0.814 \\
0.032)\end{array}$ & $\begin{array}{c}0.129 \\
(0.024)\end{array}$ & & $\begin{array}{c}0.912 \\
(0.022)\end{array}$ \\
\hline Bahre & $\begin{array}{l}19.26 \\
6.927)\end{array}$ & $\begin{array}{l}0.056 \\
(0.036)\end{array}$ & $\begin{array}{l}63.37 \\
(8.279)\end{array}$ & $\begin{array}{c}0.796 \\
(0.019)\end{array}$ & $\begin{array}{c}0.177 \\
(0.023)\end{array}$ & $\begin{array}{c}0.095 \\
(0.000)\end{array}$ & $\begin{array}{c}0.000 \\
(0.000)\end{array}$ \\
\hline Bulgai & $\begin{array}{l}12.672 \\
(9.304)\end{array}$ & $\begin{array}{l}-0.055 \\
(0.029)\end{array}$ & $\begin{array}{l}43.05 \\
(13.428)\end{array}$ & $\begin{array}{c}0.862 \\
(0.021)\end{array}$ & $\begin{array}{c}0.123 \\
(0.021)\end{array}$ & $\begin{array}{c}0.008 \\
(0.000)\end{array}$ & $\begin{array}{c}0.991 \\
(0.000)\end{array}$ \\
\hline Croati & $\begin{array}{l}18.262 \\
(8.997)\end{array}$ & $\begin{array}{l}0.117 \\
(0.028)\end{array}$ & $\begin{array}{l}62.95 \\
(20.254)\end{array}$ & $\begin{array}{c}0.882 \\
(0.028)\end{array}$ & $\begin{array}{c}0.075 \\
(0.017)\end{array}$ & & $\begin{array}{c}0.97 \\
(0.021)\end{array}$ \\
\hline Estc & $\begin{array}{c}0.722 \\
(4.021)\end{array}$ & $\begin{array}{l}0.055 \\
(0.028)\end{array}$ & $\begin{array}{l}23.117 \\
(7.745)\end{array}$ & $\begin{array}{c}0.885 \\
(0.014)\end{array}$ & $\begin{array}{c}0.113 \\
(0.016)\end{array}$ & $\begin{array}{c}0.01 \\
(0.008)\end{array}$ & $\begin{array}{c}0.971 \\
(0.031)\end{array}$ \\
\hline Jord & $\begin{array}{l}-9.463 \\
(6.598)\end{array}$ & $\begin{array}{l}0.03 \\
(0.028)\end{array}$ & $\begin{array}{l}10.947 \\
(3.763)\end{array}$ & $\begin{array}{c}0.931 \\
(0.009)\end{array}$ & $\begin{array}{c}0.06 \\
(0.009)\end{array}$ & $\begin{array}{c}0.018 \\
(0.000)\end{array}$ & $\begin{array}{c}0.000 \\
(0.377)\end{array}$ \\
\hline Kazak & $\begin{array}{c}20.051 \\
(13.142)\end{array}$ & $\begin{array}{l}0.002 \\
(0.029)\end{array}$ & $\begin{array}{l}61.38 \\
(17.927)\end{array}$ & $\begin{array}{c}0.886 \\
(0.015)\end{array}$ & $\begin{array}{c}0.103 \\
(0.016)\end{array}$ & $\begin{array}{c}0.019 \\
(0.007)\end{array}$ & \\
\hline Ken & $\begin{array}{c}0.504 \\
(4.502)\end{array}$ & $\begin{array}{l}1 \\
27)\end{array}$ & $\begin{array}{l}1.727 \\
3.874)\end{array}$ & $\begin{array}{c}0.904 \\
(0.008)\end{array}$ & $\begin{array}{c}0.09 \\
(0.01)\end{array}$ & $\begin{array}{c}0.003 \\
(0.000)\end{array}$ & $\begin{array}{c}0.992 \\
(0.000)\end{array}$ \\
\hline Kuw & $\begin{array}{l}10.011 \\
(8.087)\end{array}$ & $\begin{array}{l}0.064 \\
(0.029)\end{array}$ & $\begin{array}{l}19.95 \\
(4.344)\end{array}$ & $\begin{array}{c}0.927 \\
(0.008)\end{array}$ & $\begin{array}{c}0.06 \\
(0.007)\end{array}$ & & \\
\hline Leba & $\begin{array}{l}-5.891 \\
(8.856)\end{array}$ & $\begin{array}{l}103 \\
.032)\end{array}$ & $\begin{array}{l}87.671 \\
(21.239)\end{array}$ & $\begin{array}{c}0.738 \\
(0.039)\end{array}$ & $\begin{array}{c}0.25 \\
(0.042)\end{array}$ & $\begin{array}{c}0.008 \\
(0.007)\end{array}$ & \\
\hline Mau & $\begin{array}{l}17.926 \\
(7.167)\end{array}$ & $\begin{array}{l}0.184 \\
(0.032)\end{array}$ & $\begin{array}{l}10.551 \\
(22.575)\end{array}$ & $\begin{array}{c}0.68 \\
(0.044)\end{array}$ & $\begin{array}{c}0.282 \\
(0.046)\end{array}$ & $\begin{array}{c}0.000 \\
(0.000)\end{array}$ & $\begin{array}{c}0.576 \\
(0.000)\end{array}$ \\
\hline Nige & $\begin{array}{c}0.507 \\
(2.995)\end{array}$ & $\begin{array}{l}.381 \\
0.028)\end{array}$ & $\begin{array}{l}74.608 \\
(18.55)\end{array}$ & $\begin{array}{c}0.761 \\
(0.037)\end{array}$ & $\begin{array}{l}0.185 \\
(0.03)\end{array}$ & $\begin{array}{c}0.000 \\
(0.000)\end{array}$ & $\begin{array}{c}0.609 \\
(0.000)\end{array}$ \\
\hline $\mathrm{Om}$ & $\begin{array}{l}13.906 \\
(5.893)\end{array}$ & $\begin{array}{l}0.085 \\
(0.032)\end{array}$ & $\begin{array}{l}15.11 \\
(3.973)\end{array}$ & $\begin{array}{c}0.865 \\
(0.011)\end{array}$ & $\begin{array}{c}0.144 \\
(0.016)\end{array}$ & $\begin{array}{c}0.033 \\
(0.000)\end{array}$ & $\begin{array}{c}0.000 \\
(0.000)\end{array}$ \\
\hline rak & $\begin{array}{l}96 \\
97)\end{array}$ & $\begin{array}{l}5 \\
29)\end{array}$ & $\begin{array}{l}98.51 \\
(16.92\end{array}$ & $\begin{array}{c}0.775 \\
(0.024)\end{array}$ & $\begin{array}{c}0.167 \\
(0.021)\end{array}$ & $\begin{array}{r}0.1 \\
(0.1\end{array}$ & $\begin{array}{c}0.001 \\
(0.000)\end{array}$ \\
\hline $\mathrm{Q}$ & $\begin{array}{c}8.512 \\
(9.545)\end{array}$ & $\begin{array}{l}0.103 \\
(0.031)\end{array}$ & $\begin{array}{l}39.473 \\
(8.927)\end{array}$ & $\begin{array}{c}0.885 \\
(0.014)\end{array}$ & $\begin{array}{c}0.098 \\
(0.014)\end{array}$ & $\begin{array}{c}0.056 \\
(0.000)\end{array}$ & $\begin{array}{c}0.000 \\
(0.000)\end{array}$ \\
\hline Ro & $\begin{array}{c}20.422 \\
(13.812)\end{array}$ & $\begin{array}{l}0.017 \\
(0.027)\end{array}$ & $\begin{array}{l}17.81 \\
(6.443)\end{array}$ & $\begin{array}{c}0.965 \\
(0.003)\end{array}$ & $\begin{array}{c}0.031 \\
(0.004)\end{array}$ & $\begin{array}{c}0.011 \\
(0.005)\end{array}$ & $\begin{array}{c}0.986 \\
(0.006)\end{array}$ \\
\hline Slo & $\begin{array}{l}13.759 \\
(7.655)\end{array}$ & $\begin{array}{l}0.173 \\
(0.028)\end{array}$ & $\begin{array}{l}73.529 \\
(23.963)\end{array}$ & $\begin{array}{c}0.808 \\
(0.044)\end{array}$ & $\begin{array}{c}0.134 \\
(0.031)\end{array}$ & $\begin{array}{c}0.000 \\
(0.000)\end{array}$ & $\begin{array}{c}0.000 \\
(0.000)\end{array}$ \\
\hline Sri & $\begin{array}{c}0.497 \\
(1.874)\end{array}$ & $\begin{array}{l}0.238 \\
(0.03)\end{array}$ & $\begin{array}{l}29.249 \\
(5.824)\end{array}$ & $\begin{array}{c}0.822 \\
(0.021)\end{array}$ & $\begin{array}{c}0.175 \\
(0.025)\end{array}$ & $\begin{array}{c}0.011 \\
(0.011)\end{array}$ & $\begin{array}{c}0.925 \\
(0.064)\end{array}$ \\
\hline $\mathrm{Tu}$ & $\begin{array}{l}12.749 \\
(6.009)\end{array}$ & $\begin{array}{l}0.073 \\
(0.03)\end{array}$ & $\begin{array}{l}42.267 \\
(10.557)\end{array}$ & $\begin{array}{c}0.802 \\
(0.027)\end{array}$ & $\begin{array}{c}0.157 \\
(0.023)\end{array}$ & $\begin{array}{c}0.005 \\
(0.005)\end{array}$ & $\begin{array}{c}0.986 \\
(0.014)\end{array}$ \\
\hline & $\begin{array}{c}0.461 \\
(0.000)\end{array}$ & $\begin{array}{l}0.123 \\
(0.029)\end{array}$ & $\begin{array}{l}31.767 \\
(7.772)\end{array}$ & $\begin{array}{c}0.925 \\
(0.007)\end{array}$ & $\begin{array}{c}0.064 \\
(0.008)\end{array}$ & $\begin{array}{c}0.002 \\
(0.002)\end{array}$ & $\begin{array}{c}0.994 \\
(0.005)\end{array}$ \\
\hline
\end{tabular}

Note: *Represent statistical significance at the 5\%, and $1 \%$ levels, respectively. Numbers in parenthesis represent standard errors of estimates The estimates are based on 1456 daily observations of country returns between December 1st, 2005 and June 30th, 2011 as given by MSCI Barra country indices. All country indices are in US currency. 
Table 3.3. Dynamic Conditional Correlations (DCCs) statistics for frontier market returns versus US. The table provides mean, standard deviation, skewness, kurtosis and Jarque-Bera test statistic for DCCs. Constant correlations are given in the first column.

\begin{tabular}{|l|l|l|l|l|l|l|c|c|c|}
\hline Country & $\rho$ & Max & Min & Mean & St.Dev & Skewness & Kurtosis & Jarque-Bera & $\begin{array}{c}\text { Ljung-Box } \\
\text { Q(6) }\end{array}$ \\
\hline Argentina & 0.563 & 0.891 & 0.000 & 0.594 & 0.111 & -0.856 & 4.58 & 329.357 & 5852.113 \\
\hline Bahrain & -0.006 & 0.543 & -0.422 & 0.003 & 0.069 & -0.051 & 14.018 & 7366.275 & 5.493 \\
\hline Bulgaria & 0.128 & 0.358 & -0.15 & 0.089 & 0.145 & $0.256^{*}$ & 1.554 & 142.788 & 8587.543 \\
\hline Croatia & 0.229 & 0.359 & -0.159 & 0.152 & 0.097 & -0.389 & 3.068 & 37.126 & 7903.064 \\
\hline Estonia & 0.141 & 0.304 & 0.048 & 0.145 & 0.048 & -0.01 & 3.062 & 0.261 & 7520.882 \\
\hline Jordan & -0.024 & 0.098 & -0.183 & -0.016 & 0.017 & -0.196 & 18.31 & 14231.09 & 1.544 \\
\hline Kazakhstan & 0.175 & 0.448 & -0.18 & 0.153 & 0.091 & -0.457 & 3.756 & 85.594 & 7487.996 \\
\hline Kenya & 0.031 & 0.148 & -0.052 & 0.057 & 0.047 & -0.258 & 2.223 & 52.708 & 8471.084 \\
\hline Kuwait & 0.01 & 0.196 & -0.044 & 0.027 & 0.011 & 2.272 & 48.003 & 4124.22 & 32.761 \\
\hline Lebanon & 0.067 & 0.133 & -0.085 & 0.002 & 0.034 & $0.644^{*}$ & 4.165 & 98.605 & 7151.362 \\
\hline Mauritius & 0.042 & 0.071 & 0.000 & 0.071 & 0.002 & -26.92 & 725.99 & 7782.967 & 0.001 \\
\hline Nigeria & -0.009 & 0.000 & -0.001 & -0.001 & 0.000 & $26.92^{*}$ & 726.0 & 8157.192 & 0.001 \\
\hline Oman & -0.014 & 0.203 & -0.16 & 0.033 & 0.026 & -0.142 & 13.69 & 6937.94 & 10.362 \\
\hline Pakistan & 0.018 & 0.046 & 0.000 & 0.046 & 0.001 & -26.92 & 725.993 & 7547.11 & 0.009 \\
\hline Qatar & -0.006 & 0.539 & -0.254 & 0.021 & 0.045 & $1.119 *$ & 22.637 & 2370.062 & 7.566 \\
\hline Romania & 0.252 & 0.462 & -0.148 & 0.201 & 0.126 & -0.068 & 2.276 & 32.868 & 8440.583 \\
\hline Slovenia & 0.182 & 0.143 & 0.000 & 0.143 & 0.005 & -26.92 & 726.0 & 8255.15 & 0.001 \\
\hline Sri Lanka & 0.019 & 0.166 & -0.052 & 0.05 & 0.029 & $0.297 *$ & 4.006 & 82.954 & 5762.253 \\
\hline Tunisia & 0.072 & 0.083 & 0.000 & 0.083 & 0.003 & -26.92 & 726.001 & 8252.661 & 0.001 \\
\hline UAE & 0.072 & 0.031 & 0.000 & 0.031 & 0.001 & -26.92 & 726.0 & 8224.873 & 0.002 \\
\hline
\end{tabular}

Note: The statistics are based on 1456 daily observations of country returns between December 1st, 2005 and June 30th, 2011 as given by MSCI Barra country indices. All country indices are in US currency. The null hypothesis of no kurtosis is rejected for all countries and * indicates the null hypothesis for no skewness is rejected at 5\% level. The distribution of the Jarque-Bera test statistic is approximates $\chi^{2}(2)$, with 5.99 critical value at the 5\% level. The Ljung-Box test statistic is based on 6 lags and is asymptotically distributed as $\chi^{2}(6)$ with critical value of 12.59 at the $5 \%$ level. 
Table 3.4. Parameter Estimates for ICAPM -TVP Model ICAPM - TVP model for Frontier countries:

$$
\begin{gathered}
R_{\mathrm{k}, \mathrm{t}}=\theta_{\mathrm{k}}+\beta_{\mathrm{t}} \sigma_{\mathrm{us}, \mathrm{k}, \mathrm{t}}+\delta_{\mathrm{k}} \sigma_{\mathrm{k}, \mathrm{t}}^{2}++u_{\mathrm{k}, \mathrm{t}}, u_{\mathrm{k}, \mathrm{t}} \sim N\left(0, H_{\mathrm{k}}\right), \beta_{\mathrm{t}}=c(1-\rho)+\rho \beta_{, t-1}+n_{\mathrm{t}}, n_{t} \sim N(0, Q), \\
E\left(u_{\mathrm{k}, \mathrm{t}} n_{\mathrm{t}}\right)=0
\end{gathered}
$$

\begin{tabular}{|c|c|c|c|c|c|c|}
\hline Country & $\theta_{\mathrm{k}}$ & $\delta_{\mathrm{k}}$ & $\sqrt{H_{\mathrm{k}}}$ & $c$ & $\rho$ & $\sqrt{Q}$ \\
\hline Argentina & $\begin{array}{c}0.601 \\
(1.194)\end{array}$ & $\begin{array}{c}0.011 \\
(0.026)\end{array}$ & $\begin{array}{l}783.552 \\
(29.62)\end{array}$ & $\begin{array}{c}0.599 \\
(0.000)\end{array}$ & $\begin{array}{c}0.086 \\
(0.036)\end{array}$ & $\begin{array}{l}286.087 \\
(21.416)\end{array}$ \\
\hline $\mathrm{Bah}$ & $\begin{array}{c}64.49 \\
(17.836)\end{array}$ & $\begin{array}{l}-0.275 \\
(0.047)\end{array}$ & $\begin{array}{c}0.818 \\
(0.000)\end{array}$ & $\begin{array}{c}2.883 \\
(0.000)\end{array}$ & $\begin{array}{c}0.101 \\
(3.085)\end{array}$ & $\begin{array}{l}352.351 \\
(6.533)\end{array}$ \\
\hline $\mathrm{Bul}$ & $\begin{array}{l}135.642 \\
(26.865)\end{array}$ & $\begin{array}{l}-0.356 \\
(0.051)\end{array}$ & $\begin{array}{c}0.000 \\
(0.000)\end{array}$ & $\begin{array}{c}72.865 \\
(88.263)\end{array}$ & $\begin{array}{l}-0.819 \\
(0.000)\end{array}$ & $\begin{array}{c}496.096 \\
(9.199)\end{array}$ \\
\hline Croa & $\begin{array}{c}0.599 \\
(2.907)\end{array}$ & $\begin{array}{l}-0.002 \\
(0.027)\end{array}$ & $\begin{array}{c}1.071 \\
(3.093)\end{array}$ & $\begin{array}{c}0.599 \\
(0.000)\end{array}$ & $\begin{array}{c}0.13 \\
(0.000)\end{array}$ & $\begin{array}{l}418.565 \\
(7.76)\end{array}$ \\
\hline Eston & $\begin{array}{c}-4.639 \\
(20.081)\end{array}$ & $\begin{array}{c}0.035 \\
(0.062)\end{array}$ & $\begin{array}{l}2284.63 \\
(130.87)\end{array}$ & $\begin{array}{l}22.793 \\
29.95)\end{array}$ & $\begin{array}{c}0.127 \\
(0.057)\end{array}$ & $\begin{array}{l}367.69 \\
(15.75)\end{array}$ \\
\hline Jordan & $\begin{array}{c}35.813 \\
(23.281)\end{array}$ & $\begin{array}{l}-0.193 \\
(0.064)\end{array}$ & $\begin{array}{c}2.518 \\
(6.544)\end{array}$ & $\begin{array}{l}-335.737 \\
(395.84)\end{array}$ & $\begin{array}{c}0.999 \\
(0.000)\end{array}$ & $\begin{array}{c}342.592 \\
(6.353)\end{array}$ \\
\hline $\mathrm{Ka}$ & $\begin{array}{c}23.974 \\
(64.465)\end{array}$ & $\begin{array}{c}0.064 \\
(0.065)\end{array}$ & $\begin{array}{l}1507.75 \\
(183.78)\end{array}$ & $\begin{array}{l}-338.109 \\
(200.33)\end{array}$ & $\begin{array}{l}-0.185 \\
(0.123)\end{array}$ & $\begin{array}{c}661.198 \\
(17.192)\end{array}$ \\
\hline K & $\begin{array}{c}17.572 \\
(27.173)\end{array}$ & $\begin{array}{c}0.003 \\
(0.067)\end{array}$ & $\begin{array}{l}1554.18 \\
(161.12)\end{array}$ & $\begin{array}{c}-402.66 \\
(330.437)\end{array}$ & $\begin{array}{c}0.771 \\
(0.039)\end{array}$ & $\begin{array}{c}320.828 \\
(7.197)\end{array}$ \\
\hline $\mathrm{K}$ & $\begin{array}{c}71.539 \\
(175.98)\end{array}$ & $\begin{array}{c}-0.23 \\
(0.105)\end{array}$ & $\begin{array}{l}4223.29 \\
(1234.2)\end{array}$ & $\begin{array}{c}284.092 \\
(5080.95)\end{array}$ & $\begin{array}{c}0.267 \\
(0.415)\end{array}$ & $\begin{array}{l}386.647 \\
(12.355)\end{array}$ \\
\hline Leba & & & $\begin{array}{l}484.01 \\
05.17)\end{array}$ & $\begin{array}{l}-696.385 \\
(411.583)\end{array}$ & $\begin{array}{c}0.242 \\
(0.067)\end{array}$ & $\begin{array}{c}324.965 \\
(7.861)\end{array}$ \\
\hline $\mathrm{Ma}$ & $\begin{array}{l}-17.098 \\
(24.089)\end{array}$ & $\begin{array}{l}-0.018 \\
(0.067)\end{array}$ & $\begin{array}{l}1404.53 \\
(885.13)\end{array}$ & $\begin{array}{c}594.571 \\
(532.989)\end{array}$ & $\begin{array}{c}0.701 \\
(0.242)\end{array}$ & $\begin{array}{c}338.408 \\
(18.466)\end{array}$ \\
\hline $\mathrm{Ni}$ & $\begin{array}{c}67.662 \\
(49.493)\end{array}$ & $\begin{array}{l}-0.198 \\
(0.143)\end{array}$ & $\begin{array}{l}6824.95 \\
992.91)\end{array}$ & $\begin{array}{c}599.987 \\
(2845.61)\end{array}$ & $\begin{array}{c}0.542 \\
(0.028)\end{array}$ & $\begin{array}{c}157.604 \\
(14.131)\end{array}$ \\
\hline Oman & $\begin{array}{c}26.618 \\
(22.467)\end{array}$ & $\begin{array}{l}-0.136 \\
(0.041)\end{array}$ & $\begin{array}{c}4048.29 \\
(537.625)\end{array}$ & $\begin{array}{c}635.55 \\
(456.51)\end{array}$ & $\begin{array}{c}0.13 \\
(0.091)\end{array}$ & $\begin{array}{c}330.35 \\
(11.036)\end{array}$ \\
\hline Paki & $\begin{array}{l}150.299 \\
(67.059)\end{array}$ & $\begin{array}{c}-0.46 \\
(0.084)\end{array}$ & $\begin{array}{c}4826.03 \\
(1094.21)\end{array}$ & $\begin{array}{c}604.182 \\
(1317.96)\end{array}$ & $\begin{array}{c}0.475 \\
(0.121)\end{array}$ & $\begin{array}{l}362.806 \\
(28.454)\end{array}$ \\
\hline Qatar & $\begin{array}{c}53.807 \\
(28.169)\end{array}$ & $\begin{array}{l}-0.166 \\
(0.06)\end{array}$ & $\begin{array}{c}3408.24 \\
(588.246)\end{array}$ & $\begin{array}{c}490.002 \\
(389.849)\end{array}$ & $\begin{array}{c}0.244 \\
(0.177)\end{array}$ & $\begin{array}{c}416.4 \\
(10.294)\end{array}$ \\
\hline Rom & $\begin{array}{l}126.059 \\
(49.697)\end{array}$ & $\begin{array}{l}-0.257 \\
(0.093)\end{array}$ & $\begin{array}{l}2004.86 \\
(91.587)\end{array}$ & $\begin{array}{c}145.591 \\
(114.236)\end{array}$ & $\begin{array}{c}0.061 \\
(0.054)\end{array}$ & $\begin{array}{l}434.975 \\
(14.635)\end{array}$ \\
\hline Slo & $\begin{array}{l}186.403 \\
(27.622)\end{array}$ & $\begin{array}{l}-0.185 \\
(0.076)\end{array}$ & $\begin{array}{l}2713.04 \\
(52.661)\end{array}$ & $\begin{array}{c}-833.162 \\
(280.015)\end{array}$ & $\begin{array}{c}0.153 \\
(0.026)\end{array}$ & $\begin{array}{c}39.211 \\
(19.102)\end{array}$ \\
\hline Sri Lanka & $\begin{array}{l}-101.64 \\
(25.515)\end{array}$ & $\begin{array}{c}0.203 \\
(0.058)\end{array}$ & $\begin{array}{l}3054.165 \\
(193.183)\end{array}$ & $\begin{array}{c}951.809 \\
(371.037)\end{array}$ & $\begin{array}{c}0.402 \\
(0.077)\end{array}$ & $\begin{array}{c}286.239 \\
(7.472)\end{array}$ \\
\hline Tunisia & $\begin{array}{c}77.481 \\
(27.671)\end{array}$ & $\begin{array}{l}-0.191 \\
(0.077)\end{array}$ & $\begin{array}{c}818.001 \\
(256.396)\end{array}$ & $\begin{array}{l}-188.621 \\
(222.065)\end{array}$ & $\begin{array}{c}0.488 \\
(0.146)\end{array}$ & $\begin{array}{c}270.387 \\
(8.383)\end{array}$ \\
\hline UAE & $\begin{array}{l}119.107 \\
(39.137)\end{array}$ & $\begin{array}{l}-0.322 \\
(0.074)\end{array}$ & $\begin{array}{c}3580.96 \\
(756.751)\end{array}$ & $\begin{array}{l}400.865 \\
(571.34)\end{array}$ & $\begin{array}{c}0.648 \\
(0.091)\end{array}$ & $\begin{array}{l}512.207 \\
(12.526)\end{array}$ \\
\hline
\end{tabular}

Standard errors are reported in parentheses below the parameter estimates.

Note: Estimates are based on 1456 daily observations of country returns between December 1st, 2005 and June 30th, 2011 as given by MSCI Barra country indices. All country indices are in US currency. 
Table 3.5. Hypothesis Tests

The table presents values of test statistics obtained by examining the ICAPM - TVP model of Frontier market returns. Our ICAPM - TVP model is specified as follows:

$R_{\mathrm{k}, \mathrm{t}}=\theta_{\mathrm{k}}+\beta_{\mathrm{t}} \sigma_{\mathrm{us}, \mathrm{k}, \mathrm{t}}+\delta_{\mathrm{k}} \sigma_{\mathrm{k}, \mathrm{t}}^{2}++u_{\mathrm{k}, \mathrm{t}}, u_{\mathrm{k}, \mathrm{t}} \sim N\left(0, H_{\mathrm{k}}\right), \beta_{\mathrm{t}}=c(1-\rho)+\rho \beta_{\mathrm{t}-1}+n_{\mathrm{t}}, n_{t} \sim N(0, Q)$, $E\left(u_{\mathrm{k}, \mathrm{t}} n_{\mathrm{t}}\right)=0$.

Statistical significance of parameters is tested via the likelihood ratio (LR) test, which is approximately chi-squared. The sample spans from December 1st 2005 to June 30th 2011. The following hypotheses are tested:

1. $L R\left\{\beta_{\mathrm{t}}=0(c=Q=0)\right\}$ is a test for no impact of US covariance risk in the ICAPM - TVP model. The $5 \% \chi_{2}^{2}$ p-value equals 5.99 .

2. $L R\left\{\beta_{\mathrm{t}}=\beta\right.$, aconstant $\left.(\rho=Q=0)\right\}$ is a test for no time-variation in the $\mathrm{AR}(1)$ parameter of the ICAPM - TVP model. The $5 \% \chi_{2}^{2}$ p-value equals 5.99 .

3. $L R\{\beta=0\}$ is a test for no impact of US covariance risk in a constant coefficient ICAPM model $\left(\beta_{\mathrm{t}}=\right.$ constant $)$. The $5 \% \chi_{1}^{2} \mathrm{p}$-value equals 3.84 .

4. $L R\left\{\delta_{\mathrm{k}}=0\right\}$ is a test for no impact of Frontier market risk in the ICAPM - TVP model. The 5\% $\chi_{1}^{2}$ p-value equals 3.84 .

\begin{tabular}{|c|c|c|c|c|}
\hline & \multicolumn{4}{|c|}{ Hypothesis Tested } \\
\hline Country & $\begin{array}{c}\beta_{\mathrm{t}}=0 \\
(c=Q=0)\end{array}$ & $\begin{array}{c}\beta_{\mathrm{t}}=\text { constant } \\
(\rho=Q=0)\end{array}$ & $\begin{array}{c}H_{0}: \beta_{\mathrm{t}}=0 \\
H_{1}: \beta_{\mathrm{t}}=\text { constant }\end{array}$ & $\delta_{\mathrm{k}}=0$ \\
\hline Argentina & 289.79 & 289.663 & 0.136 & 0.176 \\
\hline Bahrain & 0.059 & 0.046 & 0.012 & 33.59 \\
\hline Bulgaria & 0.581 & 0.567 & 0.014 & 51.199 \\
\hline Croatia & 0.094 & 0.019 & 0.075 & 0.007 \\
\hline Estonia & 96.28 & 96.272 & 0.007 & 96.636 \\
\hline Jordan & 3.29 & 3.276 & 0.014 & 8.825 \\
\hline Kazakhstan & 36.808 & 36.583 & 0.225 & 37.715 \\
\hline Kenya & 81.23 & 80.804 & 0.426 & 81.572 \\
\hline Kuwait & 5.326 & 5.326 & 0.000 & 20.343 \\
\hline Lebanon & 269.973 & 269.529 & 0.443 & 270.388 \\
\hline Mauritius & 26.169 & 23.274 & 2.895 & 24.053 \\
\hline Nigeria & 344.066 & 338.501 & 5.565 & 344.642 \\
\hline Oman & 28.078 & 28.077 & 0.001 & 49.259 \\
\hline Pakistan & 40.415 & 40.414 & 0.000 & 88.761 \\
\hline Qatar & 28.949 & 22.889 & 6.06 & 31.838 \\
\hline Romania & 219.982 & 213.726 & 6.256 & 221.216 \\
\hline Slovenia & 41.154 & 41.155 & 0.000 & 50.292 \\
\hline Sri Lanka & 188.912 & 188.919 & 0.006 & 234.599 \\
\hline Tunisia & 5.448 & 5.4532 & 0.004 & 12.822 \\
\hline UAE & 28.877 & 18.501 & 10.375 & 37.575 \\
\hline & & & &
\end{tabular}


Figure 3.1.

Dynamic Conditional Correlations between US and Frontier Markets
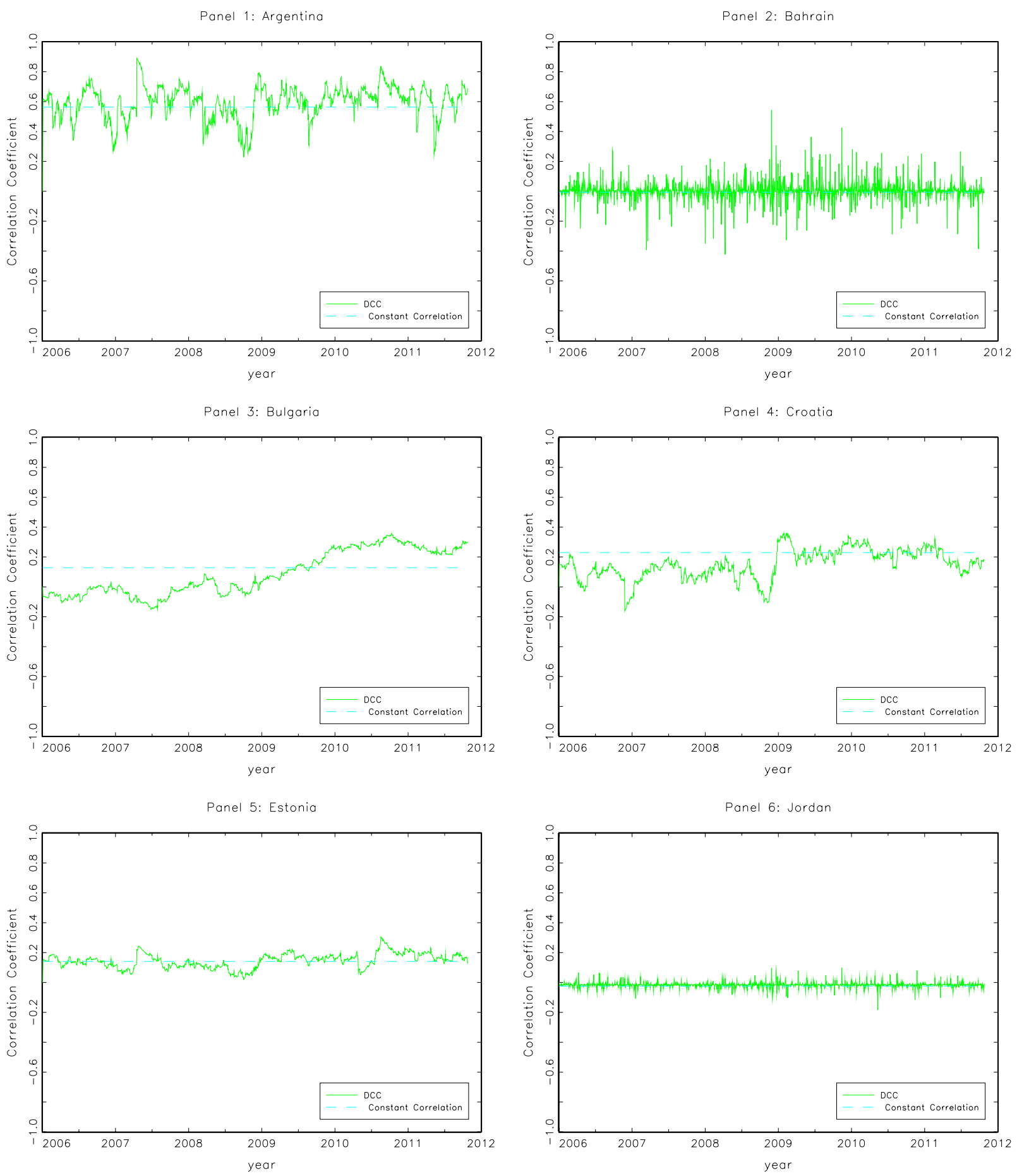
Panel 7: Kazakhstan

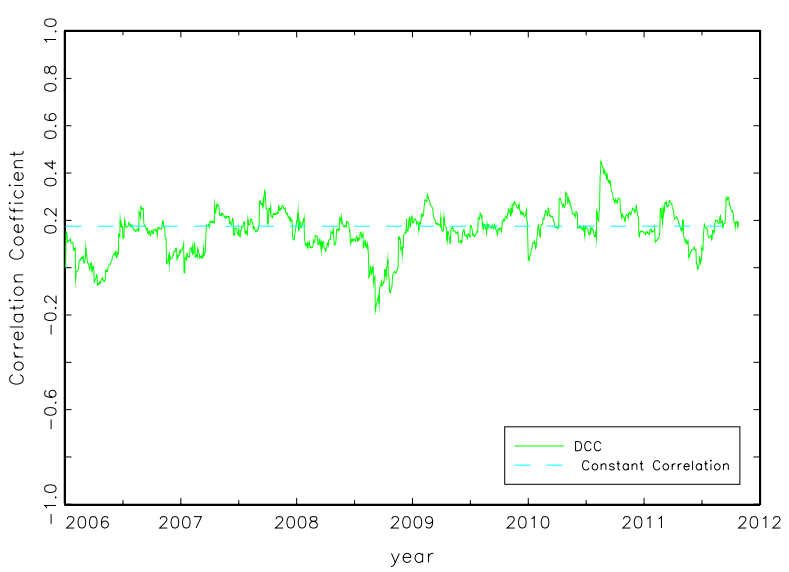

Panel 9: Kuwait

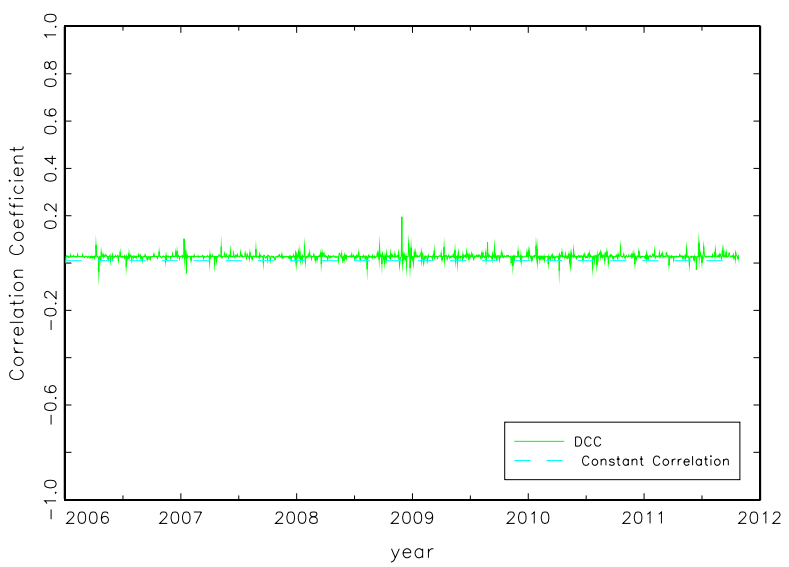

Panel 11: Mauritius

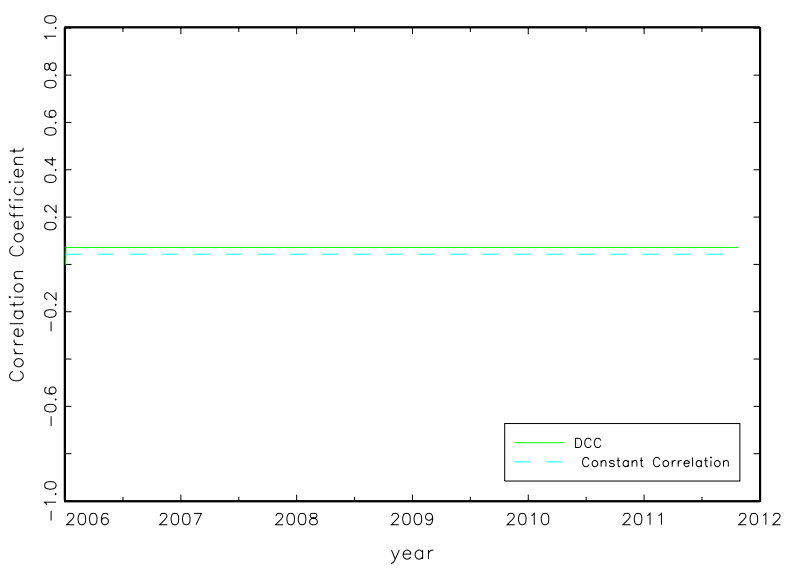

Panel 8: Kenya

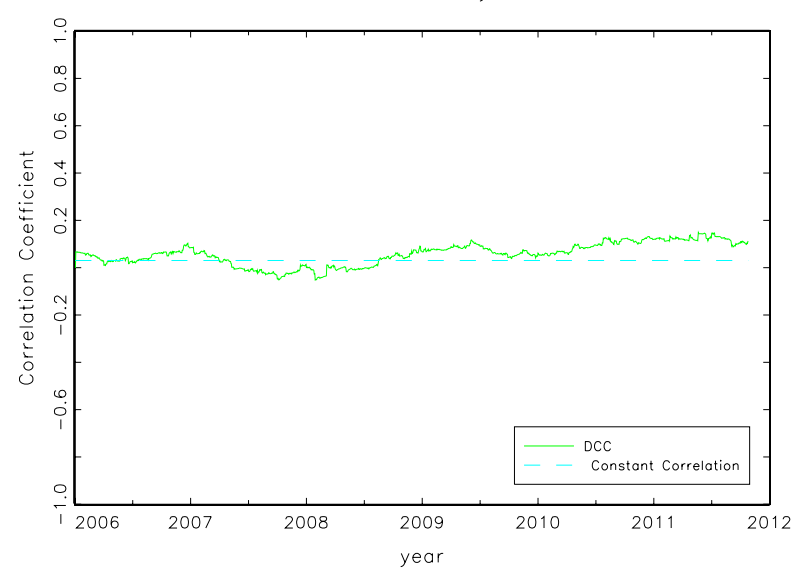

Panel 10: Lebanon

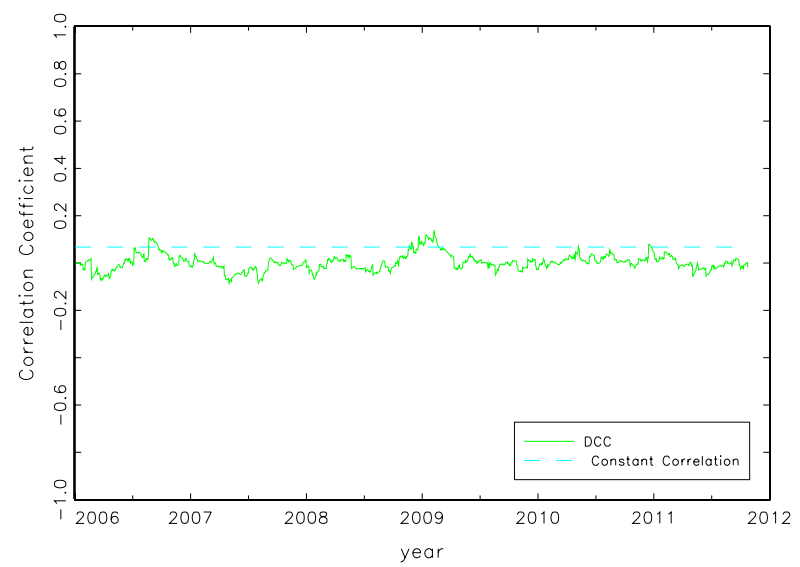

Panel 12: Nigeria

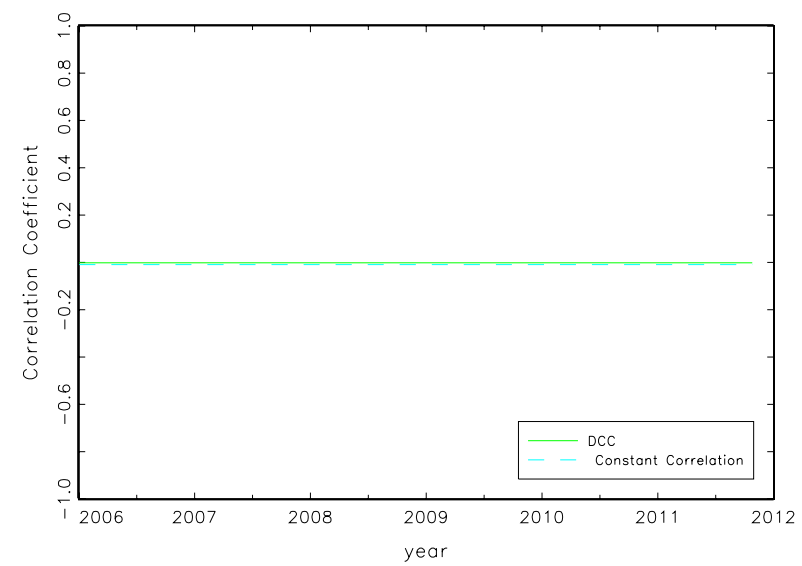


Panel 13: Oman

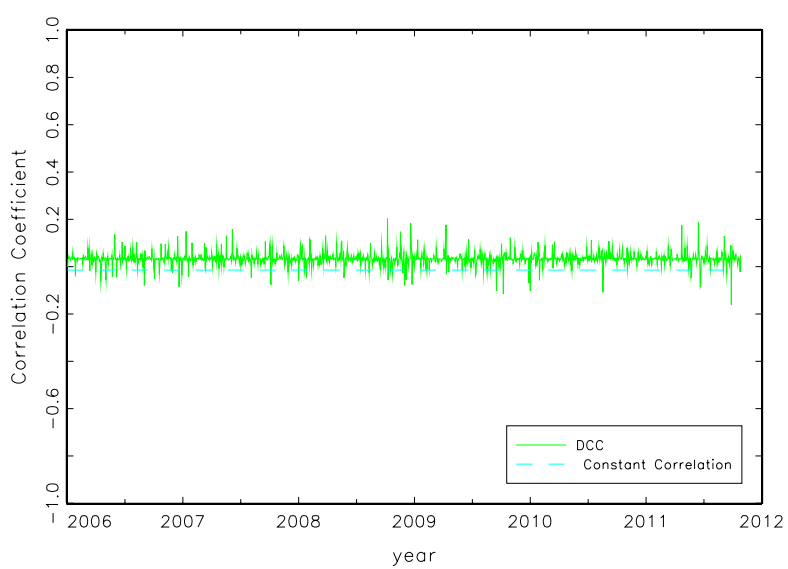

Panel 15: Qatar

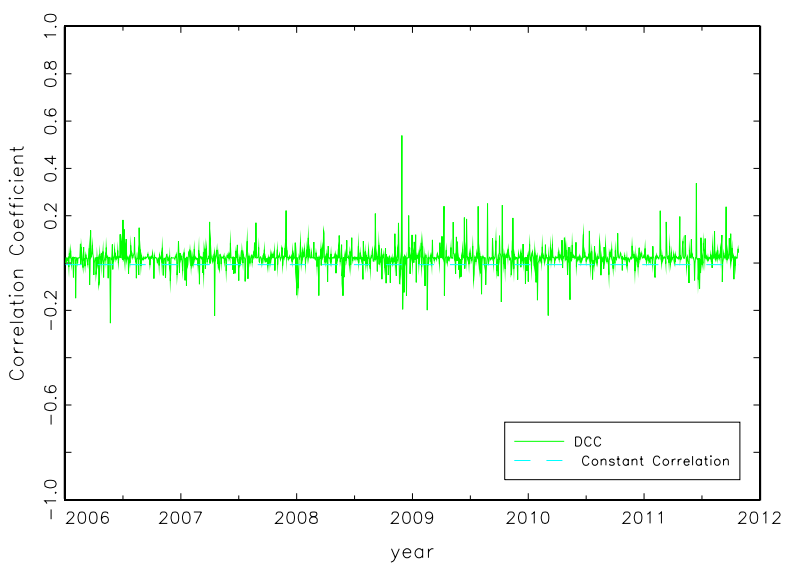

Panel 17: Slovenia

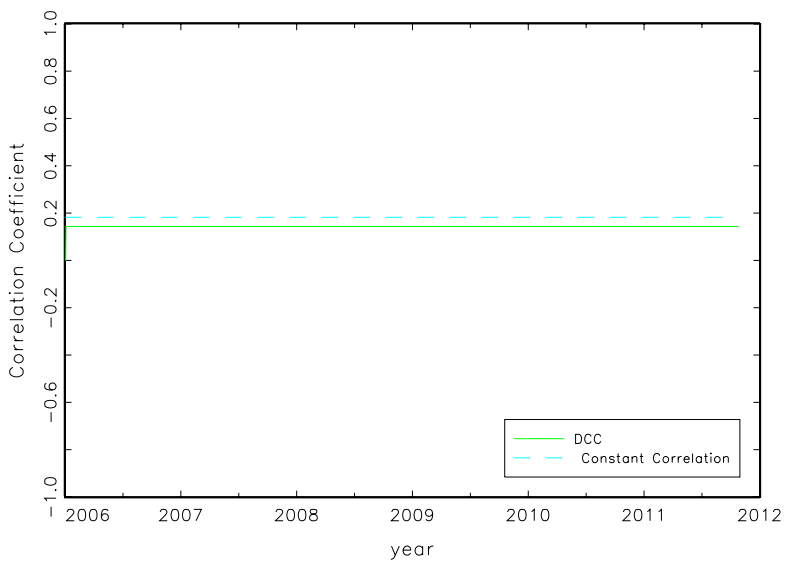

Panel 14: Pakistan

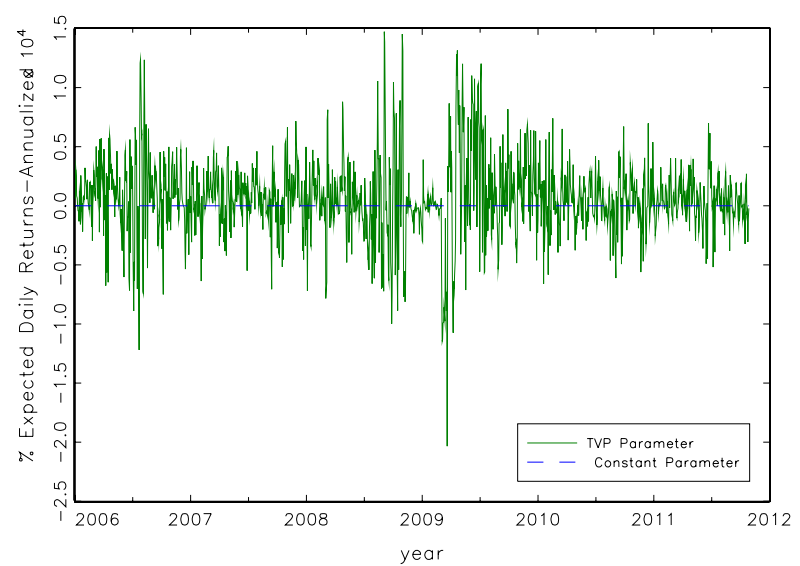

Panel 16: Romania

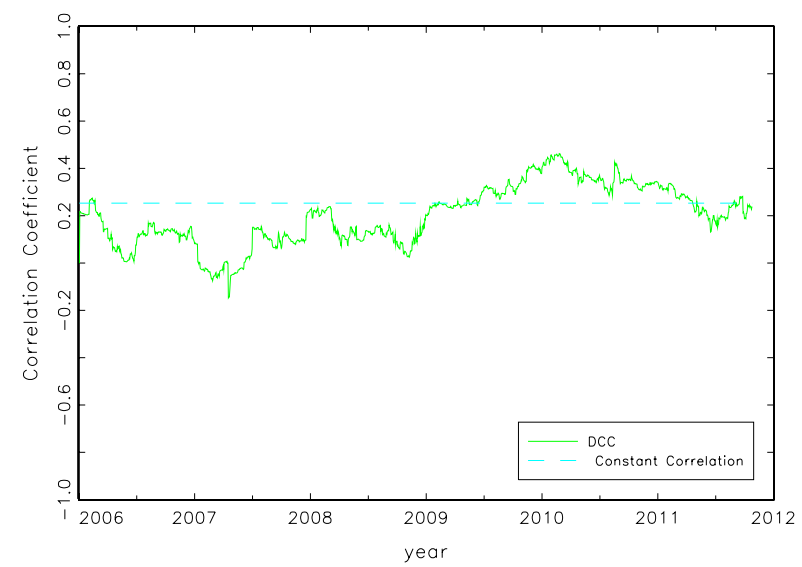

Panel 18: Sri Lanka

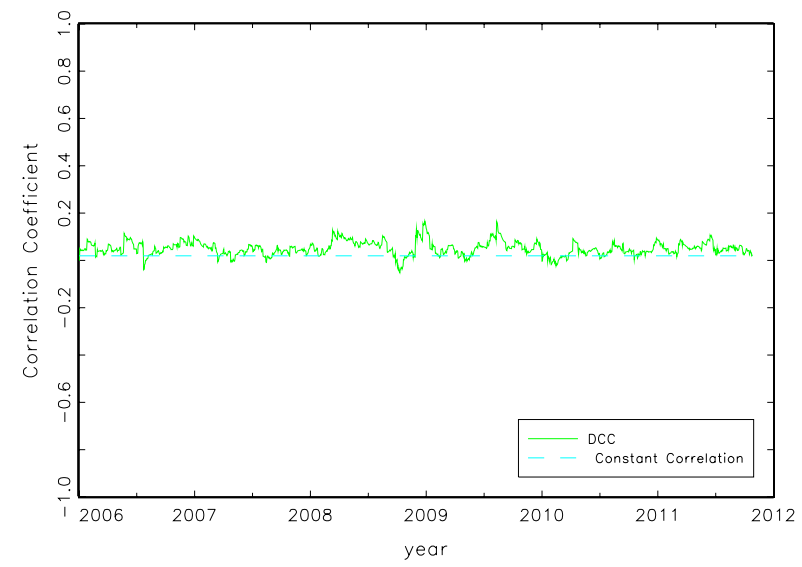



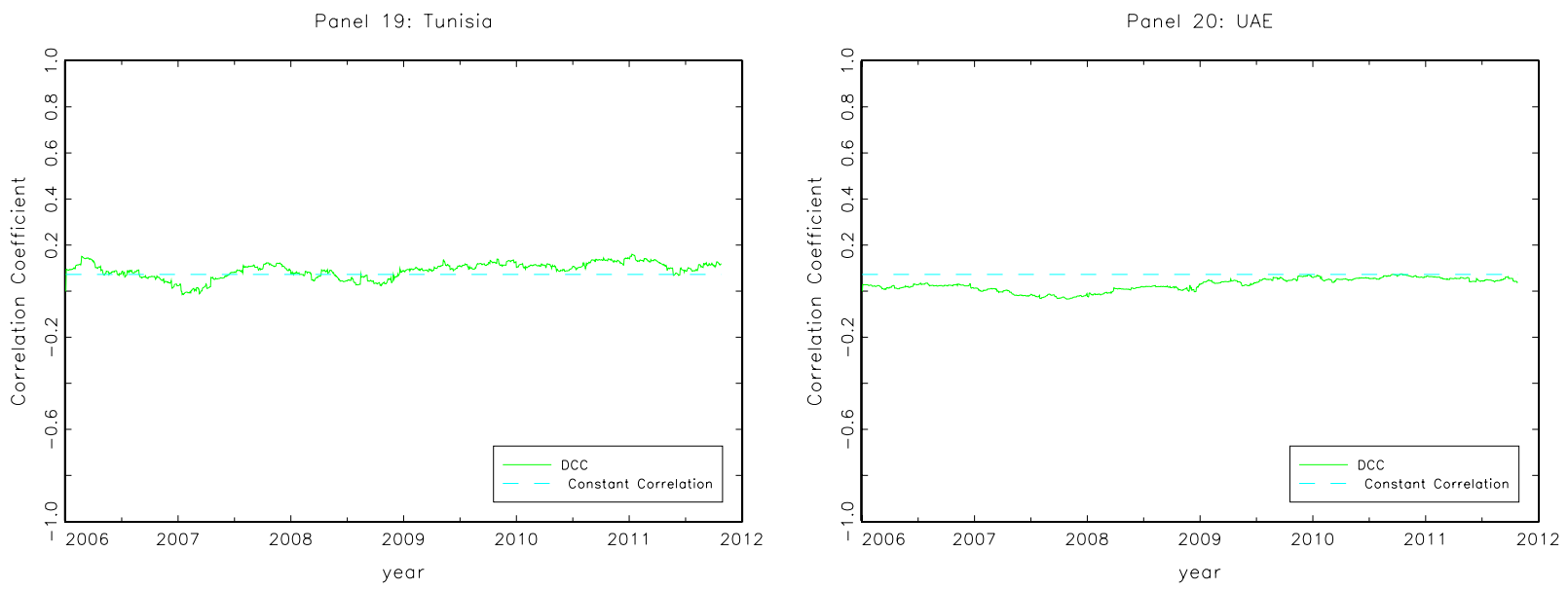
Figure 3.2.

Frontier Market Returns and Fitted Values from the ICAPM-TVP Model
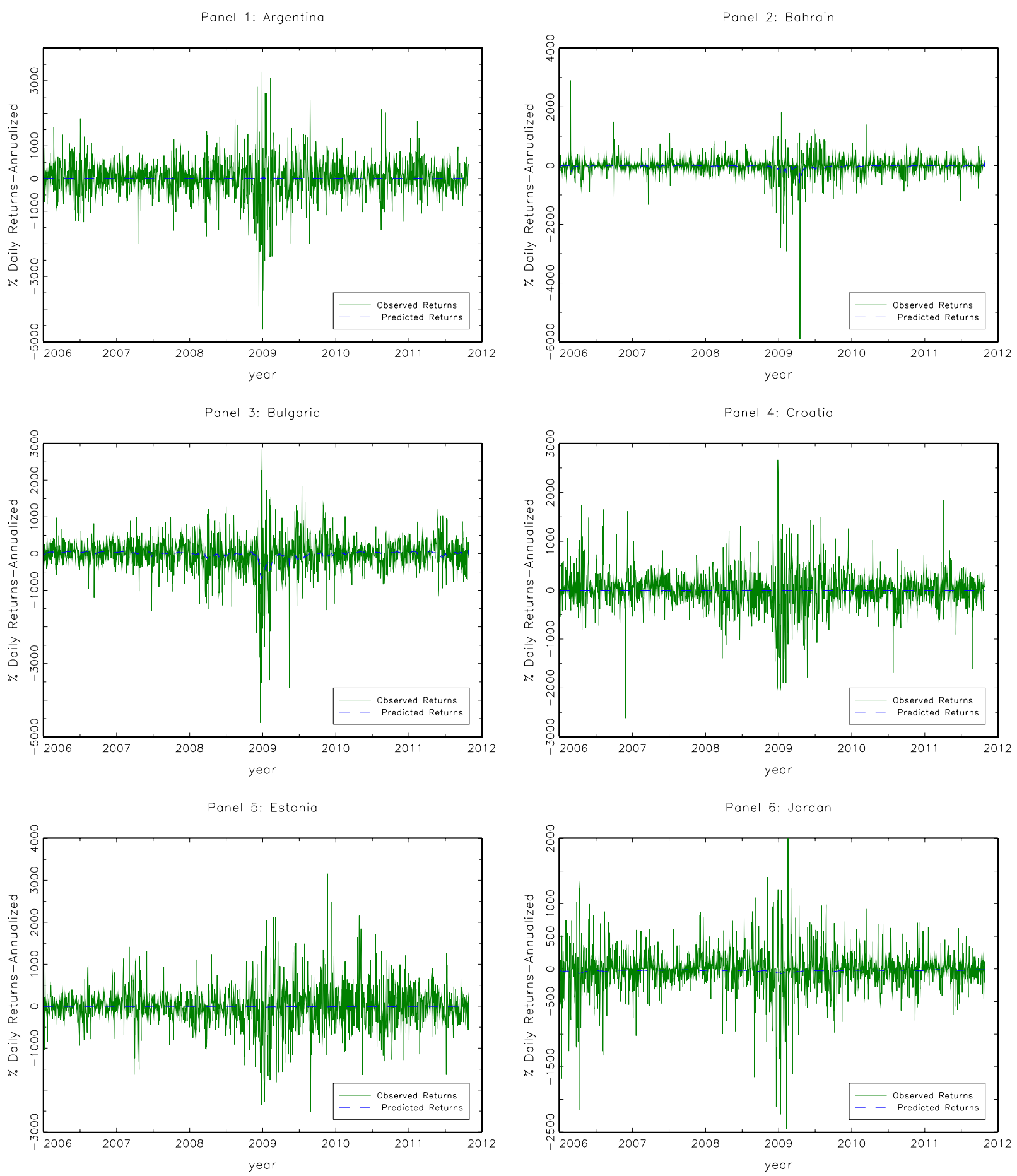

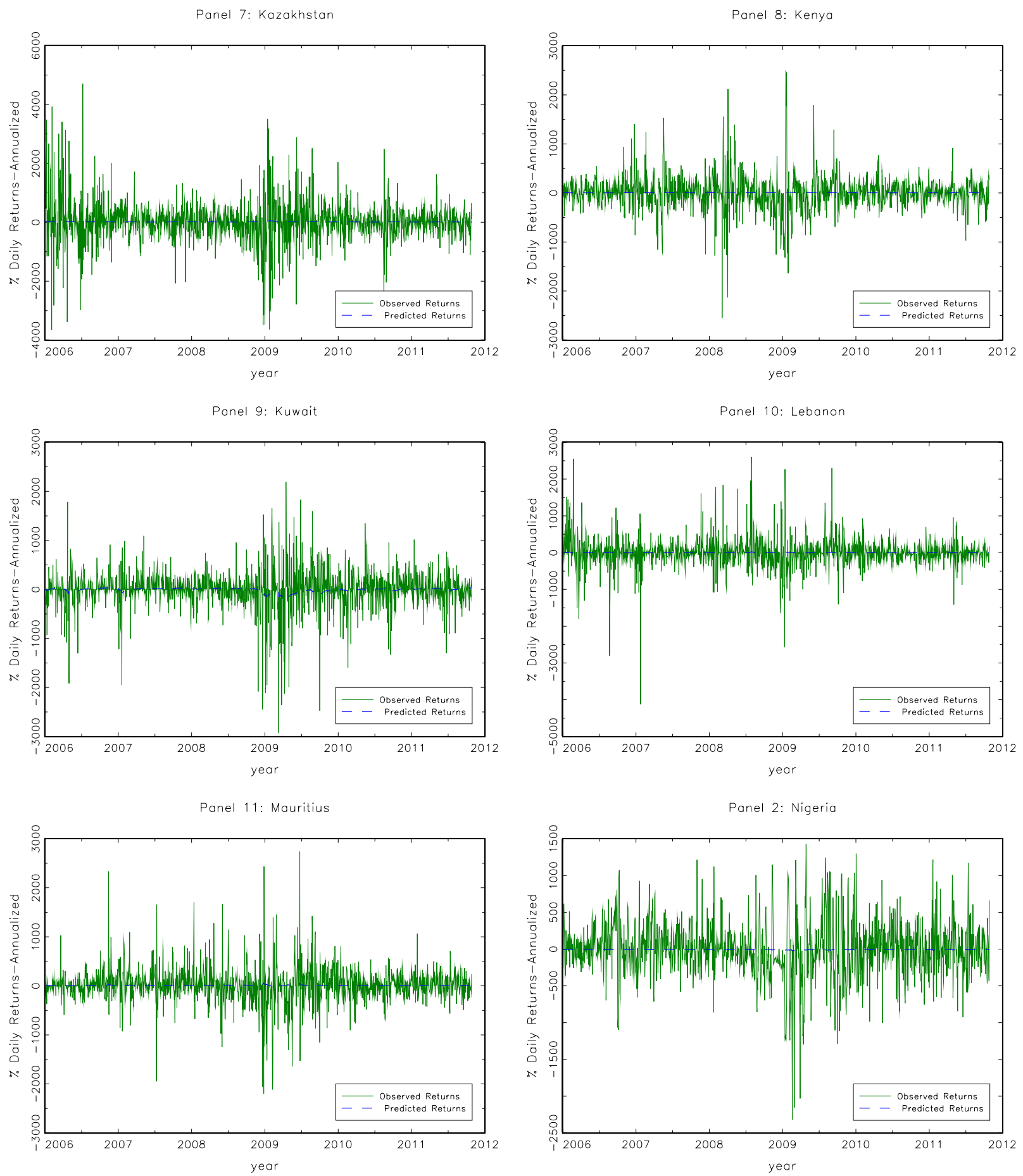

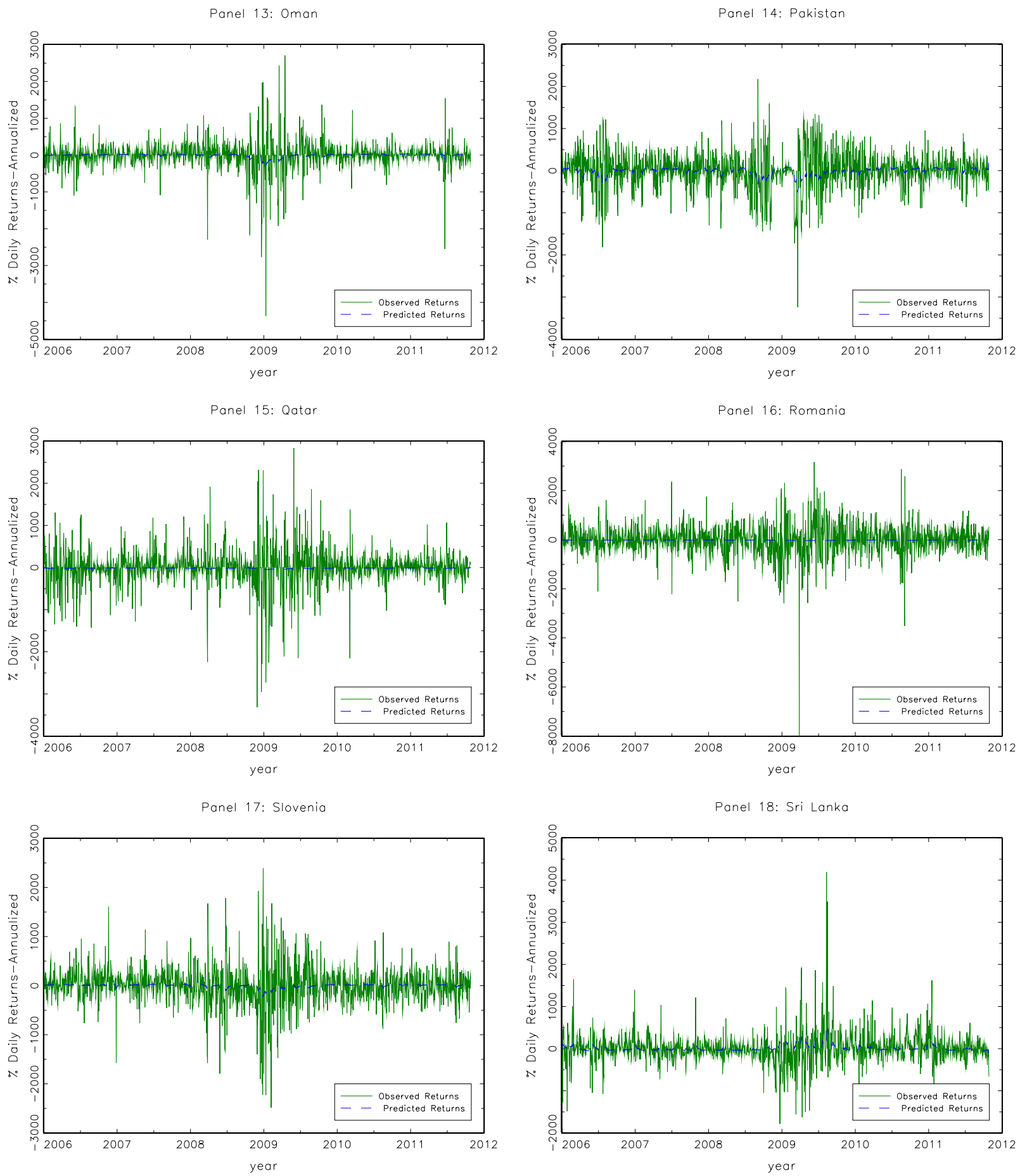

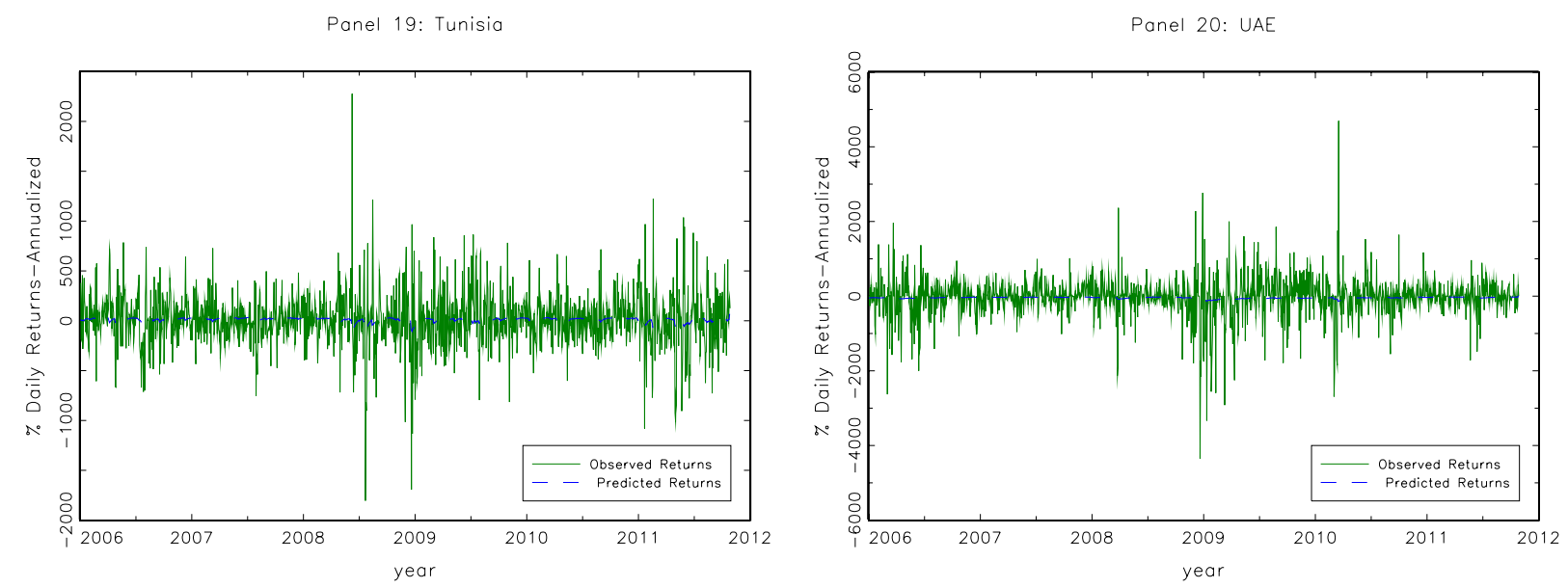
Figure 3.3.

US and Local Market Components of Frontier Market Returns Estimated by the ICAPM-TVP Model
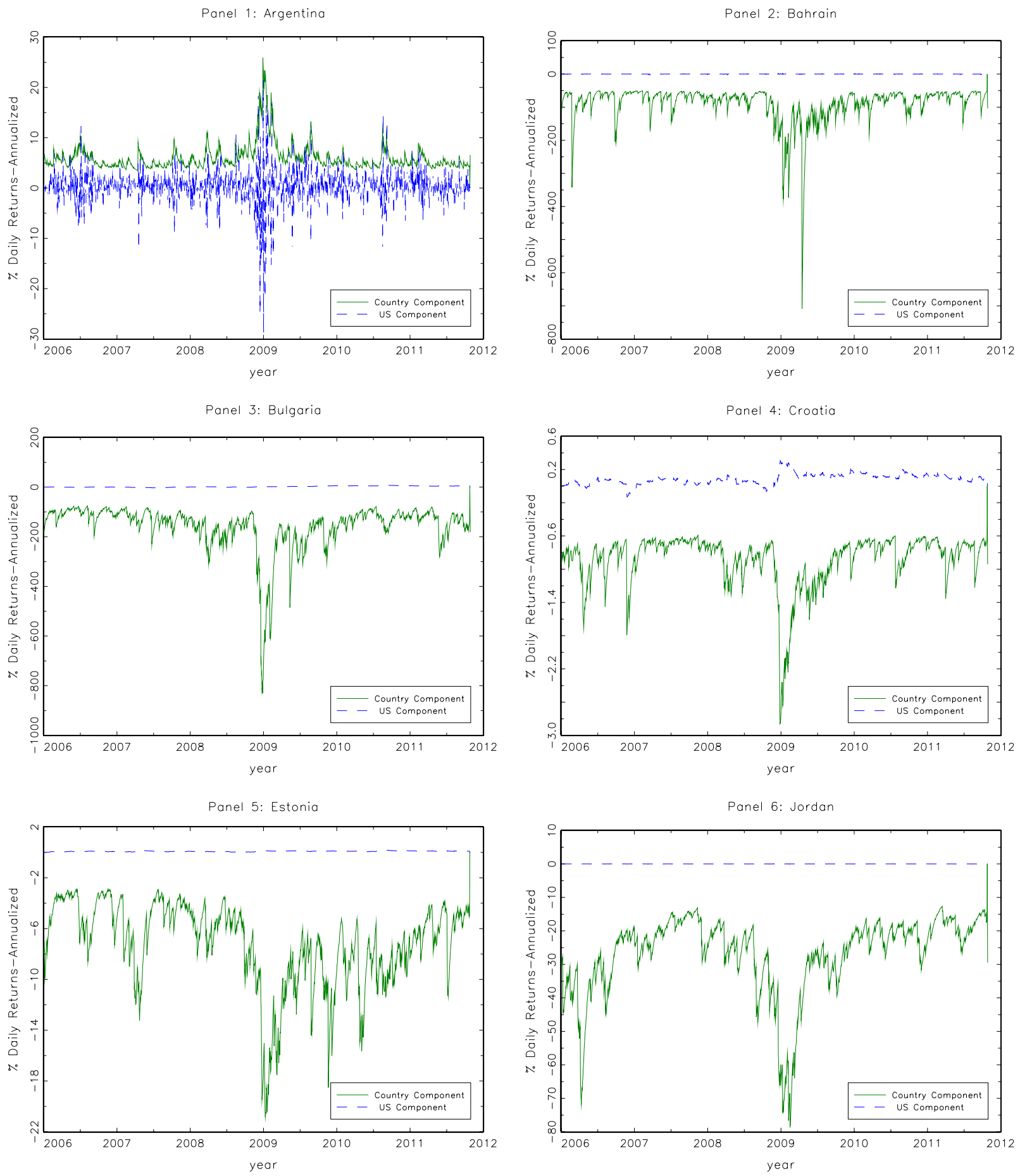

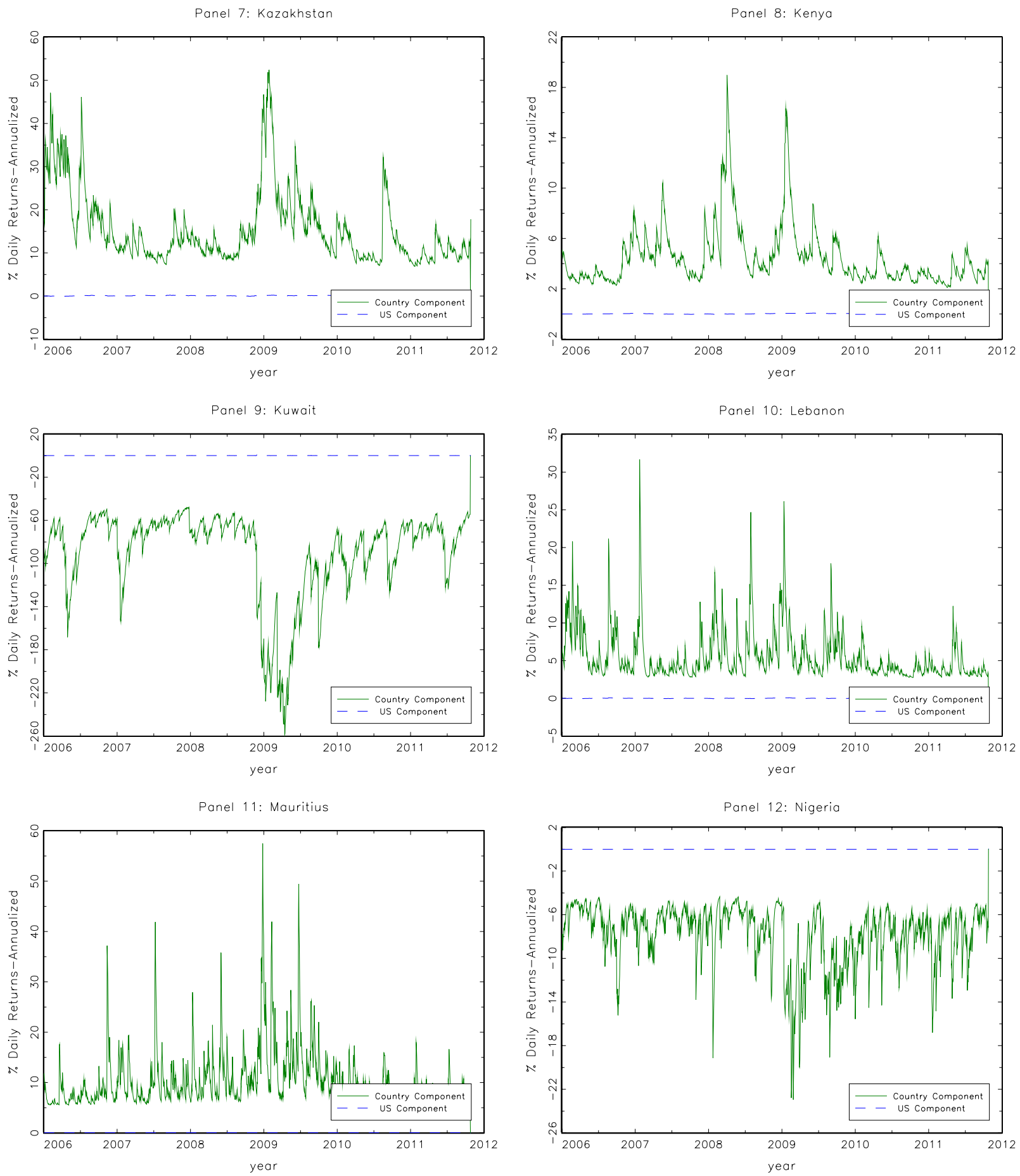

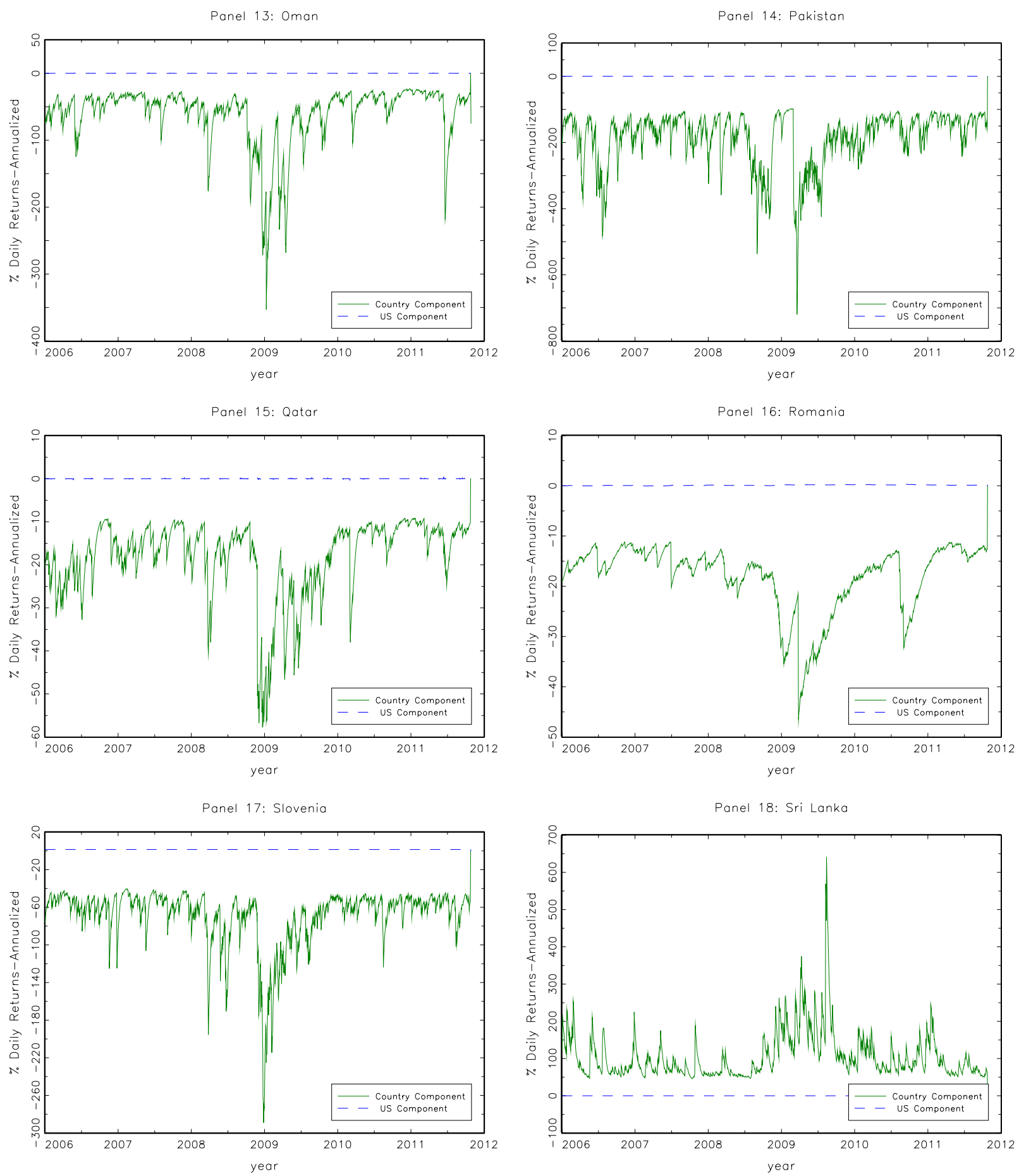

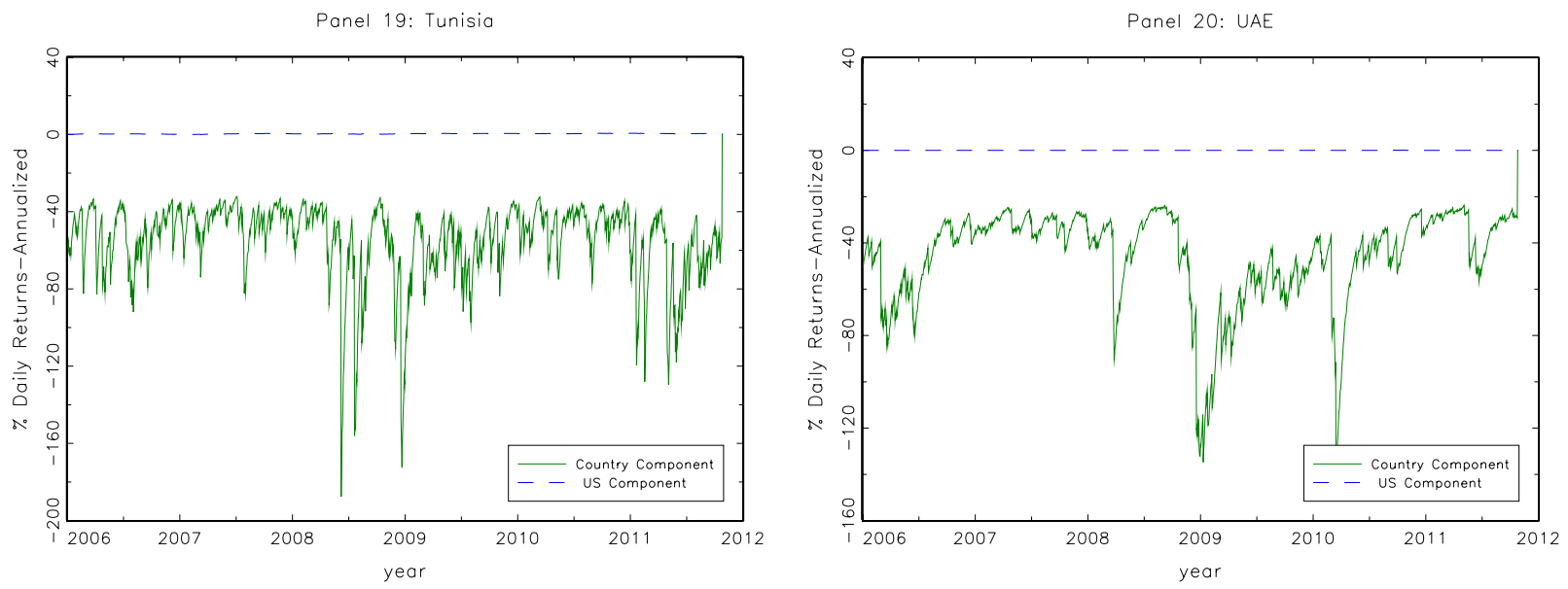
VITA

GALIN TODOROV

2006

2009

2011
BB.A., Finance

University of Georgia

Athens, Georgia

M.A., Economics

Florida International University

Miami, Florida

Doctoral Candidate in Economics

Florida International University

Miami, Florida 